\title{
La pratique du pèlerinage en Provence à la fin du Moyen Âge et au début de l'époque moderne d'après les enseignes et les ampoules
}

\author{
Olivier THUAUDET*
}

Mots clés : pèlerinage, Moyen Âge, enseigne de pèlerinage, ampoule de pèlerinage, métal

Résumé : La pratique du pèlerinage en Provence et au départ de Provence est documentée par les sources écrites, mais également par des objets achetés par les pèlerins dans les sanctuaires visités. La plupart sont des enseignes et des ampoules en étain, en plomb ou en alliage des deux métaux. L'étude de ces pièces métalliques révèle la multiplicité des moules, la persistance des motifs au cours du temps et participe à renseigner sur la renommée des sanctuaires et l'étendue de celle-ci. À la fin du xve siècle et au xvl ${ }^{e}$ siècle, la forme et le décor de certaines enseignes évoluent et annoncent l'apparition des médailles en alliage cuivreux. L'analyse des contextes de découverte des enseignes, ampoules et médailles révèle des différences dans la symbolique des objets.

Keywords: Pilgrimage, Middle Ages, pilgrim badges, pilgrim phials, metal.

Abstract: Pilgrim badges and phials as evidence of pilgrimage in Provence at the end of the Middle Ages and Early Modern Period. Pilgrimage in Provence and from Provence is well documented from written sources but also from the artefacts pilgrims would acquire in the sanctuaries they visited. Most of those artefacts are badges and phials made of tin, lead, or an alloy of these two metals. The study of these metallic elements reveals the diversity of moulds as well as the long use of the motifs throughout time. It also contributes to a better understanding of the reputation of the sanctuaries and its geographical extent. At the end of the 15th and in the 16th c., the shape and ornemental motifs of some of the badges evolve, foreshadowing the apparition of the copper alloy medallions. The analysis of the context of discovery reveals the diversity in the objects' symbolism.

\section{Schlüsselwörter: Wallfahrt, Mittelalter, Pilgerzeichen, Pilgerampullen, Metall}

Zusammenfassung: Wallfahrtswesen in der Provence am Ende des Mittelalters und zu Beginn der frühen Neuzeit im Spiegel der Pilgerzeichen und Pilgerampullen. Das Wallfahrtswesen der Provence - Wallfahrten in der Provence selbst und von der Provence aus - ist in Schriftquellen belegt, aber auch durch Objekte, die die Pilger bei ihren Besuchen der Gnadenstätten kauften. Überwiegend handelt es sich dabei um Pilgerzeichen und Pilgerampullen aus Zinn, aus Blei oder aus Legierungen beider Metalle. Die Untersuchung dieser Metallfunde zeigt die Vielzahl der Gussformen, die Beständigkeit ihrer Motive und liefert Erkenntnisse zur Popularität der Heiligtümer und zur Größe ihres Einflussbereiches. Am Ende des 15. und im 16. Jh. ändern sich die Form und die Gestaltung einiger Pilgerzeichen und kündigen so das Erscheinen der Medaillen aus Kupferlegierungen an. Die Analyse der Fundkontexte von Pilgerzeichen, -ampullen und -medaillen macht deutlich, dass es Unterschiede in der Bedeutung der Objekte gab.

* Aix-Marseille Université, CNRS, membre associé du LA3M UMR 7298, 13094 Aix-en-Provence. 
Le territoire provençal a connu de multiples centres de pèlerinages. De nombreux Provençaux les visitaient aux côtés de pèlerins d'autres origines. Ils n'hésitaient pas non plus à entreprendre des voyages à longue distance à destination de sanctuaires réputés. Les fouilles archéologiques en Provence et à l'extérieur de la région, ainsi que les sources écrites, prouvent que des souvenirs religieux spécifiques étaient proposés dans une partie des sanctuaires de Provence. Il s'agit généralement d'enseignes ou d'ampoules, ordinairement en matériau blanc - étain, alliage d'étain et de plomb ou plomb -, plus rarement, pour les enseignes, dans d'autres métaux comme les alliages cuivreux ou les métaux précieux. Ces souvenirs sont le témoignage ostensible d'une ferveur religieuse ou du moins, à l'origine, de l'accomplissement d'un pèlerinage, et peuvent détenir un pouvoir protecteur et thaumaturgique. Ils fournissent de nombreuses indications sur l'activité des sanctuaires et témoignent de leur aura. L'étude de la pratique du pèlerinage en Provence à partir de ce mobilier nécessite donc de prendre en compte l'ensemble des enseignes et ampoules découverts en Provence, ainsi que les enseignes de pèlerinages provençales retrouvées hors du territoire régional.

Les enseignes et ampoules de pèlerinage découvertes en Provence ou en provenant n'ont, jusqu'à présent, fait l'objet que de recherches peu étendues. La première étude d'envergure, dépassant donc la simple mention d'un objet, œuvre de Dominique Carru et Sylvain Gagnière, paraît en 1992. Vingtet-une enseignes et ampoules découvertes à Avignon y sont répertoriées ${ }^{1}$. Dominique Carru complète ce corpus par un court article consacré à une nouvelle enseigne en 1998². En 2001, Philippe Ferrando ajoute quatorze objets inédits découverts à Fontvieille (Bouches-du-Rhône) et à Avignon ${ }^{3}$. Les travaux de ce chercheur, difficilement accessibles, sont inconnus de Denis Bruna lorsque, deux ans plus tard, il publie un rapide inventaire descriptif des enseignes trouvées le long de la Via Tolosana, en Provence et en Languedoc ${ }^{4}$. Cinquante enseignes de sanctuaires provençaux, ou découvertes en Provence, y sont signalées. Notre présente étude rassemble cent quinze enseignes, dont quatre-vingt-trois exemplaires métalliques, ainsi que quinze ampoules. Nous y avons adjoint les résultats d'un important dépouillement bibliographique, des recherches en archives et une enquête dans la documentation de fouille. L'objectif est de replacer la pratique du pèlerinage, l'achat et l'utilisation des enseignes et ampoules dans le contexte de la Provence de la fin du Moyen Âge et du début de l'époque moderne, mais aussi de donner des renseignements d'ordre général sur les sanctuaires, lesquels ont fait l'objet d'un intérêt variable.

\footnotetext{
1. Carru et Gagnière 1992.

2. Carru 1998.

3. Ferrando 2001a et 2001b.

4. BRUNA 2003.
}

\section{PARTIR EN PÈLERINAGE : POUR QUELLES RAISONS?}

La Provence a compté de nombreux sites de pèlerinage ${ }^{5}$, auxquels on accédait de manière permanente ou, peut-être, de façon temporaire, lors de processions annuelles par exemple. Tous n'ont pas forcément perduré jusqu'à nos jours et la présence de reliques ne constitue probablement pas toujours un élément suffisant pour engendrer des visites fréquentes ${ }^{6}$. L'invention 7, la reconnaissance ou le transfert de reliques ${ }^{8}$ ont parfois été réalisés pour asseoir ou confirmer un lieu de pèlerinage. En outre, pour assurer une continuité dans les visites ou promouvoir un sanctuaire, les autorités religieuses ont favorisé la rédaction de Livres de miracles comme ceux de saint Gilles ${ }^{9}$, de sainte Marie-Madeleine ${ }^{10}$, d'Urbain $V^{11}$ pour ne citer qu'eux, ou bien encore la rédaction de la vie d'un saint comme le Roman de saint Trophime ${ }^{12}$, les Vies d'Elzéar et de Delphine de Sabran ${ }^{13}$ ou la Vie de sainte Douceline ${ }^{14}$.

Ces mêmes autorités octroyaient également des indulgences $^{15}$ pour encourager les croyants à se déplacer vers les lieux saints et les inciter, entre autres, à participer aux frais de construction, de développement ou d'entretien des édifices visités ${ }^{16}$. L'intérêt est essentiellement financier, la venue de pèlerins ayant un impact sur le commerce local : ils dépensent de l'argent en se logeant, en achetant de nouvelles chaussures, des enseignes, de la nourriture, en faisant un don monétaire ou matériel - un cierge par exemple. Ainsi, en 1154, le pape Anastase IV accorde une indulgence aux chrétiens qui visitent le tombeau de saint Gilles ${ }^{17}$. Les papes d'Avignon ont souvent eu recours à ce dispositif ${ }^{18}$. Les évêques ont également mené

5. Se reporter à BARATIER et al. 1969, carte 212, pour une carte des presque cent vingt lieux de pèlerinage répertoriés pour la région Provence-Alpes-Côte d'Azur durant l'époque moderne.

6. Régionalement, aucun recollement à grande échelle n'a été entrepris entre les sources textuelles mentionnant des reliques et celles matériellement conservées dans les églises de Provence.

7. Par exemple en 925, celles des reliques de saint Gilles et, en 1278, celles de Marie-Madeleine.

8. Le 22 juin 1277, les reliques de saint Cannat, confirmé dans son titre d'évêque de Marseille (titre accordé en 1122), et de saint Antoine font l'objet d'un acte de translation à la Major de Marseille, en présence de l'archevêque d'Arles et de l'évêque de Sisteron (Albanès et Chevalier 1899, t. 2, pièce 1255).

9. Duhil et al. (éd.) 2007.

10. SCLAFERT (éd.) 2009.

11. Albanès 1897.

12. Voir à ce sujet ZINGARELLI 1901 et GAZAY 1913.

13. PANSIER 1926.

14. Albanès 1879.

15. L'indulgence est la remise de tout ou partie des peines temporelles. Se reporter à RAPP 2000 pour plus d'informations à ce sujet dans le contexte avignonnais.

16. De nombreuses indulgences ont été accordées par les papes à ceux contribuant à l'entretien ou à la réparation de l'CEuvre du Pont d'Avignon, souvent abîmé, voire détruit, par l'impétuosité du Rhône. En août 1455, le pape Calixte III est le huitième à le faire (PANsIER 1912b, p. 169, 170-173).

17. Carru et Gagnière 1992, p. 81.

18. Voir par exemple Albanès et Chevalier 1920 (pièce 969), Hayez 1985 (p. 25), CARru et Gagnière 1992 (p. 63) et Hayez 2003 (p. 87). 


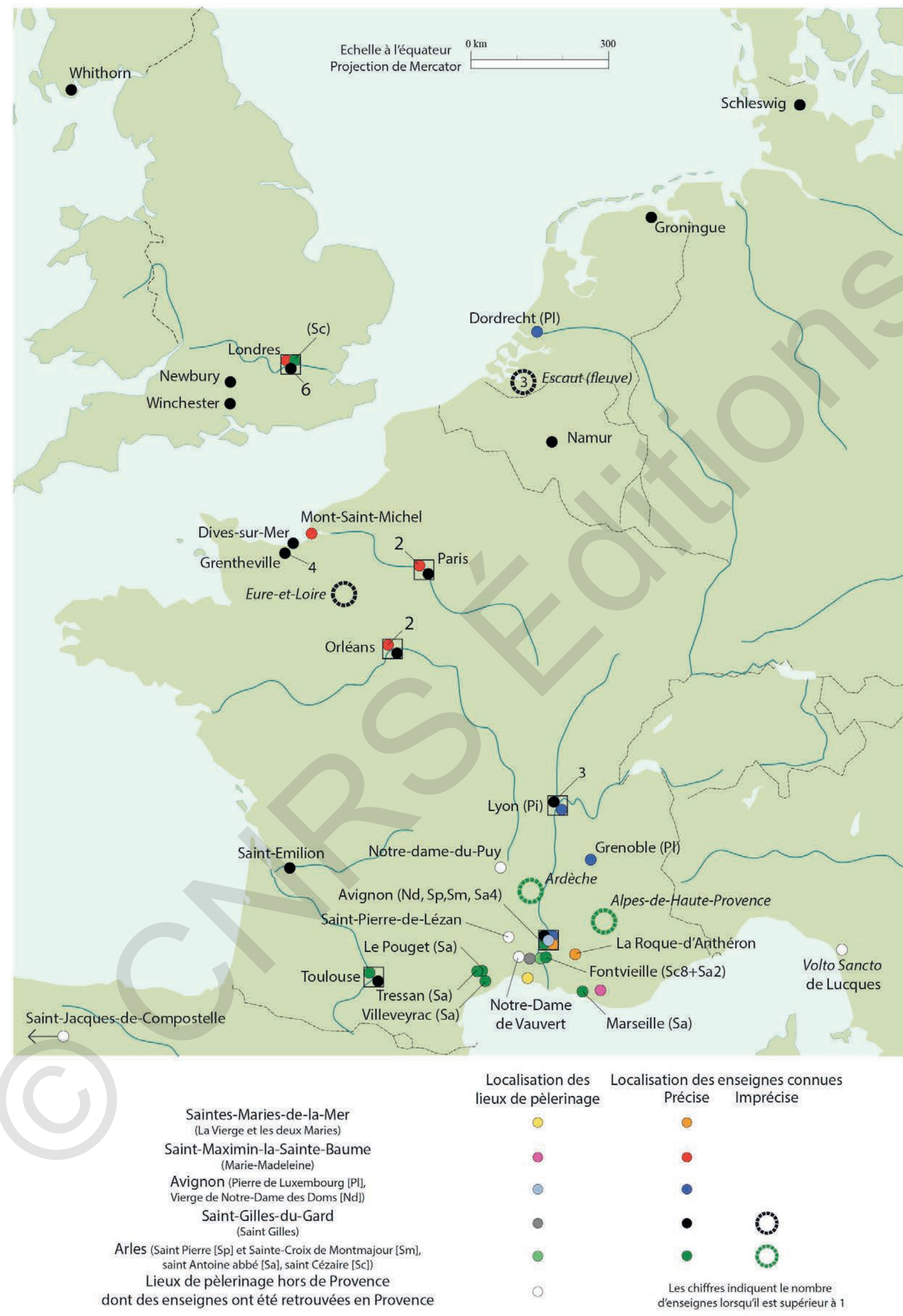

Fig. 1 Localisation des lieux de découverte des enseignes issues de sanctuaires provençaux et des lieux de culte des enseignes mises au jour en Provence. 
ce genre de politique lors de conciles ${ }^{19}$. Le commerce des indulgences perdure encore au XVI ${ }^{\mathrm{e}}$ siècle $^{20}$. Ces «libéralités» ont sans doute eu un effet, du moins à court terme, sur le taux de fréquentation des édifices religieux concernés, mais il n'est pas évident qu'elles aient toujours contribué, même quand les sanctuaires détenaient des reliques, à en faire des sites de pèlerinage importants. La renommée et le prestige d'un lieu ainsi que l'ampleur des visites effectuées sont avant tout la conséquence de la célébrité d'un saint ou des reliques conservées, de la nature et du retentissement des miracles qui s'y rapportent, de l'intensité des moyens déployés par le clergé local pour inciter à la visite et favoriser l'accueil et l'hébergement des pèlerins.

Nombre de centres de pèlerinages majeurs sont situés hors de Provence et ils en sont parfois très éloignés, tels que Rome, Saint-Jacques de Compostelle ou Jérusalem. Pour entreprendre ces voyages, longs et parfois périlleux ${ }^{21}$, le pèlerin préfère généralement partir avec un groupe pour se prémunir de l'insécurité, d'après le témoignage des miracles provençaux ${ }^{22}$. Il peut éventuellement recourir à un itinéraire écrit pour se guider ${ }^{23}$. Prenant en compte la dangerosité du trajet, il n'hésite pas, avant son départ, à mettre de l'ordre dans ses affaires et à rédiger son testament ${ }^{24}$. La sœur Elena de Sclavonia, béguine de Marseille, le fait établir chez un notaire en 1301. Un an après le jubilé de 1300, elle part en pèlerinage dans la péninsule Italienne avec l'intention de se rendre à Rome pour visiter le tombeau des saints Pierre et Paul, à Venise pour celui de saint Marc, et continuer son périple en allant au Mont Saint-Angel dans les Pouilles, au tombeau de saint François à Assise, à la basilique

19. En 1363, le concile d'Apt octroie des indulgences à ceux qui visitent, à Arles, la nouvelle chapelle Saint-Barthélemy de la cathédrale Saint-Trophime lors de certaines fêtes (Albanìs et Chevalier 1901, no 3302). Deux ans plus tard, ce même concile concède une indulgence de quarante jours sur le temps de Purgatoire à tous les fidèles qui visitent l'église de la bienheureuse Marie à Saignon - qui conserve un fragment de la Croix - pendant les fêtes de l'Invention et de l'Exaltation de la Sainte-Croix (Arnaud D'Agnel 1906, p. 383-384).

20. En 1506, le pape Jules II en accorde une à tous ceux qui, par leur contribution financière, permettent de terminer l'église de Saint-Gilles, sanctuaire dont la renommée a fortement chuté. Au milieu du Xvie siècle, une indulgence est donnée à ceux qui s'arrêtent à l'église Sainte-Croix d'Auriol, dans les Bouches-du-Rhône, et qui y laissent une aumône (RAImBAULt 1921, p. 39 et 56).

21. En 1582 et 1583, sept personnes sont condamnées à mort et (sic) au paiement d'une amende pour avoir attaqué ou participé à l'attaque de quatre pèlerins romains au-dessus de Garron, dans le Var (AD Var, 1 B 344).

22. VeYsSIÈRE 1994, p. 204.

23. Les quatre chemins définis grossièrement par le Guide du pèlerin, daté du XII siècle, ne correspondent à aucune vérité historique et ce guide était pratiquement inconnu jusqu'à sa première publication par J. VIELLIARD en 1938 (PÉriCARD-MÉa 2000, p. 16, 185). Il existe de nombreux «guides» de diffusion très restreinte rédigés à l'attention des pèlerins partant vers Jérusalem, Rome et Saint-Jacques (KolDEweij 2006, p. 88-93) : par exemple, le dernier folio d'un manuscrit de la bibliothèque de Carpentras livre un itinéraire en 58 étapes vers Saint-Jacques-de-Compostelle, avec pour point de départ Avignon (PANSIER 1930).

24. Par exemple, testent avant de partir à «Saint-Jacques en Galice», en 1386, deux pêcheurs marseillais (AD BDR Marseille, 351 E 123, fol. 105r-107r et fol. 111v-114r), en 1414, le boulanger Honorat Sperelli (AD BDR Marseille, 351 E 167, fol. 4r à 6v), en 1428, le noble Jean Forbin (AD BDR Marseille, 351 E 236, fol. 276r-279v), en 1430, Gonzales Velho (AD BDR Marseille, 351 E 239 , fol. 263r-253v).
San Nicola de Bari et au sanctuaire de la Bienheureuse Marie de Montevergine à Avellino ${ }^{25}$. Certains pèlerins prévoient un circuit de sanctuaires à visiter. Bien que la majorité des testaments ne cite qu'un ou deux sanctuaires, quelques-uns de ces documents en mentionnent beaucoup plus et attestent alors un intense parcours de vie dans la foi ${ }^{26}$.

Le pèlerinage peut aussi être accompli par un proche à qui est délégué le devoir de l'effectuer à sa place ${ }^{27}$, éventuellement contre dédommagement ${ }^{28}$, ou par rétribution d'un pèlerin ${ }^{29}$. Dans un testament daté de 1402, la femme d'un apothicaire aixois exige de son héritier un pèlerinage peu commun : celui-ci doit se rendre, dans l'année suivant le décès, jusqu'au tombeau de saint Pierre de Luxembourg dans l'église des Célestins à Avignon, pieds nus et muni d'une image de cire d'un poids de sept livres ${ }^{30}$. Quelques personnages importants parviennent à faire annuler leur vœu : l'évêque de Marseille Pierre de Montlaur se fait ainsi dispenser par le pape Honorius en $1223^{31}$.

Dans les testaments aixois datés entre 1390 et 1450, $\mathrm{N}$. Coulet remarque que les objectifs principaux du pèlerin sont l'obtention d'indulgences, le salut de l'âme et la pratique pénitentielle ${ }^{32}$. Dans la documentation provençale de G. Veyssière, constituée de témoignages lors de procès en canonisation de la seconde moitié du XIV ${ }^{e}$ siècle ${ }^{33}$ et de vies de saints de la fin du XIII e siècle et de la fin du XIV e siècle ${ }^{34}$, sur environ 700 miracles recensés, 550 sont d'ordre thérapeutique, 90 sont liés aux risques naturels, 60 à l'insécurité des temps ${ }^{35}$. Il résulte de ces écrits, qui appellent bien évidemment à une certaine prudence étant donné leur nature hagiographique, que la plupart des personnes n'accomplissent un pèlerinage qu'une fois le vœu réalisé. La différence entre les raisons invoquées dans les testaments et celles présentes dans les récits de miracles s'expliquent certainement par le fait que le testateur prépare l'au-delà et songe beaucoup plus, dès lors, à la rémission de ses péchés et au salut de son âme.

\section{Michaud 2009, p. 323-324.}

26. Le testament de 1475 de Delphine Lagier, femme de laboureur, consigne une liste de neuf pèlerinages: Saint-Lazare-de-Marseille, Notre-Dame-deMoustiers, Saint-Jean-de-Signes, Saint-Jean-de-Garguier, Saint-Elzéar-d'Apt, Sainte-Marthe-de-Tarascon et Saint-Louis-d'Arles, ainsi que deux sanctuaires hors de Provence, Notre-Dame-du-Puy et Rocamadour (Coulet 1972, p. 251).

27. En 1414, par testament, la femme du seigneur de Collongue impose à son mari le romipetagium de la bienheureuse Marie-Madeleine à Saint-Maximin (Ribie 1898, p. 176).

28. Le chanoine d'Aix, Guillaume de Littera, spécifie dans son testament, en 1423, que s'il n'a pu de son vivant réaliser le pèlerinage à Saint-Jacques de Galice, son héritier devra le faire à sa place et recevra une forte somme d'argent à cet effet (RAMière DE Fortanier 1979, p. 71).

29. Le marchand florentin Pierre Viviani teste à Salon en 1483 et lègue une somme d'argent destinée à rémunérer un pèlerin qui se rendra au SaintSépulcre (Paillard 1969, p. 29).

30. Coulet 1972, p. 249.

31. Albank̀s et Chevalier 1899, pièce 228.

32. Coulet 1972, p. 248-249.

33. Procès en canonisation du cardinal Pierre de Luxembourg, inhumé à Avignon, de la comtesse Delphine de Puimichel, dont le corps est conservé à Apt, du pape Urbain V, dont la sépulture est à Marseille.

34. La Vida de Douceline, fondatrice des béguines de Marseille, et les Vies occitanes de Delphine et Elzéar.

35. Veyssière 1994, p. 199. 
Le pèlerinage peut être une affaire personnelle, communautaire ${ }^{36}$ ou le résultat d'une décision de justice. La jurisprudence de l'Inquisition cathare reconnaissait dans la première moitié du XIII siècle deux sortes de pèlerinages, quatre majeurs avec Rome, Saint-Jacques de Compostelle, Saint-Thomas de Cantorbéry, les trois rois à Cologne, et vingt mineurs dont, en Provence, Saint-Gilles, l'abbaye Saint-Pierre de Montmajour à Arles, la Sainte-Baume et Saint-Maximin ${ }^{37}$. Dans le comté de Flandres, la pratique du pèlerinage expiatoire, apparue à partir du milieu du XIII ${ }^{e}$ siècle, devient courante au XIV e siècle, fléchit au XVI ${ }^{e}$ siècle pour disparaître au XVII ${ }^{e}$ siècle. Les guerres de Religion seraient la cause principale de cet abandon ${ }^{38}$. Le sanctuaire provençal de loin le plus connu de ces tribunaux est celui de Saint-Gilles, mais il y eut aussi Saint-Maximin, Notre-Dame des Doms à Avignon, la Sainte-Baume, SaintLouis de Marseille, Saint-Victor de Marseille, Saint-Pierre de Luxembourg à Avignon et, enfin, les Saintes-Maries-dela-Mer ${ }^{39}$. Le condamné, une fois la sentence ordonnée, se déplace jusqu'au(x) sanctuaire(x) qui lui a/ont été désigné(s) et doit en rapporter des lettres attestant de ses visites. Il peut également racheter la sentence selon une grille tarifaire ${ }^{40}$. Aucun document ne permet de prouver, contrairement à une opinion commune, le jet de l'insigne du ou des pèlerinage(s) dans une rivière.

Les tensions qui agitent la société dans la seconde moitié du $\mathrm{XVI}^{\mathrm{e}}$ siècle obligent certaines personnes à faire reconnaître leur catholicité. C'est le cas de Louis Cavalier. Ce docteur en droit et avocat au Siège, à Draguignan, bien que reconnu catholique, s'en va, en 1569, à «Sainct-Mayxemin, en romavage, voyr la Saincte Ampole " probablement pour écarter tout doute dans l'esprit d'éventuels suspicieux, et ainsi, se faire oublier quelque temps ${ }^{41}$.

La visite des sanctuaires peut aussi être affaire d'opportunité, par exemple pour un marchand passant dans les environs. Le cardinal d'Aragon, lors de son retour en Italie, en 1517, profite de sa traversée de la Provence pour s'arrêter en de nombreux endroits vénérer les reliques ${ }^{42}$.

36. La communauté de Brignoles envoie à Saint-Antoine d'Arles, en 1491, un pèlerinage portant un cierge de 25 livres pour que la ville soit épargnée par la peste. Trois ans plus tard, elle fait envoyer deux pèlerinages, l'un à Notre-Dame de Plumier, l'autre à Saint-Antoine d'Arles, pour arrêter l'épidémie en cours dans la cité (BIRABEN 1976, t. 2, p. 70).

37. VALON 1935, p. 32 et 37.

38. Ibid., p. 51.

39. Ibid., p. 40; GANSHOF 1966.

40. Ibid., p. 33, 41, 45-47, 51.

41. AD Var, 1 B 270, fol. 158r.

42. À Avignon, il visite l'église des Célestins dans laquelle est conservé le corps du bienheureux Pierre de Luxembourg et la tombe du pape Clément VII. À Arles, il prie devant les reliques de saint Antoine. À l'abbatiale Saint-Victor de Marseille, il vénère le chef du saint, celui de saint Martin, de la chaire des Saints Innocents, une côte de saint Lazare, une dent de saint Pierre, la croix de saint André dont il est possible de baiser un morceau par dévotion. Dans l'arrière-pays, il s'arrête ensuite à «l'oratoire où la glorieuse Madeleine demeura avant d'aller faire pénitence sur le Mont de la Baume», puis à SaintMaximin où il se recueille devant le reliquaire contenant la tête de Madeleine (BRETON 1991, p. 50, 54).

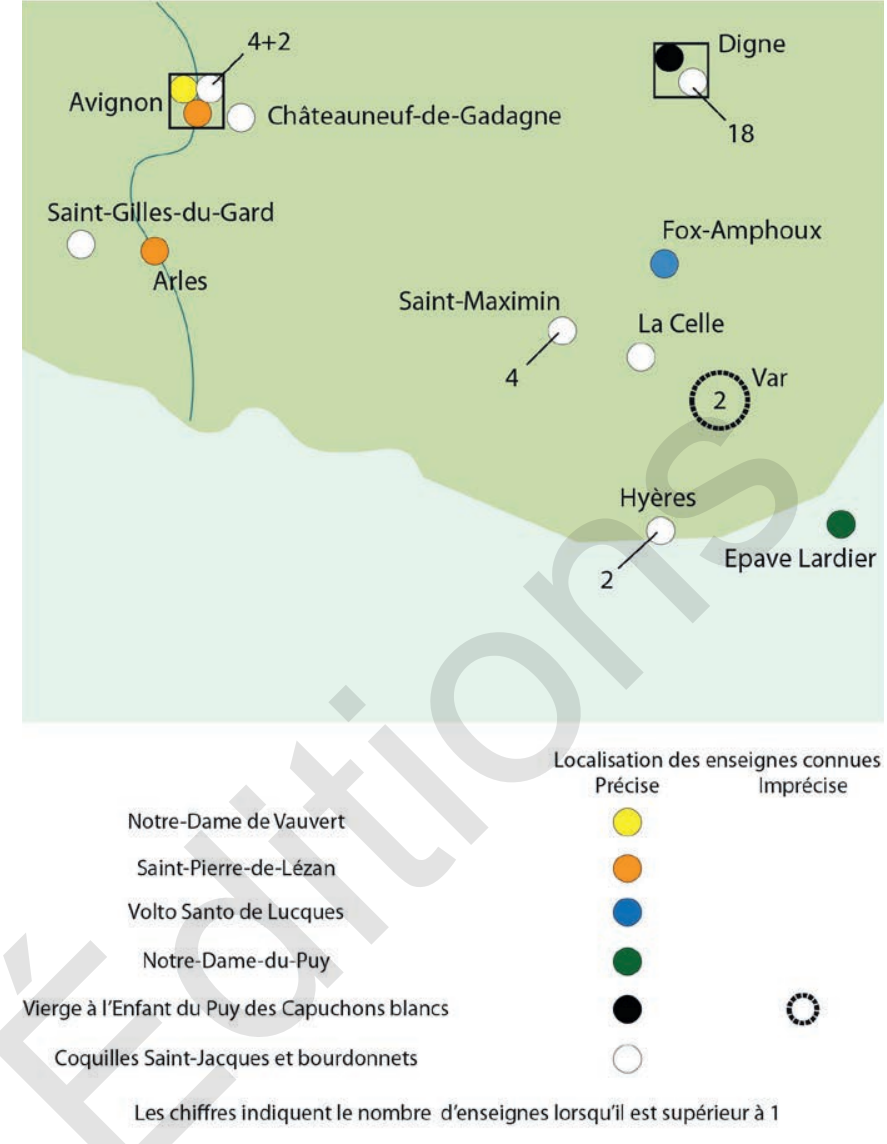

Fig. 2 Localisation des enseignes provenant de sanctuaires hors de Provence.

\section{LES ENSEIGNES ET AMPOULES DE PÈLERINAGE DÉCOUVERTES EN PROVENCE OU EN PROVENANT}

Les enseignes étudiées sont précédées d'une courte notice sur les sanctuaires et organisées selon la localisation d'est en ouest de ces derniers. Quelques considérations sur des sanctuaires provençaux de grande importance, pour lesquels il n'est pas encore connu d'enseignes de pèlerinage, sont également présentées. Par convention, sauf mention contraire, l'ensemble des objets présents dans ce chapitre, est en matériau blanc, c'est-à-dire en étain, en alliage d'étain et de plomb ou potentiellement en plomb (seules des analyses de composition permettraient d'identifier précisément le matériau). Beaucoup d'enseignes ont été retrouvées hors stratigraphie, ou dans des contextes d'une fiabilité incertaine. Les datations stylistiques proposées par les chercheurs ont été reprises avec leur éventuelle argumentation. Il est nécessaire de les considérer avec prudence. En effet, les moules peuvent avoir été utilisés pendant de longues périodes. De même, dans le long terme, l'image d'une enseigne, même archaïque, a pu être préférée lors de la production à celle d'une figuration plus récente. Elle met l'accent sur le caractère ancien du sanctuaire, sa pérennité et se fait, dès lors, le témoin de la continuité des bienfaits du lieu. 


\subsection{LES SANCTUAIRES DE SAINTE MARIE- MADELEINE}

Deux des plus célèbres centres de pèlerinage provençaux, bien que relativement récents, sont le couple grotte de la SainteBaume et abbaye de Saint-Maximin, deux sites concernés par la présence de Marie-Madeleine. Sainte Marie-Madeleine, témoin important de la vie du Christ, est célébrée depuis le $\mathrm{XI}^{e}$ siècle à Vézelay, où son corps aurait été déplacé depuis Saint-Maximin à la fin du IXe siècle, mais la vie de disciple et de pénitente qu'elle aurait menée en Provence a donné naissance à un pèlerinage dans la grotte de la Sainte-Baume, où elle se serait réfugiée pendant 30 ans après avoir été chassée de Béthanie. Saint Louis y passe en 1254 avant de partir en croisade ${ }^{43}$. Les lieux à visiter à la Sainte Balme sont ainsi décrits par le notaire nîmois Étienne Borrely en 1677 : «le rocher où la Magdeleine reposoit, la chapelle qui est au derrière du rocher et le Saint Pilon ${ }^{44}$. La création du pèlerinage à Saint-Maximin est, quant à lui, l'œuvre de Charles II. Avant de devenir comte de Provence et roi de Sicile, le prince de Salerne entreprend en 1279 de mettre au jour le «vrai» corps de la sainte. Ce dernier est reconnu comme tel par le pape Boniface VIII en $1295^{45}$. L'abbaye conserve, ainsi que le décrit Étienne Borrely, «la sainte Ampoule, la teste de la Magdeleine et ses cheveux dans une ampoule, son bras et autres reliques très précieux $»^{46}$. Le développement du culte doit beaucoup à Charles II, mais aussi à Jean Gobi l'Ancien, prieur du couvent royal de Saint-Maximin, qui compila des miracles en un livre dans le premier tiers du XIV ${ }^{e}$ siècle. L'objectif fut d'illustrer les mérites de la sainte et d'attester la présence de son corps à Saint-Maximin. D'après le contenu des miracles, la plupart des pèlerins venaient du comté de Provence, du Gard, de l'Hérault, mais aussi d'Italie, et les maladies tiennent une place prépondérante dans la formulation des motifs ${ }^{47}$. Rois de France, personnages puissants ${ }^{48}$ et anonymes ${ }^{49} s^{\prime} y$ pressent durant les XIV ${ }^{e}, \mathrm{XV}^{\mathrm{e}}$ et $\mathrm{XVI}^{\mathrm{e}}$ siècles. En février 1478, par exemple, le roi René vient au pardon de Saint-Maximin et sa petite fille y achète des enseignes. Des exemplaires en matériau précieux sont acquis ou fabriqués par la suite (fig. 3). Le pèlerinage perd de son importance durant l'époque moderne : en 1780, Jean-Pierre Papon précise : «bien que les pèlerinages de la Sainte-Baume ne soient plus aussi fréquents qu'ils l'étaient autrefois; il y a peu de personnes parmi le peuple, qui s'en dispensent la première année de leur mariage : et si ce voyage n'est pas stipulé dans le contrat, il est du moins regardé comme une preuve de la tendresse des époux pour leurs femmes $»^{50}$.

43. SCLAFERT (éd.) 2009, p. 22-24.

44. Рuech 1885, p. 463.

45. SCLAfert (éd.) 2009, p. 26-29.

46. Puech 1885, p. 463.

47. Sclafert (éd.) 2009, p. 29-33, 44-45, 57-59.

48. Se reporter à FaIllon 1865, p. 494, 1509-1511 et à Breton 1991, p. 4.

49. Par exemple, en 1471, Jean Morel, homme à tout faire au service d'un notaire de Cucuron, prend congé de son employeur pour quelques jours et, avec une avance de six gros sur son salaire, part en direction de ces lieux saints (Audisio 1988, p. 156).

50. Papon 1780, p.59. Charles de Ribbe témoigne également de cette tradition, mais il ne cite pas ses sources et cet auteur généralise souvent à partir de quelques données éparses (RibBE 1898, p. 177).

\begin{tabular}{|c|c|c|c|}
\hline & Roi René & & \\
\hline \multirow[t]{2}{*}{1447} & $\begin{array}{l}\text { Achat de dix-huit enseignes en argent de Pierre de Luxembourg } \\
\text { (Avignon) }\end{array}$ & 1,5 gr. pièce & L 537 \\
\hline & Fabrication de douze enseignes en or et de cent-huit en argent & $\begin{array}{l}3,4 \text { gr. pièce } \\
(\mathrm{Ag}) 7,5 \text { gr. } \\
\text { pièce }(\mathrm{Au})\end{array}$ & A 546 \\
\hline \multirow[t]{6}{*}{1451} & Achat d'enseignes de Notre-Dame de Béhuart (Maine-et-Loire) & & $\begin{array}{l}\text { A 1334, } \\
3382\end{array}$ \\
\hline & Achat d'enseignes de Saint-Antoine de la Lande (Maine-et-Loire) & 10 s. $10 \mathrm{~d}$. & A 2770 \\
\hline & $\begin{array}{l}\text { Achat d'enseignes "de plomb" de Saint-Eutrope de Saintes } \\
\text { (Charente-Maritime) }\end{array}$ & 87 s. 6 d. & A 2779 \\
\hline & $\begin{array}{l}\text { Achat de sept grandes enseignes "de plomb" et d'une douzaine plus } \\
\text { petites }\end{array}$ & $3 \mathrm{s.} .4 \mathrm{~d}$. & A 2461 \\
\hline & Fabrication d'une enseigne en or à la figure de saint Jean & $30 \mathrm{~s}$. & A 852 \\
\hline & $\begin{array}{l}\text { Fabrication de neuf enseignes en or et de soixante-douze en argent } \\
\text { à un orfèvre de Sainte-Catherine de Fierbois (Maine-et-Loire), } \\
\text { d'une burlette d'argent ou est la vie de saincte Catherine. }\end{array}$ & 101 & A 853 \\
\hline 1452 & Achat d'enseignes & 27 s. $6 \mathrm{~d}$. & A 2471 \\
\hline 1453 & $\begin{array}{l}\text { Commande à son armurier, pour lui et ses compagnons, de vingt- } \\
\text { trois bourdons tournants en bois à pointes retenues par des } \\
\text { viroles, pour faire une partie du trajet à pied jusqu'à Notre-Dame de } \\
\text { Cléry-Saint-André (Loiret) }\end{array}$ & $3 \mathrm{~s} .3 \mathrm{~d}$ pièce & A 1144 \\
\hline \multirow[t]{3}{*}{1476} & $\begin{array}{l}\text { Achat d'enseignes de Notre-Dame de l'Isle (Vienne, Isère) } \\
\text { données à des femmes }\end{array}$ & $10 \mathrm{~g}$. & L 88 \\
\hline & $\begin{array}{l}\text { Dépense à un homme de Valence (Drôme) pour avoir percé une } \\
\text { coquille qui est au chappeau du roy }\end{array}$ & 6 patacs & L 88 \\
\hline & $\begin{array}{l}\text { Défraiement d'un valet pour avoir emmené une branche de corail } \\
\text { enchâssée dans de l'argent à Sainte-Marthe de Tarascon }\end{array}$ & & L 88 \\
\hline \multirow[t]{9}{*}{1478} & $\begin{array}{l}\text { Achat d'ymaiges de la Magdemaine par sa petite fille au pardon } \\
\text { de Saint-Maximin }\end{array}$ & & $\begin{array}{l}\text { L 89, p. } \\
379\end{array}$ \\
\hline & Achat de dix enseignes en argent de Saint-maximin & 3 gr. pièce & A 994 \\
\hline & Achat de dix enseignes en argent doré de Saint-maximin & 4 gr. pièce & A 994 \\
\hline & Fabrication de dix enseignes en or de Saint-maximin & 1 fl. pièce & A 996 \\
\hline & $\begin{array}{l}\text { Achat à Marseille de deux enseignes de sainte Catherine, de deux } \\
\text { véroniques et de trois croix de corail }\end{array}$ & & $\begin{array}{l}\text { L 89, p. } \\
378\end{array}$ \\
\hline & $\begin{array}{l}\text { Rémunération d'un sellier d'Avignon pour avoir nerve un bordon } \\
\text { et l'avoir recouvert de parchemin }\end{array}$ & & A 2205 \\
\hline & 2 & & \\
\hline & Duc de Calabre & & \\
\hline & 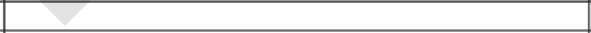 & & \\
\hline \multirow[t]{3}{*}{1478} & Achat d'enseignes en argent pour placer sur une "écharpe" en soie & 1 fl. 8 gr. & A 995 \\
\hline & $\begin{array}{l}\text { Vingt douzaines d'enseignes "d'étain" pour mettre sur des écharpes } \\
\text { en toile rouge pour les pages et d'autres }\end{array}$ & & A 2620 \\
\hline & $\begin{array}{l}\text { Achat de quatre-vingt enseignes de "plomb" au lieu de Saint-Marc } \\
\text { près d'Aix-en-Provence }\end{array}$ & & A 3339 \\
\hline
\end{tabular}

Fig. 3 Dépenses du roi René et de son fils le duc de Calabre en enseignes, bourdons de marche et autres objets relatifs à des lieux de pèlerinage. $A+n^{\circ}=$ ARNAUD D'AGNEL 1908; $L+n^{\circ}=$ LECOY DE LA MARCHE 1875.

Six enseignes du pèlerinage de Marie-Madeleine de SaintMaximin sont actuellement répertoriées : cinq exemplaires rectangulaires en matériau blanc fabriqués par la fonte et un spécimen confectionné dans une feuille d’argent estampée.

Une première enseigne en matériau blanc, fortement rognée, a été trouvée dans la Seine à Paris en 1849. Son état actuel, similaire au dessin d'Arthur Forgeais en 1863 (fig. 4, $\mathrm{n}^{\circ}$ 1a), diffère quelque peu du dessin de Éugène Hucher en 1853 (fig. 4, $\mathrm{n}^{\circ} 1$ b), mais ce dernier comporte des erreurs. Une seconde enseigne, datée stylistiquement de la fin du XIII ${ }^{e}$ ou du début du XIV ${ }^{e}$ siècle ${ }^{51}$, a été trouvée sur les berges de la Tamise, à Londres (fig. $\left.4, \mathrm{n}^{\circ} 2\right)^{52}$, une troisième est conservée au musée Carnavalet (fig. $\left.4, \mathrm{n}^{\circ} 3\right)^{53}$. Une quatrième pièce, provenant du Mont Saint-Michel, est datée stylistiquement du XIII siècle par Arthur Forgeais (fig. 4, no 4$)^{54}$. La dernière, attribuée au

\footnotetext{
51. Santiago de Compostela, p. 316, n० 216 .

52. SPENCER 2010, p. 239, fig. $246 \mathrm{f}$.

53. № 367 , tiroir 2 du médaillier de Forgeais. L'objet est très abîmé.

54. Forgeais 1865, p. 229-231.
} 


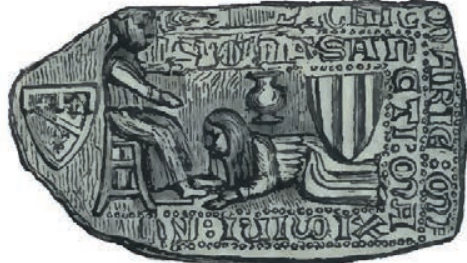

$1 \mathrm{a}$

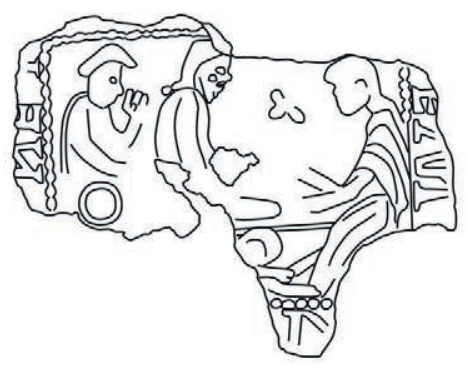

3

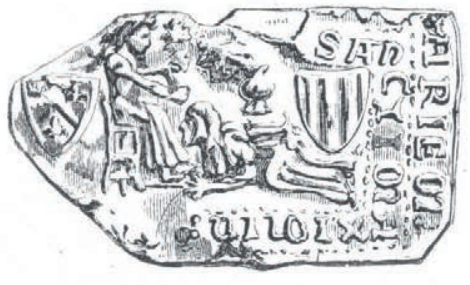

$1 \mathrm{~b}$

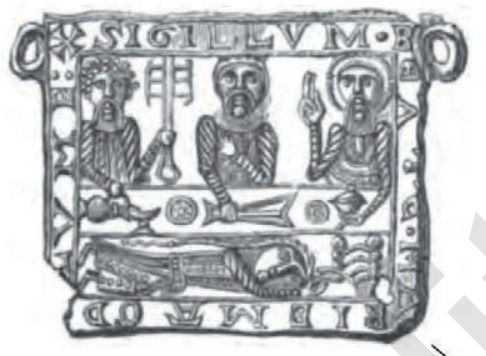

4

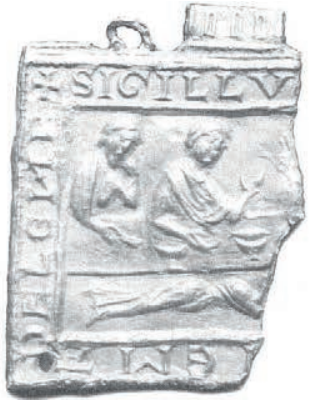

2

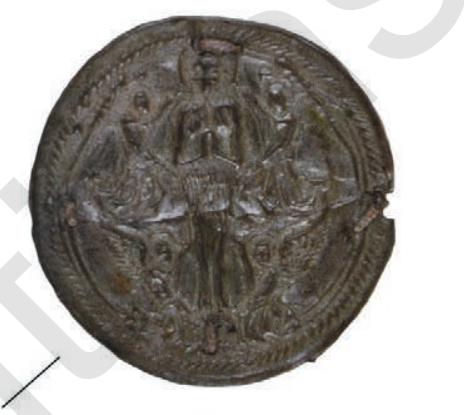

5

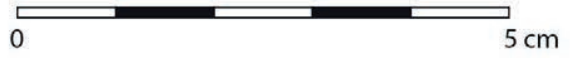

Fig. 4 Enseignes des sanctuaires de sainte Marie-Madeleine; $n^{\circ}$ 1a, Seine (Pont-au-Change), Paris, musée national du Moyen Âge à Paris, dessin : E. Hucher (HUCHER 1853); b, même objet, dessin: A. Forgeais (ForGeAls 1863); no 2, Tamise (barrage de Vintry), Londres, London Museum à Londres, cl. London Museum (SPENCER 2000, p. 239, fig. 246f); n 3, Seine, Paris, dessin, musée Carnavalet à Paris, dessin : O. Thuaudet; n 4, Mont Saint-Michel, Normandie, lieu de conservation inconnu, dessin : A. Forgeais (ForGeals 1863); n 6, Livre d'heures d'Oiselet, troisième quart du Xve siècle, Bibliothèque royale de La Haye (ms 77 L 60), cl. Bibliothèque royale de La Haye (BRUNA 1998, p. 47).

XVI e siècle par l'abbé Desnoyers, fut ramassée dans le lit de la Loire à Orléans, au début des années 1870. Elle a disparu, vraisemblablement lors de l'incendie du musée de l'Orléanais en $1940^{55}$.

Ces objets en matériau blanc reproduisent une femme prosternée devant le Christ (fig. 4, no 1 ), ou allongée sous une table à laquelle prend place le Sauveur (fig. $4, n^{\circ} 2$ à 4 ) qui, dans un cas au moins, bénit de la main droite (fig. $4, \mathrm{n}^{\circ} 4$ ). La scène se déroule dans la maison de Simon le Pharisien, au moment du repas: «Et se plaçant par derrière, à ses pieds, tout en pleurs, elle se mit à lui arroser les pieds de ses larmes; et elle les essuyait avec ses cheveux, les couvrait de baisers et les oignait de parfum» (Luc 7, 37-38). Quatre enseignes (fig. 4, no 3 à 4) figurent deux personnages supplémentaires, qui peuvent être identifiés par comparaison avec une enseigne du Mont SaintMichel (fig. 4, no 4 ) : saint Pierre, reconnaissable à sa clef, remplit une coupe. Au centre, de la table, Simon tient un couteau et fait les honneurs de la table. L'une des "clefs conjuguées» perçues par l'abbé Desnoyers sur la pièce d'Orléans ${ }^{56}$ pourrait bien être ce couteau. Dans la partie supérieure de l'objet londonien (fig. $4, \mathrm{n}^{\circ} 2$ ), trois petits arcs dans une excroissance rectangulaire figureraient le sanctuaire de Saint-Maximin ${ }^{57}$. L'inscription

55. DeSNOYERS 1876, p. 174.

56. Inscription sur la pièce d'Orléans (DESNOYERs 1876, p. 174).

57. SANTIAGo 1985 , p. $316, \mathrm{n}^{\circ} 216$. est variable : + SIGILLV[M BEATE MAR]IE MADELENE (fig. 4, no 2), + SIGILLVM BEATE MARIE MAGDALVME (fig. $4, \mathrm{n}^{\circ}$ 2) ou [SIGNUM BEATE M]ARIE M[AGDALENE] ${ }^{\mathrm{s}}$ éventuellement suivi de SANCTI MAXIMIN[I] (fig. 4, no 1 ) qui donne la localisation du sanctuaire. L'iconographie et la forme des autres pièces, très semblables, ne laissent aucun doute sur leur origine commune ${ }^{59}$. Sur l'enseigne parisienne, deux écus encadrent la scène, l'un aux armes de Sicile-Tarente à gauche - semé de France au lambel de gueules à la cotice d'argent l'autre de Provence à droite - d'or à quatre pals de gueules. Leur présence pourrait être liée, selon Arthur Forgeais et Denis Bruna $^{60}$, à une lettre du 29 avril 1354 de Louis de Tarente et de sa femme Jeanne, à destination des magistrats de Saint-Maximin, suite à une plainte émanant du prieur du couvent et des artisans habilités à procéder à la fabrication des enseignes ${ }^{61}$. Selon la coutume alléguée et remontant au moins à l'année 1311, le prieur remet les moules (ferrum ou ferrus) à enseignes de pèlerinage aux personnes de son choix, le produit de la vente des objets obtenus est ensuite vraisemblablement partagé entre les parties. Il n'y a donc d'autres marchands autorisés à faire ce commerce

58. DeSNOYERs 1876, p. 174.

59. A. Forgeais hésite entre une attribution à Vézelay ou à Saint-Maximin pour l'objet de Normandie (ForgEAIs 1863, p. 205-207).

60. Ibid., p. 205-207; BRUNA 1996, p. 170-171; ID. 2003, p. 69.

61. FAILlON 1865, t. 1, p. 971, t. 2, p. 963-968; CARRU et GAGniÈre 1992, p. 57. 


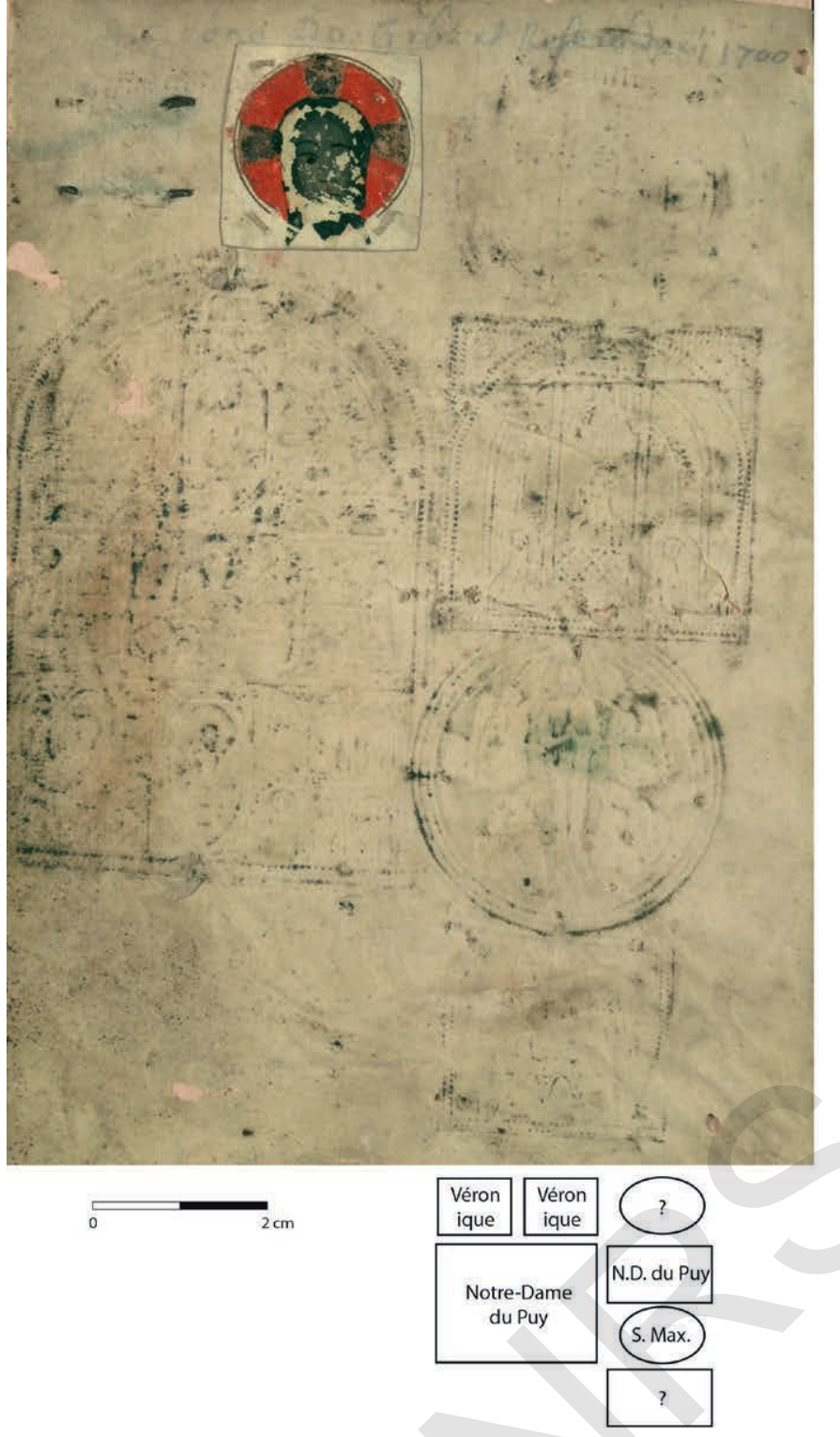

Fig. 5 Livre d'Heures, Bibl. Inguimbertine, Carpentras, ms. 59, fol. 110r, cl. Bibl. Inguimbertine.

dans le pays que ceux sélectionnés par le sacristain. Cependant, peu après la peste de 1348, des commerçants se fixent dans la ville de Saint-Maximin et font graver des moules pour leur propre compte. Le couple comtal enjoint alors aux magistrats de faire respecter le droit coutumier des religieux. Les armoiries symbolisent-elles cette décision et garantissent-elles que cette enseigne est un produit autorisé?

La dernière enseigne répertoriée est une mince tôle d'argent circulaire, estampée, cousue au moyen de huit perforations en bordure, parmi 22 autres plaquettes de différents sanctuaires, sur le dernier feuillet du livre d'heures d'Oiselet, daté du troisième quart du $\mathrm{XV}^{\mathrm{e}}$ siècle (fig. $\left.4, \mathrm{n}^{\circ} 5\right)^{62}$. Dans un cadre constitué d'un cercle cordé et d'un cercle uni, Marie-Madeleine figure auréolée, les mains jointes en un geste de prière, flanquée de quatre anges la transportant vers le ciel. Une enseigne

62. BRUNA 1998, p. 147. semblable, de 3,6 cm de diamètre (fig. 5), était cousue sur le dernier feuillet d'un livre d'heures exécuté, entre 1485 et 1490, pour Antoine Bourdin, sergent et garde du château de Beaucaire, receveur particulier au diocèse de Nîmes ${ }^{63}$. Quatre autres enseignes et une véronique peinte sur un petit rectangle de parchemin - une autre est encore en place - ont également été arrachées du feuillet.

\subsection{LES SANCTUAIRES MARSEILLAIS}

La sépulture de saint Victor, mort en 303, devint très tôt un lieu de pèlerinage. Présent dès la fin de l'Antiquité, son rayonnement atteignait la Touraine et le Poitou, comme l'attestent notamment les écrits de Grégoire de Tours et de Venance Fortunat $^{64}$. Il semble perdurer à la fin du Moyen Âge, mais peut-être avec moins d'intensité, ce qui pourrait expliquer l'absence actuelle d'enseignes de pèlerinage pour ce sanctuaire. En octobre 1365, Urbain V part en pèlerinage à l'abbaye de Saint-Victor : il y avait été abbé avant son élection à la papautées. Il s'y fait inhumer et un pèlerinage s'y établit. À Marseille est également conservé le corps de saint Louis de Marseille, évêque de Toulouse, mort à Brignoles et inhumé dans l'église des Frères mineurs de Marseille, canonisé en 1317. Il fut aussi l'objet d'un pèlerinage.

\subsection{LES SANCTUAIRES AVIGNONNAIS}

La ville d'Avignon, centre religieux de premier plan au bas Moyen Âge, est la destination de nombre de pèlerins. La plupart viennent pour prier sur la dépouille de Pierre de Luxembourg dans l'église des Célestins et devant une statue de la Vierge hautement vénérée à Notre-Dame-des-Doms. Un témoignage transcrit dans le procès en canonisation de Pierre de Luxembourg, ouvert en 1390, interrompu au décès de Clément VII en 1397 et jamais repris, fait état de l'existence d'un culte rendu au corps de la bienheureuse Marie d'Espérance conservé dans l'église Notre-Dame d'Espérance à Avignon. Il mentionne, d'une part, que ce dernier sanctuaire est délaissé par les fidèles, d'autre part, que le culte rendu au cardinal connaît un succès retentissant. Il perdure encore au XVII siècle ${ }^{66}$.

\subsubsection{Les sanctuaires de saint Pierre de Luxembourg}

Pierre de Luxembourg, d'origine germanique, est nommé évêque de Metz à quinze ans par Clément VII qui le fait ensuite venir à Avignon et le nomme cardinal-diacre. Il meurt, dans sa dix-huitième année, en 1387 à Villeneuve-lès-Avignon. Sa grande piété et son humilité sont reconnues. Il a demandé de surcroît à être enterré parmi les pauvres au cimetière Saint-Michel. Peu après son inhumation le 5 juillet, de grandes foules se pressent autour de sa sépulture. Un commerçant de

\footnotetext{
63. Ibid., p. 142-143.

64. Moulinier 1997, p. 607, 609, 611.

65. Hayez 1987, p. 21.

66. Feuillas 1985.
} 


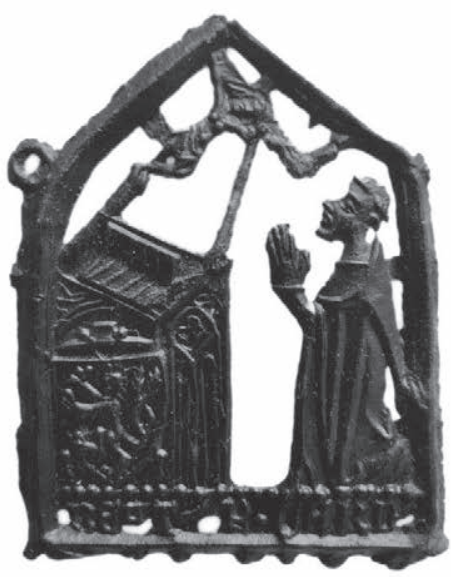

1

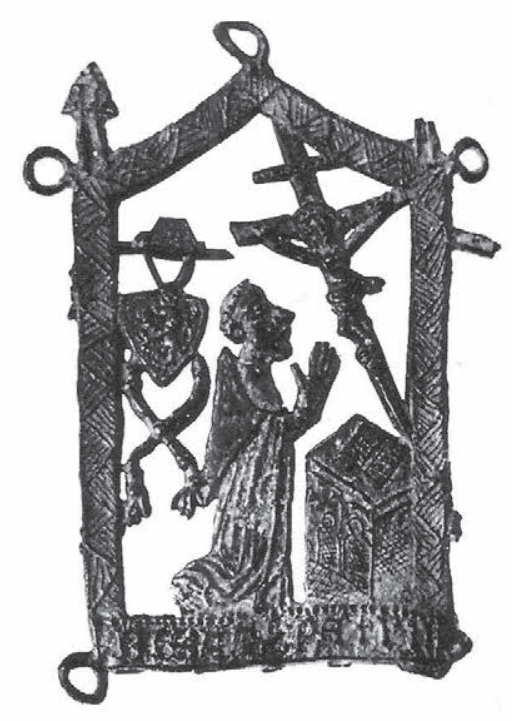

2

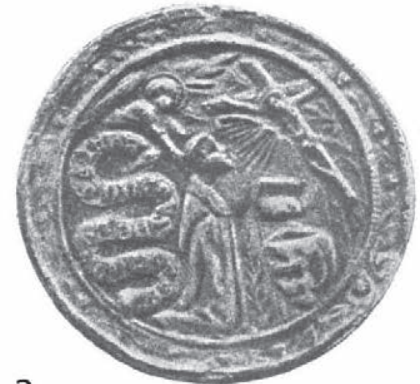

3

Taille réelle inconnue

4

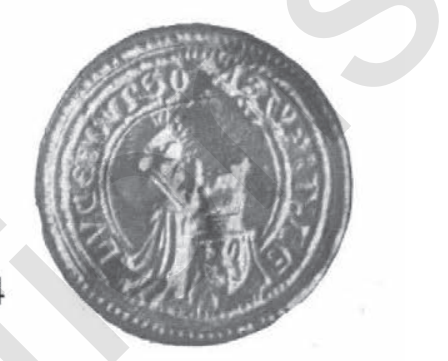

0

$5 \mathrm{~cm}$

Fig. 6 Enseignes du sanctuaire de Pierre de Luxembourg; $n^{\circ}$ 1, Dordrecht (Pays-Bas), collection particulière, cl. H. J. E. Beuningen (BRUNA 2003); $n^{\circ}$ 2, Saint-Georges, Lyon, Rhône, cl. J.-M. Degueule, (GALTIER et al., fig. 231); no 3, Environs de Grenoble?, Isère, lieu de conservation inconnu, dessin : L. Maxe-Werly (LABANDE 1899); no 4, Provenance inconnue, Musée Calvet, cl. L. H. Labande (LABANDE 1899).

la succursale avignonnaise de la compagnie Datini rapporte à la mi-juillet que «le savant comme l'ignorant, l'idiot, le pauvre $\mathrm{y}$ vont comme ils iraient à un grand pardon, et cela le matin, à midi et le soir. Songez que chaque nuit 200 personnes dorment et veillent par dévotion en cet endroit. Beaucoup de malades y sont allés et, la neuvaine faite, ont été complètement guéris ${ }^{{ }^{67}}$. Une chapelle de bois est financée en 1389 par Marie de Blois, veuve de Louis Ier d'Anjou. La même année, le roi Charles VI venu à Avignon pour requérir auprès du pape la canonisation de Pierre de Luxembourg, fait disposer une statue de cire grandeur nature à son image devant le tombeau du cardinal, pour le remercier d'une guérison ${ }^{68}$. En 1394, sous l'impulsion de Clément VII, est entreprise la construction de l'église des Célestins dans laquelle sont ensuite transférés les restes du bienheureux ${ }^{69}$. La fabrication d'enseignes à l'effigie du cardinal a probablement débuté rapidement, le succès financier étant assuré par la fréquentation. En 1447, le roi René fait acheter à Avignon des enseignes d'argent de saint Pierre de Luxembourg (fig. 3). Des images de papier (signa sive imagines) sont également vendues. En 1441, leur fabrication est confiée par les Célestins au maître cartier Gillet Courier, originaire du diocèse de Meaux et habitant la cité papale ${ }^{70}$. Elles semblent avoir eu un pouvoir particulier pour prémunir le décès des femmes lors de l'accouchement, d'après les témoignages rapportés dans le procès en canonisation en $1397^{71}$. Ce procès, interrompu cette même année, montre que les pèlerins venus témoigner sont,

67. BRUN 1935, p. 100.

68. VALLet De Viriville 1858, p. 344-346.

69. Laclotte et Thiébaut 1983, p. 240.

70. СноваUт 1943, p. IV-V.

71. JANNINCK et al. 1719, p. $79, \mathrm{n}^{\circ} \mathrm{CCI}$ et CCII. pour la majeure partie, originaires du diocèse d'Avignon et des diocèses limitrophes ${ }^{72}$. Néanmoins, la procédure, mise en place peu de temps après le décès du cardinal, accroît la renommée de ce saint homme et elle se propage par la suite beaucoup plus largement. Le sanctuaire devient d'ailleurs la destination de pèlerinages pénitentiels depuis les Flandres et la Wallonie ${ }^{73}$ et de ce fait, une enseigne de Pierre de Luxembourg a été découverte à Dordrecht, aux Pays-Bas ${ }^{74}$ (fig. 6, no 1 ).

Quatre objets ont été répertoriés pour le sanctuaire d'Avignon. Outre la pièce susmentionnée, un deuxième artefact (fig. $6, \mathrm{n}^{\circ} 2$ ) a été découvert en position intrusive dans un niveau daté de la fin XII ${ }^{-}$-début XIII ${ }^{e}$ siècle sur le site de Saint-Georges à Lyon ${ }^{75}$. La première enseigne prend la forme d'une arcade gothique en ogive, la seconde, celle d'une nef aux murs surmontés de pinacles. Une enseigne ou médaille circulaire qui pourrait avoir été trouvée dans les environs de Grenoble (fig. 6, no 3$)^{76}$. Un coin cylindrique en acier, de $3,3 \mathrm{~cm}$ de diamètre pour $12,5 \mathrm{~cm}$ de haut, surmonté d'un appendice destiné à l'emmanchement, ayant servi à la fabrication d'une «médaille» ou d'une «enseigne» à l'effigie du bienheureux

\footnotetext{
72. VeYsSiÈre 1987, t. 1, p. 19-21, t. 2, p. 390-392; VeYsSiÈre 1994, p. 209. 73. VALON 1935, p. 40.

74. Beuningen et Koldeweij 1993, p. 188; Bruna 2003, p. 1.

75. Galtier et al. 2013, p. 283

76. MAXe-Werly 1898, p. 52. L'objet est connu par une reproduction en métal établie d'après un estampage en papier d'étain. Le terme de «médaille» employé par L. Maxe-Werly instille un doute: s'agit-il réellement d'une médaille ou d'une enseigne circulaire, comme le pense Denis Bruna (BRUNA 2003, p. 71). Dans ce dernier cas, l'objet originel serait en tôle et quelques-uns des grènetis visibles dans le cadre marqueraient l'emplacement de perforations pour une fixation par couture.
} 


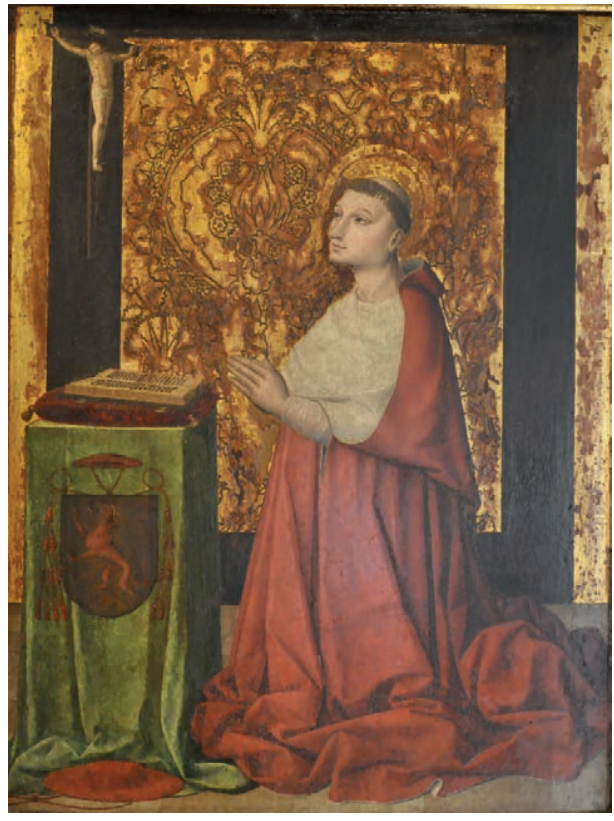

Fig. 7 Peintre provençal, Le bienheureux Pierre de Luxembourg, vers 1470/1475, Musée du Petit Palais à Avignon (cl. O. Thuaudet).

appartient, selon Louis-Honoré Labande, aux collections du musée Calvet (fig. 6, $\left.\mathrm{n}^{\circ} 4\right)^{77}$.

Ces objets figurent le récit de l'extase du saint à Châteauneuf, tel qu'il est rapporté par le dossier en vue de la canonisation. Plongé dans une longue oraison, le bienheureux Pierre de Luxembourg, voit apparaître devant lui le Christ sur la croix. Sa tête est dirigée vers l'apparition par un ange sur une pièce (fig. 6, n 3). Un tableau daté vers 1470-1475, autrefois disposé au-dessus du tombeau et actuellement conservé au Musée du Petit Palais d'Avignon, a servi de modèle à ces enseignes, à moins que ce soit le contraire (fig. 7) ${ }^{78}$. Pierre y est représenté le regard levé en direction de l'apparition divine située au-dessus d'un prie-Dieu. Le prie-Dieu sur lequel repose un livre ouvert est couvert d'un tissu arborant sur le côté un écu aux armes des Luxembourg, d'azur au lion de gueule rampant couronné d'or, surmonté d'un chapeau cardinalice à cordons, terminés par vingt houppes, rappelant la dignité du personnage. Sur deux objets, le meuble, sans tissu, est richement ouvragé de motifs architecturaux gothiques. L'enseigne lyonnaise est la seule sur laquelle l'écu est déplacé derrière le saint (fig. 6, nº 2). Il est sommé d'un chapeau cardinalice d'où pendent deux cordons à houppes. Le titre de bienheureux, octroyé officiellement en 1527, lui avait déjà été donné par la ferveur populaire depuis longtemps ${ }^{79}$. Il se retrouve dans une inscription au bas d'une pièce - BEAT[VS] P[ETRVS] CARD[INALIS] (fig. 6, no 1) -, dans un listel serpentiforme sommé d'un ange - BEATVS PETRVS LVCEMBOVRG (fig. 6, n 3) - sur une autre. La dénomination de saint qui apparaît sur le coin - S[ANC]TVS P[ETRVS] DE LVCE[M]BVRGO (fig. 6, no 4 ) - est reprise dans les comptes du roi René en 1447 (fig. 3).

77. L'objet pourrait provenir des anciens fonds de la monnaie d'Avignon et avoir été donné au musée par la préfecture en 1835 (LABANDE 1899).

78. Pour plus d'informations sur ce tableau, se reporter à LACLotte et Thiébaut 1983, p. 240-241.

79. Maxe-Werly 1898, p. 52.
L'«enseigne» répertoriée à Dordrecht (Pays-Bas) (fig. 6, $\mathrm{n}^{\circ} 1$ ) est datée par Louis-Honoré Labande de l'extrême fin du $\mathrm{XV}^{\mathrm{e}}$ siècle et le coin d'Avignon (fig. $6, \mathrm{n}^{\circ} 4$ ) de la première moitié du même siècle ${ }^{80}$. Dans ce cas, la peinture du musée du Petit Palais, dont l'exécution est fixée aux années 1470-1475, qui présente de nombreuses similitudes avec les objets étudiés, s'inspirerait des enseignes et autres images produites à destination des pèlerins.

\subsubsection{Notre-Dame-des-Doms}

Le sanctuaire de Notre-Dame-des-Doms abrite une statue de la Vierge hautement vénérée, qui fut emportée par les chanoines $^{81}$ lors de l'expulsion du chapitre par les Catalans en 1409, dans le cadre du conflit qui opposait les Avignonnais au pape Benoît XIII. En 1316, Jean XXII octroie une indulgence à ceux visitant le lieu lors de certaines fêtes ${ }^{82}$. Il fut également une destination de pèlerinages pénitentiels ${ }^{83}$.

Une enseigne de Notre-Dame-des-Doms a été mise au jour à Avignon, rue Pasteur, lors de travaux de voirie (fig. 8). L'objet est de forme globalement rectangulaire et ses œillets de fixation ont disparu. Un cadre, disposé sur trois côtés, comprend l'inscription S[IGNVM] BEATES M[ARIAE] DE DOM[O] AVINIONIS. Une Vierge couronnée, tenant dans sa main droite un sceptre et dans son bras gauche l'Enfant, auréolé, prend place sous un portail à deux colonnes torses à chapiteaux - ornés d'une feuille d'acanthe? Un clocher composé de quatre étages d'arcades à deux ou trois baies surmonte le tout. De part et d'autre de celui-ci se détachent deux probables candélabres. D’après Dominique Carru, «le style, la découpe du sujet, et la graphie des lettres de la légende (E en onciale romane), permettent d'en situer la fabrication vers la fin du XIII' siècle ou durant le siècle suivant, mais à coup sûr avant 1405 », puisqu'à cette date, le clocher s'effondre et que sa reconstruction ne s'achève ensuite, avec un résultat quelque peu différent, qu'au milieu du XVe siècle ${ }^{84}$. Une précision est nécessaire : ce n'est pas tant la fabrication de l'objet qui peut être ainsi datée, mais la période d'exécution de l'empreinte originelle, puisque le moule a très bien pu rester en service après les travaux, ou même être reproduit ultérieurement à l'identique, une fois le premier exemplaire devenu inutilisable ${ }^{85}$. Mais, cette méthode de datation n'est pas non plus fiable, car les graveurs ont certainement fait le choix d'un rendu approximatif du bâtiment.

\subsection{LES SANCTUAIRES D'ARLES ET DE SA RÉGION}

Les principaux lieux de pèlerinage sont l'église collégiale SainteMarthe de Tarascon et surtout l'abbaye de Montmajour. Il convient également de citer Saint-Trophime d'Arles où repose le premier évêque d'Arles et où le Guide du pèlerin conseille

80. LABANDE 1899 , p. 410

81. PANSIER 1912a, p. 106

82. Albanès et Chevalier 1920, pièce 904.

83. VAlON 1935, p. 40; GANShof 1966.

84. CARru 1998, p. 49, 52, 53.

85. Voir à ce propos Bruna 1996, p. 9. 


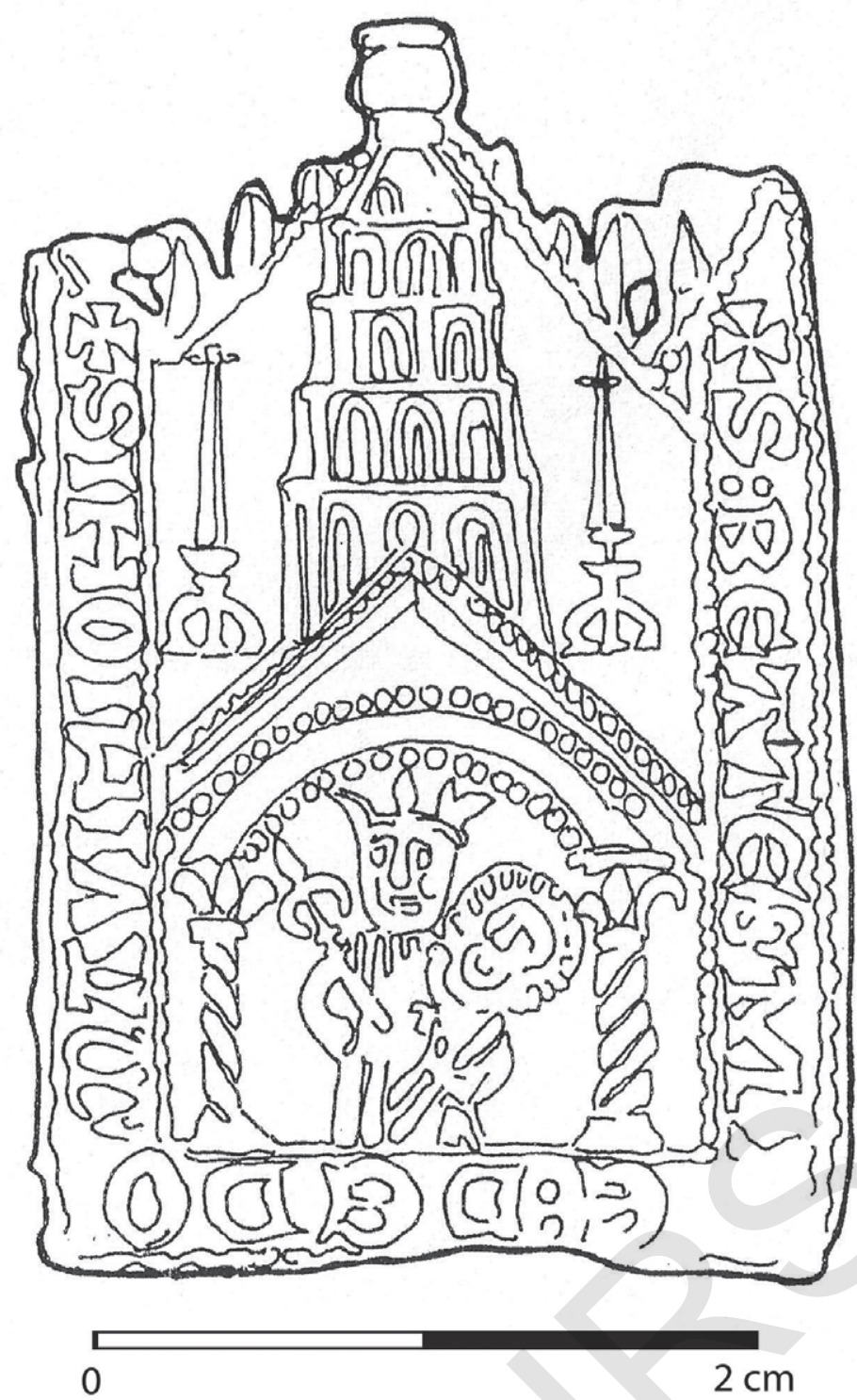

Fig. 8 Enseigne de l'église Notre-Dame des Doms, rue Pasteur, Avignon, Vaucluse, Service archéologique du Vaucluse, dessin: D. Carru (CARRU 1998).

une halte ${ }^{86}$. Mais, aucune enseigne se rapportant à ce sanctuaire n’a encore été retrouvée.

\subsubsection{L'église collégiale Sainte-Marthe de Tarascon}

L'église collégiale de Tarascon conserve les reliques du corps de sainte Marthe. Le territoire de l'actuel Tarascon était soumis à la terreur de la Tarasque depuis de nombreuses années lorsque Marthe, qui avait débarqué avec Marie-Madeleine à Marseille, décida, sur la prière du peuple, d'aller capturer le monstre. Elle le trouve en train de dévorer un homme, lui lance de l'eau bénite et lui montre la croix. Le monstre aussitôt se soumet; elle lui passe alors sa ceinture autour du cou et le conduit au village voisin où il meurt lapidé. Le lieu de la capture est

86. Vielliard (éd.) 1984, p. 34-35.

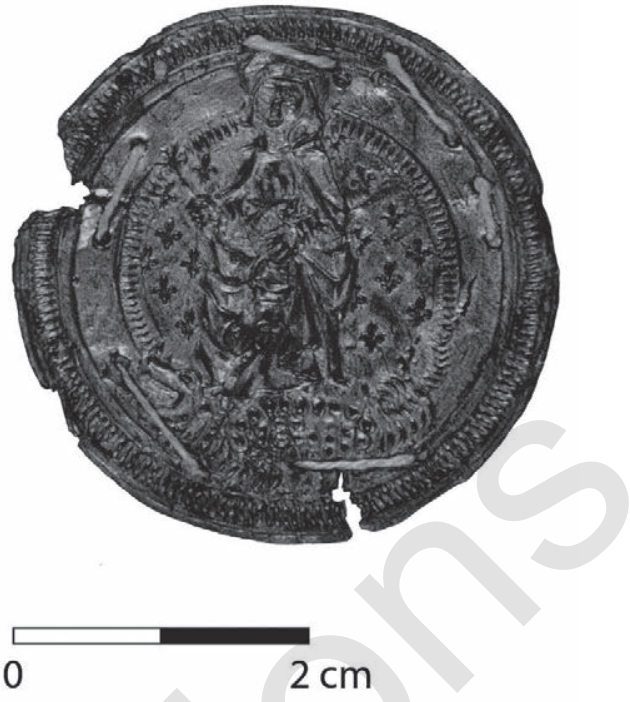

Fig. 9 Enseigne de l'église Sainte-Marthe de Tarascon, Livre d'Heures, Bibliothèque de l'Arsenal, ms 1776 A Rés., fol. Av., cl. Bibliothèque de I'Arsenal (BRUNA 1998).

nommé Tarascon d'après la légende. Une grande attention fut portée à la sainte au $\mathrm{XV}^{\mathrm{e}}$ siècle ainsi que l'illustrent des travaux commencés en 1436 sur le reliquaire ${ }^{87}$, la réalisation d'un retable confiée en 1446 à Enguerrand Quarton ${ }^{88}$ et la sculpture d'un gisant de la sainte par Francesco Laurana dans le troisième quart du $\mathrm{XV}^{\mathrm{e}}$ siècle ${ }^{89}$. Le reliquaire est pourvu de perforations grâce auxquelles les pèlerins pouvaient toucher les reliques, les mettre en contact avec des enseignes ou d'autres objets. Le roi René éprouve une vénération pour la sainte (fig. 3), de même que le roi de France Louis XI qui, en 1470, offre à l'église une châsse en or aujourd'hui détruite ${ }^{90}$.

Un livre d'heures du $\mathrm{Xv}^{\mathrm{e}}$ siècle à l'usage de Paris conserve, au verso du premier feuillet, une enseigne de pèlerinage circulaire obtenue par estampage d'une feuille d'argent (fig. 9). Dans un cadre alternant baguettes cordées et cordons nus, sur fond d'un semis de fleur de lys, sainte Marthe, auréolée, vêtue d'un long manteau, est figurée debout sur la Tarasque qu'elle asperge d'eau bénite avec un goupillon. Douze trous ont été réalisés en bordure pour la fixation par couture. Une pièce de broderie figurant les instruments de la Passion autour du monogramme du Christ, ainsi qu'une véronique, sont également disposés sur le même folio ${ }^{91}$. Ce type d'enseigne en tôle perforée pour la couture apparaîtrait dans les années 1460-1470².

87. Arnaud d'Agnel 1908, nº 2724.

88. Ibid., n' 619 .

89. Mognetti 1981, p. 171.

90. Esquieu 1979, p. 130.

91. BRUNA 1998, p. 141.

92. Ibid., p. 129-130. 


\subsubsection{L'abbaye bénédictine de Saint-Pierre-de- Montmajour}

L'abbaye bénédictine de Saint-Pierre-de-Montmajour fut fondée en 949. En 1019, l'abbé Rambert y institue le "pardon", à l'occasion de la consécration par l'archevêque d'Arles, Pons de Marignane, de la crypte de la première église Notre-Dame, alors en cours de construction. Cette crypte contenant un fragment de la vraie croix est dédiée à la Sainte-Croix. La cérémonie du "pardon» de Montmajour, célébrée le 3 mai, jour de l'invention de la Sainte-Croix, accorde l'absolution des péchés aux fidèles qui y participent et qui laissent une offrande pour l'achèvement de l'édifice. Face au succès grandissant du pardon, une chapelle-reliquaire à plan cruciforme, au vocable de sainte Croix, fut construite à l'extérieur du monastère pour le service des pèlerins vers $1170-1180^{93}$. Ce pèlerinage, qui donnait aussi lieu à une vénération à saint Pierre, concourut à la prospérité du nouveau sanctuaire, de l'abbaye et de la ville. Le 3 mai 1409, la cérémonie du pardon de Saint-Pierre de Montmajour réunit, d'après l'arlésien Bertrand Boysset, des pèlerins (romieus) du monde entier au nombre de 150000 de ce qu'il en a vu et entendu. Elle est honorée de la présence du roi Louis II, en noble compagnie, qui séjourne alors en Provence pour préparer la conquête de Naples ${ }^{94}$. Ce chiffre est largement exagéré, mais il donne une idée de l'ampleur de la manifestation. Un compte de péage de 1425 enregistre 12000 pèlerins passant par Arles ${ }^{95}$. En 1504, il est institué une indulgence plénière pour le pèlerinage à Montmajour.

Cas rare, la fabrication de souvenirs est renseignée. Par contrat daté du 15 avril 1359, les religieux s'engagent à fournir à un plâtrier d'Arles, maître Jean de Squire de Tournai, les moules nécessaires à la fabrication des «images de saint Pierre», vraisemblablement des statuettes en plâtre, celles-ci devant être vendues à bénéfice égal entre les parties ${ }^{96}$. En 1424, un mercier et un boulanger arlésien reçoivent le monopole de la confection des images de saint Pierre et des clefs de plomb et d'étain ${ }^{97}$. Ces personnes ne sont pas des artisans du métal, mais agissent en tant que capitalistes. Elles ont très probablement délégué ou employé des artisans, versés dans la confection des moules et dans le travail de l'étain, du plomb et de ses alliages. N'était-il fabriqué à cette occasion que des enseignes?

Des niveaux d'occupation de maisons des XIII ${ }^{e}-\mathrm{XIV}^{\mathrm{e}}$ siècles, rue du Limas à Avignon, ont permis, en 1989, la découverte d'une enseigne à l'effigie de saint Pierre (fig. 10, $\mathrm{n}^{\circ} 1$ ). Le cadre pentagonal de cette pièce contient une légende agencée de façon malhabile entre deux rangées de grènetis : + S[IGNVM] SAN[C]TI PETRI MONTIS MAIORIS. Dans le champ, Pierre, drapé, chaussé et coiffé d'une mitre ou d'une tiare, assis sur un

93. Benoit 1927, p. 110; Gagnière 1981, p. 50; Stouff 1999, p. 32. 94. Bonnemant 1876, p. 127-128; Stouff 1999, p. 25-29. Le $1^{\text {er }}$ décembre 1400 , la femme du roi Louis II visite Saint-Trophime avec le prince de Tarente et le comte de Prade (Bonnemant 1876, p. 60).

95. FERrando 2001a.

96. Benoît 1927, p. 112-113; Baudat 1999, p. 18-19; Baudat 2001, p. 43. Paul Benoît, qui ne donne pas l'origine de cette information, spécifie que les religieux doivent également livrer le plomb, mais Michel Baudat ne mentionne pas le plomb lorsqu'il fournit le renseignement et renvoie à un manuscrit du chanoine Louis Bonnemant à la bibliothèque municipale d'Arles, qu'il ne m'a pas été possible de consulter.

97. STOUfF 1999, p. 29. trône stylisé, bénit de la main droite et tient une clef dans la main gauche. Un globe surmonté d'une croix, sous son coude droit, évoque probablement la situation de l'abbaye en terre d'Empire. La dévotion à saint Pierre ne paraît pas être fondée sur une légende quelconque. Saint Pierre étant le dédicataire de l'abbaye, peut-être en possédait-elle des reliques?

Les enseignes de la Sainte-Croix de Montmajour, en matériau blanc, sont plus nombreuses et peuvent être regroupées en trois types. Appartenant au premier type, un exemplaire a été découvert au $\mathrm{n}^{\circ} 5$ de la rue Collège-de-la-Croix, lors de travaux de sondage, dans un sol remanié, aux abords d'une ancienne livrée cardinalice d'Avignon (fig. 10, no 2). Cette croix aux larges et courtes branches porte la figuration du Christ les yeux ouverts, couronné, les membres droits, vêtu d'une longue tunique s'arrêtant aux poignets et aux chevilles. La croix-support comporte une inscription marginale : + SIGNVM S[AN]C[T] E CRVCIS DE MONTE MAIORE. Huit œillets permettent sa fixation. Trois fragments de branches, appartenant à une enseigne similaire, ont été découverts par un particulier lors de travaux dans son jardin au Castelet à Fontvieille (fig. 10, $\left.n^{\circ} 3\right)$. Une telle figuration du Christ s'observe sur des crucifix du XII ${ }^{\mathrm{e}}$ siècle, notamment celui de la cathédrale Saint-Martin de Lucques, le Volto Santo, dont les plus anciennes enseignes de pèlerinage reprennent l'image. L'enseigne de Montmajour est peut-être la réplique d'un crucifix conservé à l'abbaye et sujet de vénération ${ }^{98}$. Elle est attribuable au XIII ${ }^{e}$ siècle d'après des critères stylistiques avancés par Dominique Carru et Sylvain Gagnière ${ }^{99}$.

Le second type d'enseignes de la Sainte-Croix de Montmajour, trouvé lors des mêmes travaux au Castelet à Fontvieille, montre cette fois-ci deux versions d'un Christ seulement vêtu du perizonium, la tête nimbée et penchée vers sa droite, les jambes repliées (fig. 10, no 1 à 7). Cinq enseignes sont connues. Elles portent pour la plupart l'inscription latine + SIGNVM S[AN]C[T]E CRVCIE MAIORE - le E de CRVCIE est disposé à l'envers du sens de lecture -, limitée extérieurement par une ligne de grènetis. Un fragment non classifiable comporte les lettres TIS de MONTIS MAIORE (fig. 10, no 8). Une première version figure le Christ mort, la tête tombante (fig. 10, no 4 et 7). La seconde le présente vivant, de face avec la tête légèrement relevée (fig. $10, n^{\circ} 5$ et 6 ). L'absence presque totale de percement des œillets placés aux extrémités d'un objet démontre, d'après Paul Ferrando, que l'objet n'a pas été fini et donc vendu ${ }^{100}$. Cependant, de telles observations ne peuvent constituer une preuve, comme le montre l'enseigne de Volto Santo de Lucques découverte à Fox-Amphoux, qui n'a vraisemblablement pas été portée (fig. 16, n 5 ). Ces objets pouvaient être conservés précieusement dans un sac ou une bourse.

Une dernière enseigne, assez fruste dans son dessin et son modelé, découverte également au Castelet, appartient au troisième type (fig. 10, no 9 ). De forme quadrangulaire, elle reprend dans un encadrement de grènetis, entre une suite de cinq arcs ou voûtes en partie inférieure et des hachures en partie supérieure, l'iconographie du Christ sur la croix. Trois petits traits situés au-dessus de la tête pourraient repré-

\footnotetext{
98. Cette hypothèse a été formulée pour la première fois par CARRU et GAGNiÈre 1992, p. 77

99. CARru et GaGniÈre 1992, p. 92.

100. FERRANDO 2001a, p. 8.
} 

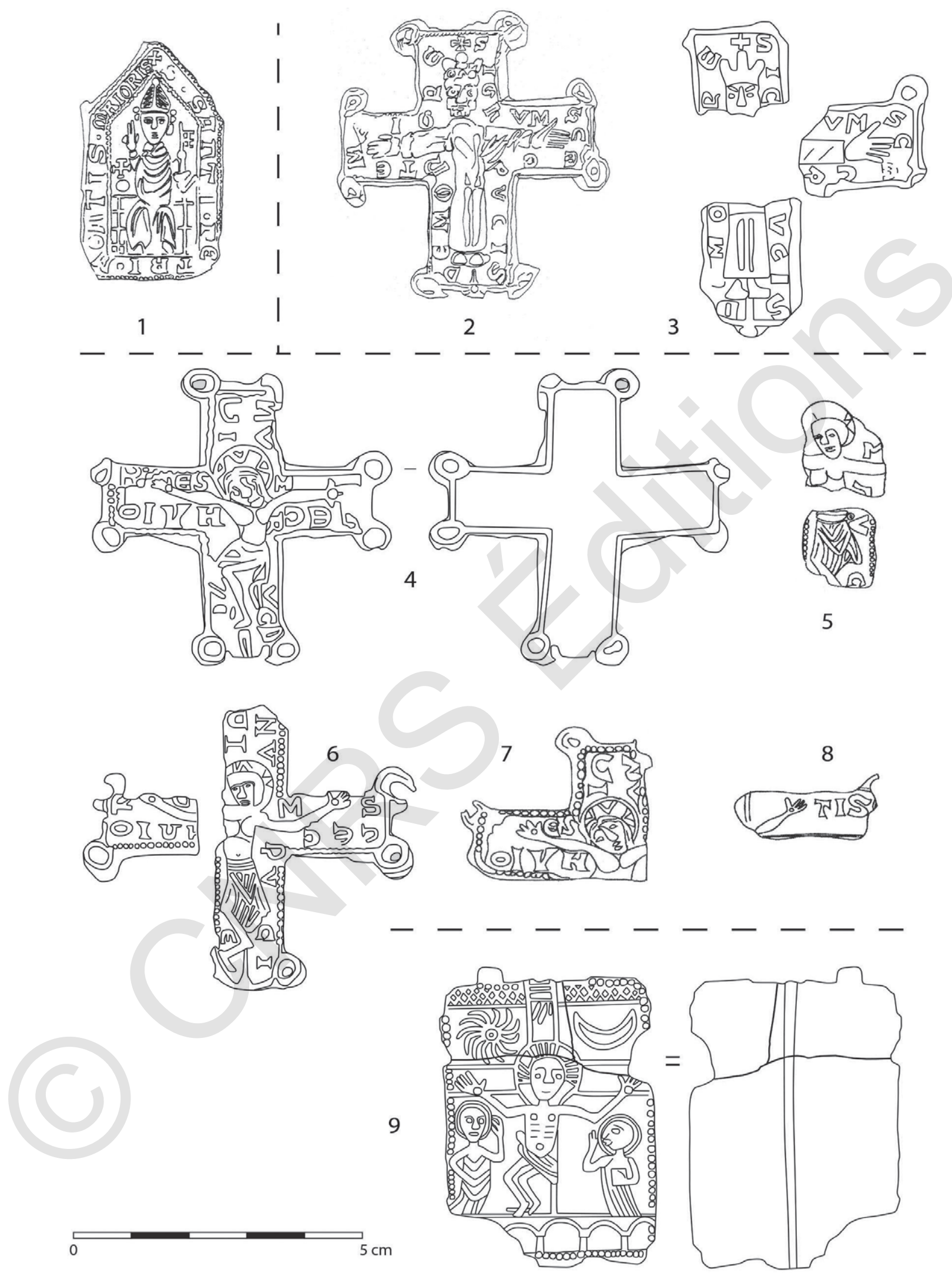

Fig. 10 Enseignes à l'effigie de saint Pierre et de la Sainte-Croix de l'abbaye de Montmajour; n 1, Rue du Limas, Avignon, Vaucluse, Service archéologique du Vaucluse, dessin : D. Carru (CARru 1998); n², Rue Collège-de-la-Croix, Avignon, Vaucluse, Service archéologique du Vaucluse, dessin : D. Carru (CARRu 1998); no 3, Castellet, Fontvieille, Bouches-du-Rhône, collection particulière, dessin : O. Thuaudet; no 4 à 9 , Castellet, Fontvieille, collection particulière, dessins : O. Thuaudet. 

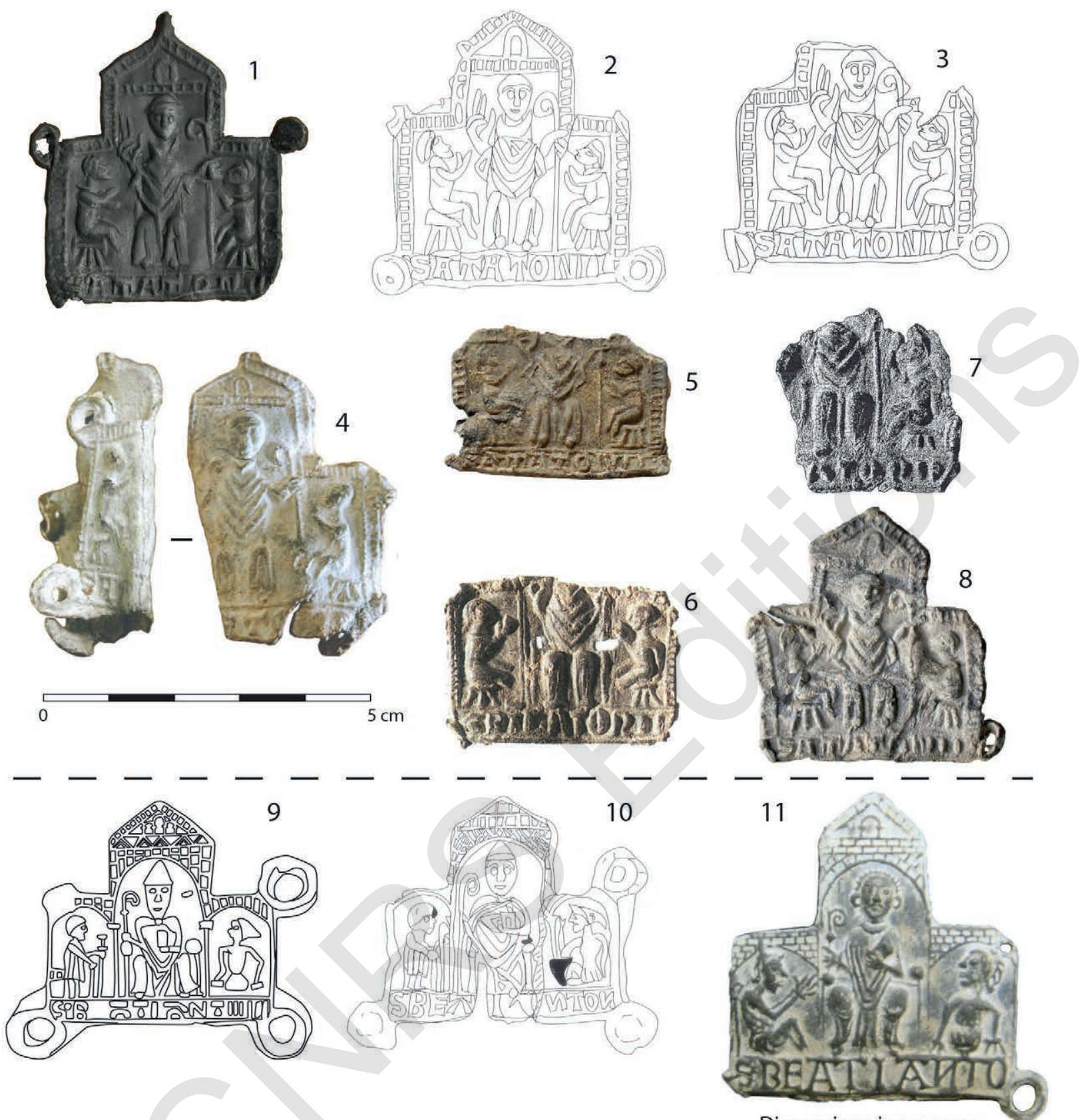

Dimensions inconnues

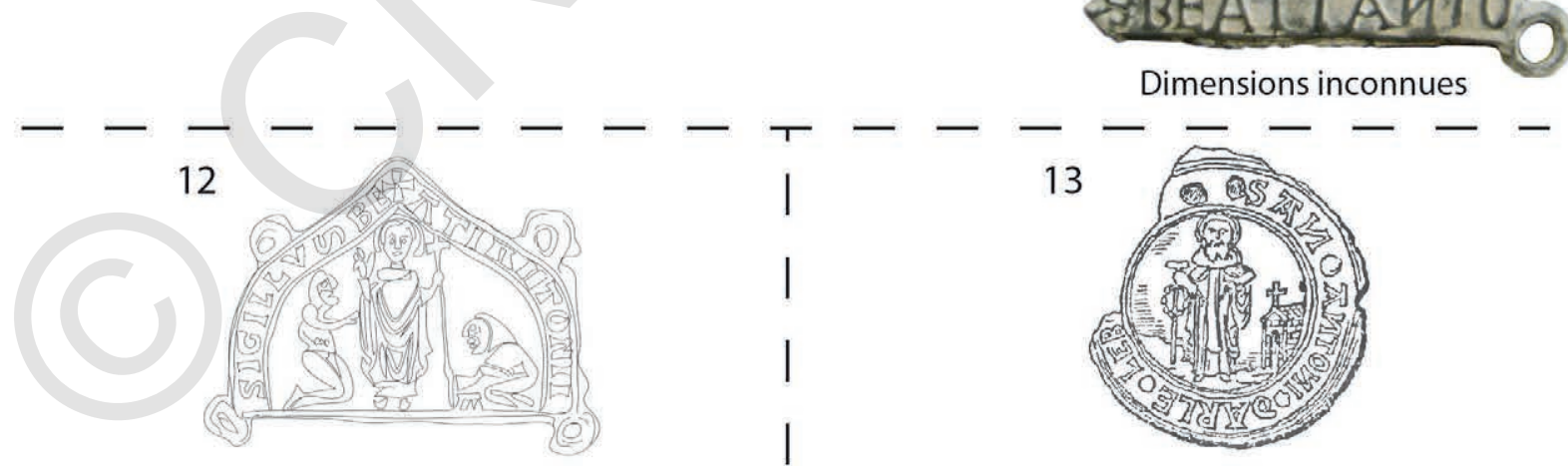

Fig. 11 Enseignes à l'effigie de saint Antoine de l'abbaye de Montmajour; no 1, Le Castelet, Fontvieille, Bouches-du-Rhône, musée de l'Arles antique, cl. O. Thuaudet; no 2, Avignon, Vaucluse, collection particulière, dessin: P. Ferrando (FerRANDo 2001b); no 3, Musée Calvet, Avignon, Vaucluse, collection particulière, dessin : P. Ferrando (FERRANDO 2001b); $n^{\circ} 4$, Alpes-de-Haute-Provence, cl. L. Berton (BERTON 2011); $n^{\circ} 5$, Villeveyrac, Haute-Garonne, collection particulière, photo: auteur inconnu (http://artefacts-encyclopedie.org, ESP-9024); $n^{\circ}$ 6, Lycée Ozenne, Toulouse, Haute-Garonne, cl. H. Améglio (Lassure et Villeval 2002); no 7, Saint-Jean-Sainte-Eulalie, Puget, Hérault, cl. H. Améglio (LaSSure et Villeval 2002); $n^{\circ} 8$, La Condamine, Tressan, collection particulière, cl. auteur inconnu (http://artefacts-encyclopedie.org, ESP-9024); $n^{\circ}$ 9, Le Castelet, Fontvieille, Bouches-du-Rhône, collection particulière, dessin : O. Thuaudet; $n^{\circ}$ 10, Avignon, Vaucluse, collection particulière, dessin : P. Ferrando (FERRANDO 2001b); no 11, Ardèche, collection particulière, cl. L. Berton (BerTon 2011); no 12, Garage Régina, Avignon, Vaucluse, dessin : D. Carru (CARRU et GAGNIÈRE 1992); no 13, Cabinet des médailles de la Bibliothèque de Marseille (Guillaume 1884). 
senter l'acronyme INRI (Ihesus Nazarenus Rex Iudeorum) souvent figuré dans la peinture contemporaine. Deux personnages debout et auréolés saluent la croix; celui placé à gauche du Christ tient un livre. Peut-être peut-on y voir la Vierge et saint Jean? Les bras de la croix sont surmontés du Soleil à main droite du Christ et de la Lune à main gauche, symboles païens repris par le christianisme. «Placés à droite et à gauche de l'être suprême, le Soleil et la Lune en proclamant le caractère divin, affirment sa qualité, céleste, cosmique, son rôle de maître du monde, et en forment l'escorte d'honneur ${ }^{101}$ du moins pour les premiers chrétiens. Pour le second Moyen Âge, les interprétations ont pu évoluer. Ces astres veulent-ils rappeler les ténèbres qui suivirent la mort du Christ sur la croix? Dans l'Évangile (Mt 27, 45), le jour de la mort du Sauveur, depuis la sixième heure (midi) jusqu'à la neuvième heure ( 3 heures), toute la terre fut couverte de ténèbres. Symbolisent-ils la douleur de la création? Eux qui commencent et finissent le jour, illustrent-ils le commencement (de tout) et la fin (du monde), l'Alpha et l'Oméga auxquels le Christ s'est assimilé dans la tradition chrétienne, et par incidence, la naissance, point de départ, et la mort, point final de l'existence humaine? Signifient-ils ainsi les deux natures du Christ : humaine et divine, l'Ancienne et la Nouvelle Loi, l'espérance chrétienne, l'Éternité divine? Ou encore jouent-ils le rôle de génies funèbres, psychopompes, comme ceux du symbolisme gréco-romain ${ }^{102}$ ? Les crucifixions accompagnées du Soleil et de la Lune diminuent considérablement au $\mathrm{XV}^{\mathrm{e}}$ siècle et deviennent rares après le début du $\mathrm{XVI}^{\mathrm{e}}$ siècle $^{103}$. Au revers, l'enseigne présente un bourrelet pour lequel aucune justification n'a été trouvée.

Paul Ferrando avance que la figure du Christ vivant, habillé et la tête droite (fig. 10, n 2 et 3) est un signe d'ancienneté et appartient généralement à une imagerie du XII ${ }^{e}$ siècle. Il date donc sur cette base les pièces du type 1 de la fin du XII ${ }^{\mathrm{e}}$ siècle voire du XIII ${ }^{e}$ siècle. Toutefois, une enseigne de Volto Santo de Lucques figurant un tel Christ est attribuée par Denis Bruna au début du XIV ${ }^{\text {e }}$ siècle, sur la base de comparaisons avec des exemplaires découverts dans une sépulture suédoise ${ }^{104}$. Paul Ferrando propose de dater les enseignes du type 2

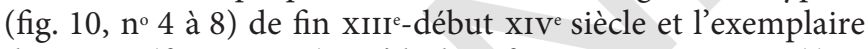
du type 3 (fig. 10, no 9 ), qu'il identifie être en étain pur (!) et donc plus tardif - sur quelle base? -, du milieu du XIV ${ }^{\text {e }}$ siècle. La destruction du site castral du Castelet, dans la seconde

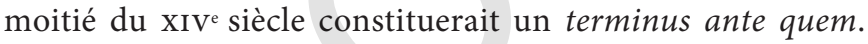
L'argumentation de Paul Ferrando est assez faible, mais faute de contexte stratigraphique, il paraît bien difficile de progresser dans la datation de ces objets.

L'abbaye de Montmajour conserva pendant un temps des reliques du saint anachorète et "abbé» Antoine. Ses ossements furent rapportés de Terre Sainte au XI ${ }^{e}$ siècle par un seigneur du Dauphiné et déposés dans l'église de Saint-Antoine-l'Abbaye (Isère). Une vingtaine de moines de l'abbaye de Montmajour sont appelés pour s'installer dans le prieuré et, en 1082, l'abbaye en prend officiellement possession. Assez rapidement, la fondation bénédictine entre en conflit avec les Hospitaliers qui les expulsent de leur monastère en 1290, emportant

\footnotetext{
101. DeONna 1946, p. 39; ID. 1947, p. 62.

102. ID. 1947, p. 61-62.

103. Ibid., p. 62.

104. BRUNA 1996, p. 64.
}

sans doute les reliques de saint Antoine avec eux. En 1490, les reliques sont transférées à l'église Saint-Julien à Arles, à laquelle est adjoint le vocable de saint Antoine. Les restes saints déménagent une dernière fois dans la nouvelle église SaintJulien-Saint-Antoine un an après sa consécration en $1662^{105}$. Un bréviaire de 1514 mentionne la date du 11 juin comme la fête de la translation des reliques du Dauphiné jusqu'à Arles ${ }^{106}$. Les Arlésiens portent, jusqu'au XVIII ${ }^{\mathrm{e}}$ siècle, une attention toute particulière aux reliques de saint Antoine ${ }^{107}$, ainsi que l'attestent également l'existence d'une foire de la Saint-Antoine et celle de processions en son nom deux fois par an ${ }^{108}$. De tels cortèges sont envoyés par la communauté de Brignoles en 1491 pour demander à être épargné de la peste, en 1495 pour implorer l'arrêt de l'épidémie ${ }^{109}$ ou par celle d'Allauch en $1551^{110}$. Les délibérations municipales conservent la trace du passage de quelques personnalités venues en pèlerinage ${ }^{111}$.

La fabrication d'enseignes pour le sanctuaire est illustrée dans les archives par la notification d'un contrat passé le 19 février 1490 entre les moines de Montmajour et l'orfèvre Antoine Fet. Ce document stipule que la fabrication et la vente d'images en or et en argent sont dévolues à cet artisan pendant un an, moyennant la somme de 12 florins par an ${ }^{112}$.

Quinze enseignes de pèlerinage en matériau blanc de saint Antoine abbé, que nous avons divisées en trois groupes, sont actuellement reconnues ${ }^{113}$. Paul Ferrando signale également l'existence de deux autres exemplaires, mis au jour à Avignon et appartenant à une collection particulière - sans plus d'information -, qu'il n'a pas pu étudier ${ }^{114}$.

La forme des pièces du premier type, à quatre œillets, évoque la coupe transversale d'une église à trois nefs. Un exemplaire a été découvert sur le site du Castelet par Louis Poumeyrol en 1973, dans une couche contenant de la céramique datée entre le $\mathrm{XIV}^{\mathrm{e}}$ siècle et les XVI ${ }^{\mathrm{e}}$-XVII ${ }^{\mathrm{e}}$ siècles (fig. 11, $\left.\mathrm{n}^{\circ} 1\right)^{115}$. Un deuxième (fig. 11, $\mathrm{n}^{\circ} 2$ ) a été découvert dans le centre d'Avignon, un troisième (fig. 11, no 3 ) dans des remblais de terrassement du bas Moyen Âge lors de travaux effectués dans la cour nord du musée Calvet. Un individu provenant d'un site inconnu dans les Alpes-de-Haute-Provence (fig. 11, n 4), ainsi que trois autres mis au jour dans l'Hérault, à Villeveyrac (fig. 11, no 5), au lieu-dit Saint-Jean-Sainte-Eulalie au Pouget (fig. 11, $\mathrm{n}^{\circ} 7$ ), sur le site de La Condamine à Tressan (fig. 11, no 8 ), et dans un niveau de la première moitié du $\mathrm{Xv}^{\mathrm{e}}$ siècle lors d'une opération

\footnotetext{
105. BAudat 1994, p. 4-5, 10, 16-17; ID. 1999, p. 75. 106. ID. 1994, p. 12.

107. En 1494, le voyageur allemand Jérôme Münzer, de passage à Arles, note la vénération des reliques de saint Antoine par les pèlerins et les arlésiens (STOUfF 1991, p. 570).

108. BAUdAT 1994, p. 23-26, 28; ID. 1999, p. 79, 82, 83.

109. Biraben 1976, t. 2, p. 70.

110. Baudat 1994, p. 27-28; ID. 1999, p. 82-83.

111. Entre 1498 et 1517, deux conseillers du roi, le grand maître des Hospitaliers de Rhodes, la reine Claude de France, le général de Languedoc et de Provence et sa femme (BAudat 1994, p. 27-28; ID. 1999, p. 82-83). 112. Ibid. 1999, p. 19.

113. Guillaume 1884; Carru et Gagnière 1992; Berton 2011; Ferrando 2001b; Lassure et Villeval 2002.

114. Ferrando 2001b, p. 39.

115. Informations stratigraphiques tirées de la documentation de fouille conservée au musée de l'Arles antique.
} 
d'archéologie préventive au Lycée Ozenne à Toulouse (fig. 11, $\mathrm{n}^{\circ} 6$ ) se rattachent également par leur champ au type 1 .

La nef centrale présente une toiture en bâtière dont le mur pignon est percé à son sommet d'une fenêtre en plein cintre. De petits rectangles imitant des pierres font le tour de l'enseigne, sauf dans la partie basse où se retrouve l'inscription SA[NC] T[I] A[N]TONII. Il est tentant de voir, dans la bande de petits rectangles au-dessous de la fenêtre, la limite supérieure d'un mur pignon. Dans l'espace intérieur de l'église trône saint Antoine, assis de face, tonsuré, imberbe, vêtu d'une dalmatique aux plis lourds passée par-dessus une aube. Les mains sont démesurées, sans doute pour mettre en évidence leur importance. Il bénit de la main droite et tient de la main gauche une crosse. De part et d'autre, rejetés dans les collatéraux, deux plus petits personnages de profil, tonsurés, assis sur un tabouret tripode, lèvent leur regard vers lui. La disposition de leurs bras semble traduire une conversation animée ou plutôt un état de ravissement dû à l'écoute de la parole du saint.

Le type 2 comprend trois enseignes récupérées par des particuliers au Castelet (fig. 11, no 9), à Avignon (fig. 11, no 10) et en Ardèche (fig. 11, no 11). Elles se différencient des précédentes par la présence d'arcs en plein cintre dont les claveaux sont figurés verticalement ou de biais. Sur l'artefact du Castelet (fig. 11, no 9), des colonnes à chapiteaux stylisés reçoivent les retombées des arcs. Le pignon peut être percé d'une ou de trois fenêtres à arc en plein cintre. Au centre de ces enseignes, comme sur celles de type 1, saint Antoine se présente assis de face, mais dans un large fauteuil aux accoudoirs circulaires. Il peut être coiffé d'une mitre. La position des mains est également différente : il tient dans sa main gauche un livre et la crosse est, cette fois, dans sa main droite. Dans les bas-côtés, les deux petits personnages ne sont plus assis sur un tabouret. Celui de droite peut être tête nue ou porter un chapeau pointu, s'asseoir par terre (fig. 11, no 10 ) ou être cul-de-jatte. Dans ce cas, son buste peut reposer sur une sorte de socle avec un pied (fig. 11, $\mathrm{n}^{\circ} 11$ ) ou ses mains tenir des poids sur lesquels il devait s'appuyer pour se déplacer (fig. 11, n 9). Le personnage de gauche est assis par terre et lève les mains (fig. 11, no 11) ou se tient debout, appuyé sur des bâtons (fig. $11, \mathrm{n}^{\circ} 9$ et 10). La légende est variable : S[ANCTI] B[E]ATI ANTIIII, S[ANCTI] BEATI АИТОИ[II] ou S[ANCTI] BEAТI АИТО[ИII]. Dans le premier cas (fig. 11, no 9), d'après Paul Ferrando, l'artisan qui a gravé le moule a mal évalué la place nécessaire pour intégrer l'ensemble des lettres : les cinq barres finales symboliseraient les lettres manquantes. Le «E» de BEATI, totalement effacé, est interprété comme la conséquence d'une usure du moule ou de la présence de plomb d'une fonte précédente obstruant l'empreinte $^{116}$. Selon Paul Ferrando, la présence de $\mathrm{N}$ inversés est probablement due à une inattention du graveur (fig. $11, \mathrm{n}^{\circ} 10$ et 11). L'auteur propose de voir dans l'exemplaire d'Avignon une copie de celui du Castelet à cause notamment de son graphisme plus fruste. Les manques de matériau, l'inversion des $\mathrm{N}$ et la présence de deux œillets non percés tendraient à montrer d'après lui que cet objet n'a pas été vendu et aurait été produit à Avignon ${ }^{117}$. Pour étayer cette hypothèse, des données plus solides seraient nécessaires. Il a déjà été exposé que l'absence de perforation des œillets n'est en aucun cas la caractéristique

116. FERRANDo 2001b, p. 34.

117. Ibid., p. 34-35. d'un objet mis au rebut. En outre, il paraît vraisemblable que, dans un tel cas, l'artefact eut été refondu. Enfin, l'inversion des $\mathrm{N}$ est fréquente sur les sceaux et enseignes : peut-être est-elle le résultat d'une convention de style ou d'une erreur dans le moule, qui s'est perpétuée dans les gravures ultérieures à cause de l'illettrisme de certains artisans. Pour cette même raison, ce genre de défauts n'a sans doute pas semblé rédhibitoire pour une large part de la population.

Au type 3 ne peut être rattaché qu'une seule enseigne retrouvée en 1989, sur le site de l'ancien garage Régina à Avignon, dans un sol de terre battue du milieu du XIV ${ }^{\text {e }}$ siècle (fig. 11, no 12). Cette enseigne en forme d'arc en ogive, figure les trois personnages habituels dans un même espace, au-dessous de l'inscription SIGILLVM BE+ATI ANTONII. Le saint abbé, se présente, cette fois, debout et nimbé, vêtu d'une dalmatique par-dessus une aube, tenant une croix pattée de la main gauche, bénissant de la main droite. Deux personnages agenouillés et implorant l'encadrent. Celui de droite est appuyé sur un tabouret tripode.

Le type 4 est illustré par une petite enseigne circulaire fragmentaire de $3 \mathrm{~cm}$ de diamètre en matériau blanc (fig. 11, $\mathrm{n}^{\circ} 13$ ), conservée au Cabinet des médailles de la Bibliothèque de Marseille. Le cadre, limité par des bandes nues, est parcouru de l'inscription SAN • ANTONI D['] ARLE • LEB[LANC]. «Le blanc» est un surnom qui fut souvent attribué au saint à Arles ${ }^{118}$. Le saint âgé est figuré debout au centre, la tête nimbée, vêtu comme d'ordinaire, un livre ouvert dans la main gauche, un bâton en forme de tau et des clochettes dans la main droite. À l'arrière-plan, une petite chapelle est surmontée d'une croix. Deux perforations au-dessus de la tête du saint ont servi à la fixation.

Les trois premiers types d'enseignes sont postérieurs à la translation des reliques du saint à l'abbaye de Montmajour en 1290 et, pour celles découvertes au Castelet, probablement antérieures à 1386, date à laquelle le site fut abandonné suite aux destructions de Raymond de Turenne et aux incursions des Grandes Compagnies ${ }^{119}$. En outre, certains attributs comme les flammes du feu de saint Antoine, le cochon avec sa clarine et le tau à clochettes, absents de ces enseignes, ne se fixent, selon Michel Baudat, qu'à partir du $\mathrm{Xv}^{\mathrm{e}}$ siècle ${ }^{120}$. Les enseignes du type 1 seraient antérieures à celles du type 2, car elles sont plus grossières, présentent moins de détails et ont une graphie des lettres plus archaïque. Michel Baudat propose de dater les

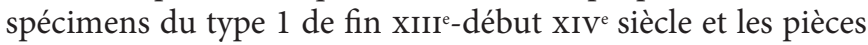
du type 2 de la première moitié du XIV ${ }^{e}$ siècle ${ }^{121}$, suivant sur cette dernière datation Denis Carru et Sylvain Gagnière ${ }^{122}$. Ces datations sont peut-être un peu restrictives, les modèles d'enseigne pouvant perdurer, voire être employés concurremment. Quant à la pièce marseillaise, les attributs du saint la datent au plus tôt du $\mathrm{XV}^{\mathrm{e}}$ siècle.

Il semble opportun, à ce moment de l'étude, de remarquer le nombre conséquent d'enseignes retrouvées sur le site du Castelet à Fontvieille, à quelques centaines de mètres de l'abbaye de Montmajour. Une telle concentration d'enseignes

\footnotetext{
118. Guillaume 1884.

119. FERRANDO 2001a, p. 13.

120. BAUDAT 1999 , p. 39-40

121. Ferrando 2001b, p. 38 ; Baudat 2001, p. 40.

122. CARru et GAGnière 1992, p. 92.
} 

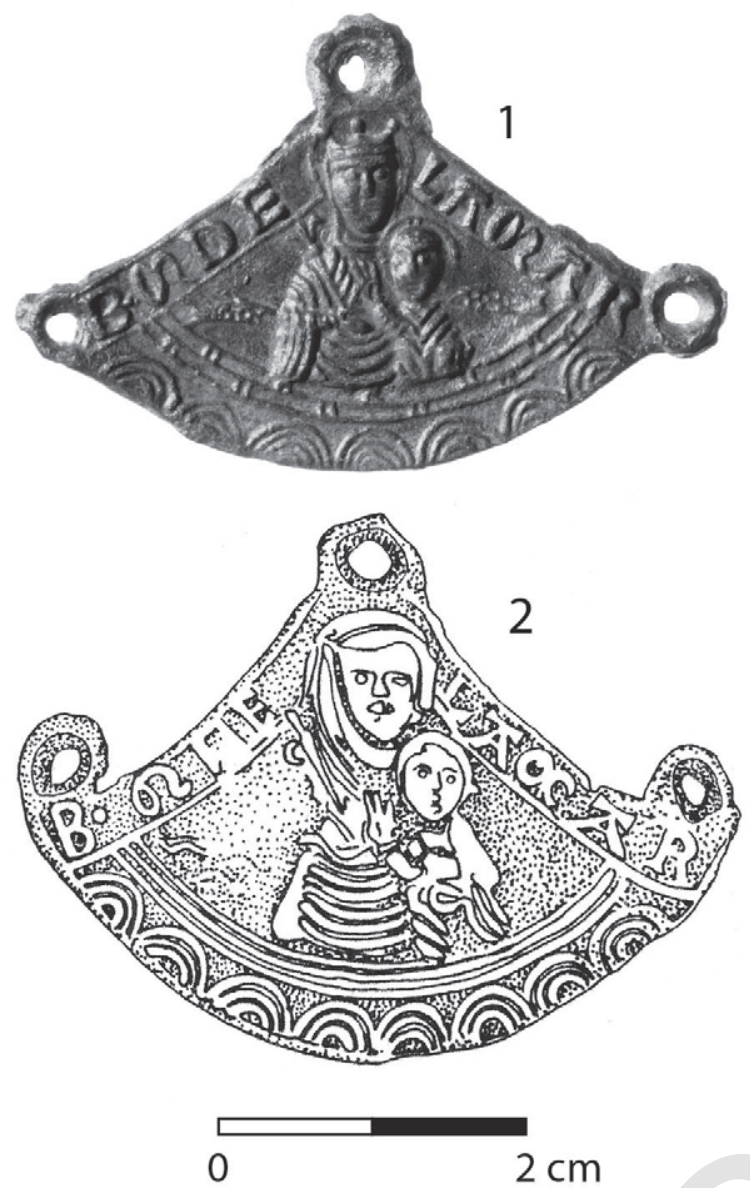

Fig. 12 Enseignes du sanctuaire des Saintes-Maries-de-la-Mer; no 1, Abbaye de Silvacane, La Roque-d'Anthéron, Bouches-du-Rhône, cl. J.-P. Pelletier (FIXOT et PELLETIER 1990);

$n^{\circ}$ 2, Rue du Limas, Avignon, Vaucluse, Service archéologique $d u$ Vaucluse, dessin : D. Carru (CARru et GaGNiÈre 1992).

de la Sainte-Croix - neuf exemplaires et fragments d'enseignes de Saint-Antoine abbé - deux individus - et l'existence attestée d'une vénération particulière attachée au saint et à la Sainte-Croix à l'abbaye de Montmajour, toute proche, laissent supposer la présence d'un atelier de fabrication sur le site du Castelet. L'absence de contextes stratigraphiques est malheureusement préjudiciable et ne permet pas de répondre à certaines questions comme la contemporanéité ou non dans la fabrication de ces objets. Toujours est-il que la localisation des enseignes de l'abbaye de Montmajour atteste une diffusion essentiellement régionale de ces deux cultes, Avignon, un peu plus au nord, servant de point de départ à de nombreux pèlerins. De multiples lieux de culte et institutions religieuses de la cité vauclusienne sont, en outre, placés sous la protection de saint Antoine ${ }^{123}$.

Dans la ville d'Arles, le Guide du pèlerin préconise aussi de visiter les reliques de saint Césaire, évêque et martyr de la ville, de l'évêque saint Honorat et du martyr Genès ${ }^{124}$. Une enseigne de l'abbaye de Saint-Césaire a été découverte à Londres, sur les

123. PANSier 1912a, p. 233, PANSIEr 1929.

124. Vielliard (éd.) 1984, p. 35. rives de la Tamise. De forme losangique, elle montre, à l'avers, le saint évêque et l'inscription S[AN]C[TVS] CESARIUS d'après Brian Spencer, qui n'en fournit pas d'image ${ }^{125}$.

\subsection{LE SANCTUAIRE DES SAINTES-MARIES-DE- LA-MER}

Plus au sud, le sanctuaire des Saintes-Maries-de-la-Mer aurait été édifié à l'endroit même où seraient inhumées sainte Marie Jacobé, sainte Marie Salomé et Sarah qui, avec MarieMadeleine et d'autres saints personnages, seraient arrivés sur les côtes de Provence. Les saintes Marie Jacobé et Marie Salomé sont respectivement fêtées le 25 mai et le 22 octobre, mais d'après le témoignage en 1357 d'un carme du couvent de Paris, "aucuns font toutes les deus suers ensemble en may, pour ce qu'il (sic) ont le service, qui est commun aux deux ensemble». Les intempéries de l'automne, la moindre longueur des jours et l'obligation de devoir dormir sous tente faute de suffisamment de logements sont très certainement la cause de cette préférence ${ }^{126}$. L'un des pèlerins les plus célèbres serait l'évêque de Saint-Pol, Pierre de Nantes qui, au milieu du $\mathrm{XIV}^{\mathrm{e}}$ siècle, aurait été guéri de la goutte par l'intercession des saintes $^{127}$. En 1448, des fouilles sont commanditées par le roi René afin de retrouver le corps des saintes, avec l'accord du pape Nicolas V. Les squelettes retrouvés près de l'autel sont alors disposés dans des reliquaires ${ }^{128}$.

À l'abbaye de Silvacane (La Roque-d'Anthéron), une enseigne des Saintes-Maries-de-la-Mer a été découverte dans un sol antérieur au dernier quart du XIV ${ }^{e}$ siècle (fig. 12, no 1$)^{129}$. En quart de cercle, elle possède trois œillets percés. La partie inférieure du cadre comporte sept ensembles de demi-cercles superposés. La légende B[EATE] M[ARIE] DE LA MAR, en caractère gothique, se développe dans la partie haute. Sur fond d'une onde marine, la figure centrale représentée est celle d'une femme nimbée drapée avec la tête couronnée, portant de sa main droite un sceptre fleurdelisé et tenant sur son bras gauche un enfant auréolé bénissant. Cette représentation de la Vierge à l'Enfant fait allusion au vocable de l'église Notre-Dame-dela-Mer. Une enseigne similaire, mais avec huit ensembles de demi-cercles et un personnage féminin non plus couronné, mais à la tête voilée, a été retrouvée, rue du Limas à Avignon, hors stratigraphie (fig. 12, no 2). Elle peut cependant probablement être mise en relation avec l'occupation médiévale du lieu située entre la fin du XIII ${ }^{\mathrm{e}}$ siècle et le milieu du XV ${ }^{\mathrm{e}}$ siècle ${ }^{130}$. Un fragment d'enseigne très dégradé et incomplet provient de

125. Spencer 2010, p. 237. L'objet est également absent de la base de données en ligne Kunera (www.kunera.nl), consultée le $1^{\text {er }}$ janvier 2017.

126. FAILlON 1865, vol. 1, p. 1315.

127. Ibid., p. 1316-1317.

128. Ibid., p. 1320-1331.

129. Denis Bruna (Bruna 2003, p. 74.) affirme qu'elle était vraisemblablement contenue dans une bourse avec dix-huit florins trouvés dans le sol de la même pièce. C'est une erreur, car si le trésor monétaire et l'enseigne sont bien issus de la même ièce, ils ne proviennent pas du même contexte stratigraphique, comme l'a révélé le dépouillement des archives de la fouille et comme le sous-entend également l'analyse stratigraphique de Michel Fixot et Jean-Pierre Pelletier (Fixot et Pelletier 1990, p. 201 et 207). Se reporter également à CHARLET 1986 pour l'étude des monnaies « cachées sous un mur. » 130. CARru et Gagnière 1992, p. 69. 
l'impasse de l'Oratoire ${ }^{131}$ et un autre objet découvert dans la région de Toulouse a été signalé à Denis Bruna ${ }^{132}$. Les deux enseignes d'Avignon sont datées du point de vue stylistique de la première moitié du XIV ${ }^{\text {e }}$ siècle par Dominique Carru et Sylvain Gagnière ${ }^{133}$.

\subsection{LE SANCTUAIRE DE SAINT GILLES}

Le plus important centre de pèlerinage de la région est assurément celui de Saint-Gilles-du-Gard. D'après la Vie de saint Gilles (fin du $\mathrm{X}^{\mathrm{e}}$ siècle) ${ }^{134}$, dont le contenu a été repris par la Légende dorée de Jacques de Voragine ${ }^{135}$, Gilles, athénien de famille noble du viI siècle, craignant la renommée après s'être illustré par plusieurs guérisons miraculeuses, décide de s'exiler. Après différentes péripéties, il se retire afin de vivre une existence solitaire dans une grotte où, par faveur divine, une biche vient lui donner, à certaines heures, son lait. Des chasseurs découvrent un jour la retraite de l'ermite en poursuivant l'animal que les chiens, cependant, refusent d'approcher. Le roi, informé de cet événement, revient avec les chasseurs. L'un d'entre eux, par mégarde, blesse Gilles avec une flèche. Le roi, par repentance et sur les conseils de l'ermite, fait construire un monastère dont Gilles devient l'abbé sur la prière du souverain.

Ce sanctuaire est, aux $\mathrm{XI}^{\mathrm{e}}$ et $\mathrm{XII}^{\mathrm{e}}$ siècles, un centre religieux majeur dans la chrétienté. Son port, anciennement au débouché du Rhône, permet de se rendre à Rome par la mer. Par sa localisation, la cité de Saint-Gilles est aussi une étape obligée sur les routes qui mènent de Provence, d'Italie ou par la voie du Rhône jusqu'en Galice. La preuve en est établie par la longue notice consacrée à l'église et aux reliques dans le Guide du Pèlerin ${ }^{136}$. La renommée du sanctuaire, soutenue par une indulgence accordée par le pape en 1154 à ceux qui le visitent ${ }^{137}$, est relayée par des témoignages de contemporains, comme celui du rabbin Benjamin de Tudèle ${ }^{138}$, au XII ${ }^{e}$ siècle. Le Livre des Miracles de saint Gilles rédigé en deux fois durant le XII ${ }^{e}$ siècle atteste également la vitalité du sanctuaire gardois à cette époque ${ }^{139}$, d'autant plus qu'il apparaît évident que n'y sont présentés que les miracles les plus exemplaires ${ }^{140}$. Le début de la construction d'une nouvelle église abbatiale, dont le premier autel fut consacré en 1096 par Urbain II, est entrepris grâce aux libéralités des pèlerins. Elle ne fut toutefois achevée qu'au début du XIV ${ }^{e}$ siècle ${ }^{141}$. Les tarifs de la Leyde et du Péage de Saint-Gilles au XII ${ }^{\mathrm{e}}$ siècle illustrent, par la longueur de leurs enregistrements, mais aussi par la nature des produits mentionnés, parfois luxueux, l'ampleur de l'activité

\footnotetext{
131. Carru et Gagnière 1992, p. 69.

132. BRUNA 2003, p. 74.

133. CARru et GagniÈre 1992, p. 92.

134. PARIS 1881

135. Wyzewa (éd) 1998, p. 490-492.

136. Vielliard (éd.) 1984, p. 37-47.

137. Carru et GagniÈre 1992, p. 81.

138. SAINT-JEAN 1985, p. 288-289.

139. DuHil et al. (éd.) 2007.

140. Girault et Girault 2007b, p. 288. Trop d'épisodes miraculeux nuiraient à la crédibilité selon Marcel et Pierre-Gilles Girault.

141. Carru et Gagnière 1992, p. 81.
}

dans la cité142. L'attractivité économique de Saint-Gilles avec son port, ses nombreuses tables de changeur ${ }^{143}$, son importance militaire, le passage incessant des acteurs de la vie économique et politique et l'influence des établissements bénédictins, dont le saint ermite est l'un des patrons, ont contribué à diffuser le renom du sanctuaire et de son saint. D'après Kurt Köster, un épisode de la vie du saint ermite pourrait être également un élément déterminant dans le succès du culte qui lui est rendu : un roi le fait venir auprès de lui et lui demande de prier en sa faveur pour la rémission d'un péché inavouable; Gilles s'exécute lors d'une messe et reçoit de Dieu une feuille sur lequel il est écrit que la faute est pardonnée et que quiconque invoquera le saint ermite obtiendra de même, pourvu que le pêcheur promette de ne pas recommencer ${ }^{144}$. De nombreuses personnalités sont venues comme le comte Philippe de Flandre en $1170^{145}$, ou bien encore Saint Louis en 1254 et en 1270, avant son embarquement pour la croisade ${ }^{146}$. Cependant, différents événements politiques, économiques, religieux et naturels tels que les guerres albigeoises et l'ensablement du port, ont peu à peu réduit l'attractivité de Saint-Gilles ${ }^{147}$. Déjà, en 1324, le tarif de péage révèle cette décadence ${ }^{148}$. La ville reste cependant un centre religieux d'une certaine importance : en attestent la place qu'elle tient dans les pèlerinages pénitentiels de Flandres et de Wallonie à la fin du Moyen Âge ${ }^{149}$ et l'admission, au XIV ${ }^{\text {e }}$ siècle, de saint Gilles parmi les cinq confesseurs «privilégiés » vénérés principalement en Allemagne ${ }^{150}$. De même, les tarifs de péage de Tarascon des $\mathrm{XIII}^{\mathrm{e}}$ ou $\mathrm{XIV}^{\mathrm{e}}$ siècles font mention de romieus espagnols, anglais, allemands et autres venant du nord de Lyon pour visiter Saint-Jacques ou Saint-Gilles et qui doivent payer une taxe pour leur passage ${ }^{151}$. Aux $\mathrm{XV}^{\mathrm{e}}$ et $\mathrm{XVI}^{\mathrm{e}}$ siècles, le culte de Saint-Gilles décline inexorablement ${ }^{152}$, même si des pèlerins provençaux continuent de s'y rendre ${ }^{153}$. À contre-courant des autres saints, saint Gilles est surtout invoqué pour préserver sa vie ou pour être délivré de la captivité plus que pour être guéri d'une maladie ou d'une infirmité. L'origine des pèlerins est en outre souvent lointaine, même si le choix effectué pour la rédaction du Liber miraculum sancti Egidii fausse la perception : la moitié des récits met en scène des Germaniques.

Le sanctuaire de Saint-Gilles est, avec ceux de Notre-Dame de Rocamadour et de Saint-Léonard-de-Noblat, l'un des sanctuaires français qui offre le plus grand nombre d'enseignes

142. Bondurand 1901; Bligny-Bondurand 1915.

143. Il y avait 134 tables de changeurs en 1178 , ce qui permettait de servir 50000 pèlerins en trois jours (KösTER 1983, p. 92).

144. Köster 1983, p. 91 ; WyzeWA (éd.) 1998, p. 492.

145. KÖSTER 1983, p. 93.

146. Carru et Gagnière 1992, p. 81.

147. Girault et Girault 2007a, p. 18-19.

148. La comparaison entre la liste des marchandises citées dans le péage du XII ${ }^{e}$ siècle (BondurAND 1901, p. 285-288; ID. 1915, p. 242-243) et celles de 1324 (FALGAIROLLE 1898, p. 557-559) est éloquente.

149. VAlON 1935, p. 35, 41, 43, 44, 46, 47; GANshof 1966.

150. Girault et Girault 2007a, p. 20.

151. BoNDURAND 1891, p. 155-157; BARATIER 1959, p. 387; AD BDR, B 1021, fol. $85 \mathrm{v}-86 \mathrm{r}, \mathrm{B} 1152$, fol. 22v-23v. Se conférer à la figure 1, no 101, 107, 112 et 121.

152. Köster 1983, p. 97-98; Girault et Girault 2007a, p. 20.

153. Charles de Ribbe rapporte le cas d'un jeune jurisconsulte d'Avignon et de son épouse qui, en 1548, s'y rendent dès le lendemain de leur mariage (DE RibBe 1898, p. 177) 

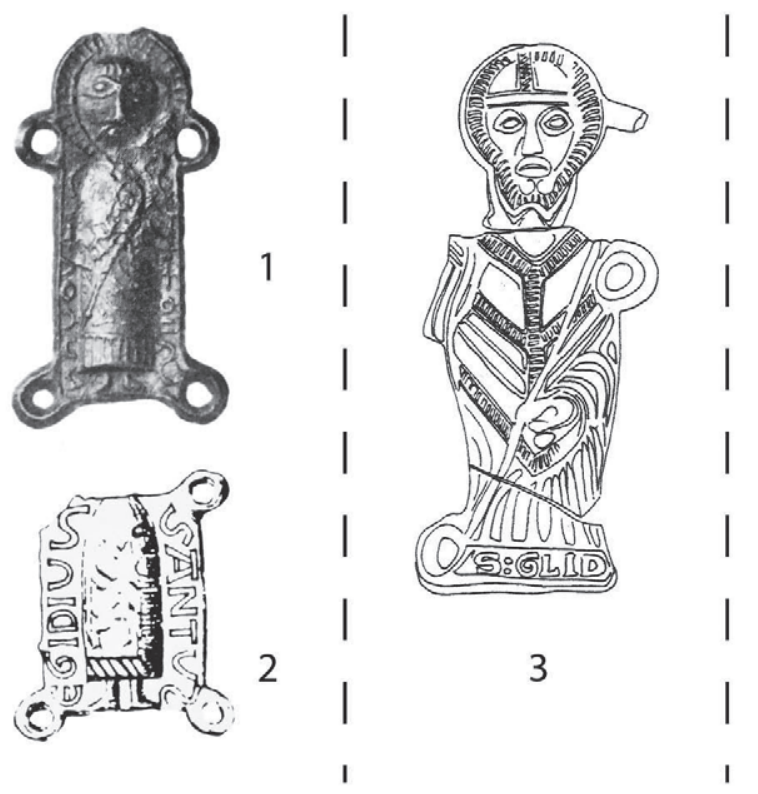

3
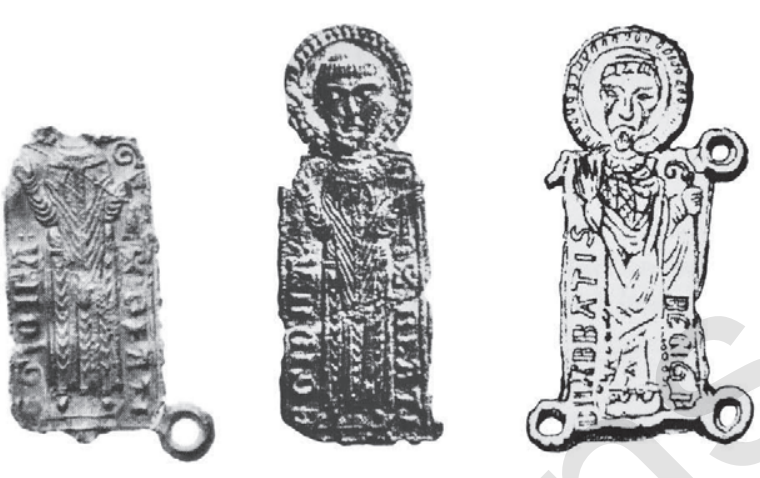

4

5

6

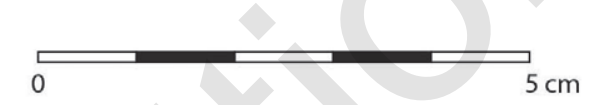

Type 1, sous-type 1

\begin{tabular}{|l|l|l|l|}
\hline $1171-1250$ & $\begin{array}{l}\text { Vintry House } \\
\text { (Londres) }\end{array}$ & Fig. 13, $\mathrm{n}^{\circ} 1$ & SPENCER 2010, p. 238, fig. 246e \\
\hline$/$ & $\begin{array}{l}\text { Walter Art Gallery } \\
\text { de Baltimore }\end{array}$ & Non figuré & $\begin{array}{l}\text { B. SPENCER y renvoie pour } \\
\text { comparaisons avec l'objet } \\
\text { londonien }\left(2010^{2}, \mathrm{p} .238\right) .\end{array}$ \\
\hline Découvert en 1871 & Loire (Orléans) & Fig. 13, $\mathrm{n}^{\circ} 2$ & $\begin{array}{l}\text { DESNOYERS 1873; KöSTER } \\
1983, \mathrm{p} .105-106, \mathrm{n}^{\circ} \mathrm{G} 11\end{array}$ \\
\hline Boues de rivière, 1979 & $\begin{array}{l}\text { Newbury } \\
\text { (Berkshire) }\end{array}$ & Non figuré & $\begin{array}{l}\text { Décrit comme identique à celui } \\
\text { d'Orléans dans Santiago de } \\
\text { Compostela (1985). }\end{array}$ \\
\hline
\end{tabular}

Type 1, sous-type 2

\begin{tabular}{|l|l|l|l|}
\hline $\begin{array}{l}\text { Gravats d'effondrement de } \\
\text { maisons. Céramique du second } \\
\text { tiers du XIV } \\
\text { monétaire des années et trésor } 1309-1310\end{array}$ & $\begin{array}{l}\text { Rue Favart } \\
\text { (Avignon) }\end{array}$ & Fig. 13, $\mathrm{n}^{\circ} 3$ & $\begin{array}{l}\text { CARRU et GAGNIERE 1992; } \\
\text { FERRANDO 2001b. }\end{array}$ \\
\hline
\end{tabular}

Type 2

\begin{tabular}{|l|l|l|l|}
\hline H.S. & $\begin{array}{l}\text { Billingsgate Market } \\
\text { lorry Park } \\
\text { (Londres) }\end{array}$ & Fig. 13, $\mathrm{n}^{\circ} 4$ & $\begin{array}{l}\text { SANTIAGO 1985, p. 317, } \\
\mathrm{n}^{\circ} \text { 270; SPENCER 2010, p. 238, } \\
\text { fig. 246a. }\end{array}$ \\
\hline $\begin{array}{l}\text { Apparu sur le marché de l'art } \\
\text { néerlandais en 1944 }\end{array}$ & $\begin{array}{l}\text { Lit de l'Escaut ? } \\
\text { (Pays-Bas) }\end{array}$ & Fig. 13, $\mathrm{n}^{\circ}$ 5 & KöSTER 1983, p. 100, $\mathrm{n}^{\circ} \mathrm{G1.}$ \\
\hline Découvert en 1870 & Sambre (Namur) & Fig. 13, $\mathrm{n}^{\circ} 6$ & $\begin{array}{l}\text { KÖSTER 1983, p. 100-101, } \\
\mathrm{n}^{\circ} \mathrm{G} 2 .\end{array}$ \\
\hline
\end{tabular}

Fig. 13 Enseignes du sanctuaire de Saint-Gilles de types 1 et $2 ; n^{\circ}$ 1, cl. London Museum (SPENCER 2010²); no 2, dessin : F.-E. Desnoyers (DESNOYERS 1873); no 3, dessin : D. Carru (CARRU et GAGNIĖRE 1992); $n^{\circ} 4$, cl. London Museum (SPENCER 2010²); no 5, cl. F. Cajot (Köster 1983); no 6, dessin : E. Meyer (KÖSTER 1983). 
de pèlerinage connues. Aux dix exemplaires inventoriés par Kurt Köster en $1983^{154}$, il convient d'ajouter vingt et un autres individus signalés ou publiés depuis ${ }^{155}$. Trois autres enseignes portant la représentation de saint Gilles ont été fabriquées, d'après Kurt Köster, pour d'autres lieux de culte du saint. Cependant, l'une d'elles semble, à l'aune des données actuelles, pouvoir être attribuée au sanctuaire gardois (fig. 13, no 2) ${ }^{156}$. La totalité du mobilier a été classée en quatre groupes, à l'exception d'une enseigne mise au jour dans une sépulture des XIII ${ }^{\mathrm{e}}$-XIV ${ }^{\mathrm{e}}$ siècles à Saint-Émilion (Gironde) et pour laquelle il n'a pu être trouvé ni description ni iconographie ${ }^{157}$.

Toutes les enseignes sont construites sur un modèle similaire soumis à quelques variations de détail : l'ermite, les yeux grands ouverts, tonsuré, barbu, prend place dans une plaque rectangulaire terminée par une excroissance accueillant la tête auréolée. Il est vêtu d'une dalmatique par-dessus une aube. L'auréole est généralement constituée d'un grènetis. Pour les enseignes du premier type (fig. 13, no 1 à 3), l'auréole, formée d'une bande de petits traits limités par deux bandeaux, est peu saillante. Aucun bras n'est visible, mais la main gauche tient une crosse disposée en travers du corps. Sur un premier sous-type (fig. 13, no 1 et 2), le corps prend la forme d'une ogive. Pour un deuxième sous-type (fig. 13, n 3), l'enseigne prend la forme de l'abbé. Il est ici mitré et nimbé. L'extrémité de la crosse devait se situer à gauche de la tête de saint Gilles, comme le laisse supposer l'amorce d'une petite languette, probablement un renfort. Comme de nombreuses enseignes des types suivants, la dalmatique comporte des plis en V. Pour les enseignes des groupes 2 à 4 (fig. 13, nº 4 à 6 , fig. 14 et 15 ), les mains sont clairement séparées du corps : Gilles tient de la main gauche une crosse et fait de la main droite le signe de la bénédiction. Un manipule à franges terminé par des pompons pend sur l'avant-bras gauche pour les types 2 et 4 (fig. 13, no 4 à 6 ; fig. 15). Les groupes 3 et 4 (fig. 14 et 15) figurent deux attributs de la vie érémitique de saint Gilles : une biche la tête levée, à quatre pattes (fig. 14, n 1 et 2 ; fig. $15, \mathrm{n}^{\circ} 11$ et 12 ) ou au corps dressé et les pattes avant appuyées sur le saint; une ou deux plantes (fig. 15, no 11 et 12) - évoquant peut-être la végétation humide de la grotte - dont les branches ont des extrémités perlées. Il peut s'y ajouter une petite tige, sommée de trois points, plantée dans le creux du coude gauche (fig. 14, no 1 ) ou droit (fig. 15, no 1 et 2 ), ou au revers du coude gauche (fig. 15, no 5 à 7,13$)^{158}$, symbolisant la flèche ayant blessé saint Gilles. Sur un objet parisien, la tête est représentée sous un arc brisé (fig. 14, n 1 ). Il possède au revers un quadrillage en relief. Un enseigne du site de Bull Warf à

154. KÖSTER 1983, p. 99-107.

155. Santiago de Compostela 1985, p. 316-318; Beuningen et Koldeweij 1993, p. 161; Bruna 2003, p.75; Vallet 2008, p. 240; Spencer 2010, p. 237-239.

156. Chiara Guarnieri attribue une enseigne trouvée à Argenta, dans la province de Ferrare (Italie), au sanctuaire de Saint-Gilles (GuARnieri 1998, p. 268-269). Cette identification est reprise par Denis Bruna (Bruna 2003, p. $\left.75, n^{\circ} 34\right)$. Pourtant, la figuration est assez éloignée des enseignes de saint Gilles provenant du corpus et la légende qui fait le tour de l'enseigne, même si elle est difficilement compréhensible, ne mentionne pas le saint.

157. Quatre autres enseignes se trouvaient dans la même inhumation: une enseigne de Notre-Dame-du-Puy, une seconde de Notre-Dame de Vauvert, un saint Michel terrassant le dragon et une enseigne d'un sanctuaire indéterminé (BRUNA 2003, p. 75, note 1).

158. La qualité des figures en rend la perception difficile voire impossible.
Londres (fig. 11, $\mathrm{n}^{\circ}$ 6), appartenant au type 4, se distingue par le schématisme de la représentation ${ }^{159}$. L'auréole est ici composée de triangles et de grènetis.

À l'exception des enseignes du groupe 4, tous les objets ont une légende. Sur des pièces d'Orléans (fig. 13, no 2) et de Newbury se lit la légende SANTUS EGIDIUS, de part et d'autre du corpus du saint. Celle d'un exemplaire londonien est totalement incompréhensible (fig. 13, n 1 ). On y reconnaît certaines lettres comme des $\mathrm{S}$ et des $\mathrm{U}$, disposées là où elles devraient être, mais les autres ne correspondent pas. Le graveur du moule a très certainement réalisé son ouvrage d'après une enseigne originale, mais il n'a pas compris la signification des lettres prises pour des motifs décoratifs. Sur d'autres artefacts court la légende S[ANCTVS] : BEATI EGIDII A[BBAS] : (fig. 13, no 4 et 5) ou [SANCTVS] BE[ATI] EGIDII ABBATIS (fig. 13, $n^{\circ} 6$ ). Pour quelques exemplaires, un cartouche, au bas de l'enseigne, reçoit l'inscription S[ANCTVS] [E]GID[II]

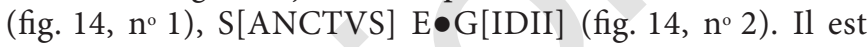
inscrit S.G.G. (?) ou S[ANC]T[VS] EGID[IVS] pour des objets du Calvados ${ }^{160}$. Pour un artefact de Whithorn (fig. 14, no 4), une inscription, presque illisible, est reportée sur les côtés : $\mathrm{B}[\mathrm{E}]$ ATI à gauche et peut-être [EG]IDII à droite. Les lettres MIO A - peut-être les restes d'une inscription plus longue - dont la signification reste obscure s'observent sur une enseigne de Winchester (fig. 14, no 3).

Toutes les enseignes à l'effigie de Saint-Gilles sont en matériau blanc. Des analyses de composition font apparaître des taux d'étain de 56 ou $66 \%$ et de plomb de $43^{161}$ ou $33 \%{ }^{162}$. À chacune des vingt-cinq enseignes connues par une photo ou un dessin correspond un moule distinct, puisqu'il n'a pas pu être répertorié deux objets identiques. Elles sont d'une manière générale de dimensions semblables et leur iconographie montre de nombreuses similitudes qui établissent leur appartenance à un même sanctuaire, très probablement celui de Saint-Gilles dans le Gard. En se fondant sur les datations stylistiques de Kurt Köster, les enseignes du groupe 2 seraient du XIII ${ }^{\mathrm{e}}$ siècle et celles des groupes 3 et 4 des XIII ${ }^{e}$ et XIV ${ }^{e}$ siècles, les exemplaires $\mathrm{n}^{\circ} 11$ et 12 de la figure 15 étant à situer plus précisément dans le $\mathrm{XIV}^{\mathrm{e}}$ siècle $^{163}$.

\subsection{LES SANCTUAIRES HORS DE PROVENCE}

\subsubsection{Les sanctuaires français et italiens}

Les enseignes de pèlerinage métalliques mises au jour en Provence et ne concernant pas les sanctuaires provençaux sont moins nombreuses. Seuls cinq exemplaires ont été identifiés, mais trois d'entre eux viennent de lieux de culte assez proches comme le sanctuaire marial de Vauvert (Gard), un peu à l'ouest de Saint-Gilles, qui acquiert sa renommée

159. Santiago de Compostela 1985, p. 317 , no 272 ; Spencer 2010, p. 238, fig. $246 \mathrm{~d}$.

160. Vivre Au Moyen ÂGe 2002, notice 279.

161. Analyse par XRF sur un objet de Bull Warf (SPENCER 2010, p. 238).

162. Analyse par XRF sur un objet de Thames Exchange (SPEncER 2010, p. 238) et par radiofluorescence (SANTIAGo DE Compostela 1985, p. 18, n 274b)

163. Köster 1983, p. 99-106, 108-113. 


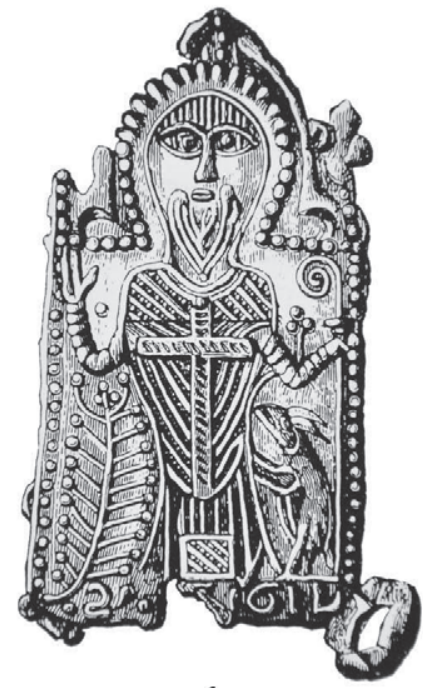

$1 a$

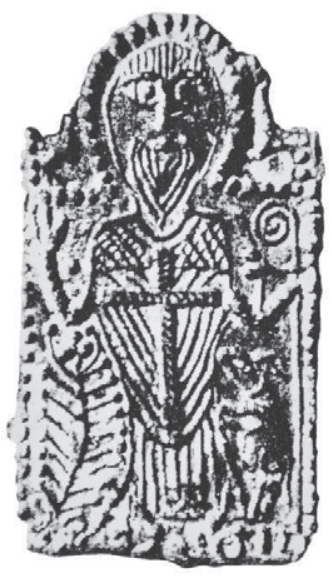

$1 b$

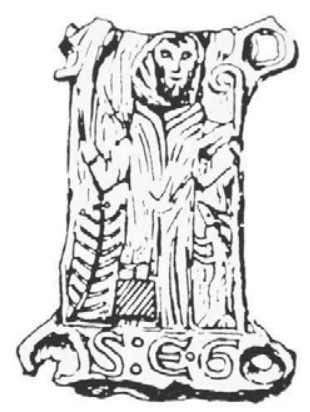

2

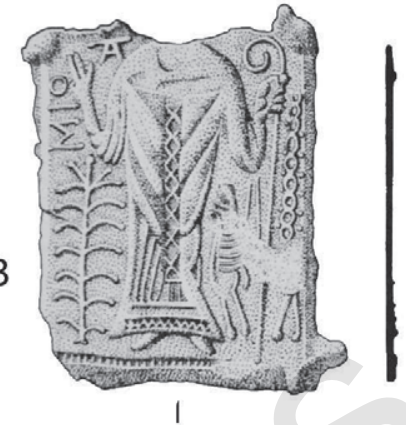

4

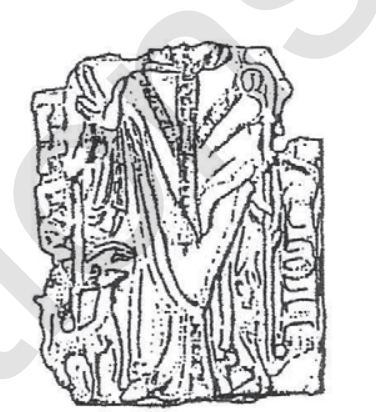

\begin{tabular}{|c|c|c|c|}
\hline Ancienne collection A. Forgeais & \multirow[t]{2}{*}{ Seine (Paris) } & Fig. $14, \mathrm{n}^{\circ} 1 \mathrm{a}$ & \multirow[b]{2}{*}{$\begin{array}{l}\text { FORGEAIS } 1863 \text {, t. II, p. } 4 \text {; } \\
\text { KÖSTER 1983, p. 101-102, } \\
\text { n G3 ; SANTIAGO 1985, p. 318, } \\
\text { n² 274a ; BRUNA 1996, p. } 148- \\
149 \text {; BRUNA 2003, fig. } 6\end{array}$} \\
\hline $\begin{array}{l}\text { Photo actuelle montrant la perte } \\
\text { de fragments }\end{array}$ & & Fig. $14, n^{\circ} 1 b$ & \\
\hline $\begin{array}{l}\text { Découvert en 1872-1874. A } \\
\text { disparu avec la destruction du } \\
\text { musée lors de la seconde Guerre } \\
\text { mondiale }\end{array}$ & Loire (Orléans) & Fig. $14, \mathrm{n}^{\circ} 2$ & $\begin{array}{l}\text { DESNOYERS } 1873 ; \text { KÖSTER } \\
1983 \text {,p. 102-103, n G4. }\end{array}$ \\
\hline $\begin{array}{l}\text { Effondrement de la première } \\
\text { moitié du XIII }{ }^{\mathrm{e}} \text { siècle d'une } \\
\text { maison }\end{array}$ & $\begin{array}{l}\text { Brook Street } \\
\text { (Winchester, } \\
\text { Hampshire) }\end{array}$ & Fig. $14, n^{\circ} 3$ & $\begin{array}{l}\text { SANTIAGO } 1985, \text { p. } 316-317, \\
\mathrm{n}^{\circ} 269 ; \text { SPENCER } 2010, \text { p. } 802, \\
\mathrm{n}^{\circ} 2480 .\end{array}$ \\
\hline $\begin{array}{l}\text { Cité monastique. Contexte non } \\
\text { daté }\end{array}$ & $\begin{array}{l}\text { Whithorn et Saint- } \\
\text { Ninian (Dumfries } \\
\text { and Galloway) }\end{array}$ & Fig. $14, n^{\circ} 4$ & NICHOLSON 1998, p. 361-362. \\
\hline $\begin{array}{l}\text { Deux objets mis au jour sur le } \\
\text { site. Datation inconnue. }\end{array}$ & $\begin{array}{l}\text { Trainecourt } \\
\text { (Gentheville, } \\
\text { Calvados) }\end{array}$ & Non figuré & $\begin{array}{l}\text { VIVRE AU MOYEN ÂGE 2002, } \\
\text { notice } 279 .\end{array}$ \\
\hline
\end{tabular}

Fig. 14 Enseignes du sanctuaire de Saint-Gilles du type 3; no 1a et 1b, dessin : A. Forgeais, cl. musée de Cluny (FORGEAIS 1863, KÖSTER 1983, Base Joconde); no 2, dessin : F.-E. Desnoyers (DeSNOYERs 1873); n 3, dessin : B. Spencer (SPENCER 20102); n 4, dessin : A. Nicholson (NiCHOLSON 1998).

dès la fin du XII siècle $^{164}$. Une enseigne en forme de navette avec originellement quatre oillets (fig. 16, no 1 ), a été mise au jour à Avignon, rue Guillaume Puy, dans un remblai superficiel remanié où abondaient les céramiques du XIVe siècle. Une inscription en caractères gothiques court en bordure : + S[IGILLUM ou IGNUM] BEATE MARIE DE VALLE VIRIDI. Au centre de la navette, la Vierge couronnée, assise sur un trône hachuré, tient un sceptre fleurdelisé dans sa main droite et porte l'Enfant auréolé sur son bras gauche. L'enseigne

164. BRUNA 2003, p. 76. est datée stylistiquement du XIVe siècle par Dominique Carru et Sylvain Gagnière ${ }^{165}$.

Des contextes provençaux ont livré deux enseignes issues du même moule, en provenance de Saint-Pierre de Lézan (Gard), lieu de pèlerinage qui n'a laissé que peu de traces historiques ${ }^{166}$. Le premier objet a été découvert en 1909 dans le Rhône à Arles (fig. 16, no 2) ${ }^{167}$, le second dans des niveaux remaniés riches en céramique du XIV e siècle, rue Guillaume Puy à Avignon (fig. 16,

165. BRUNA 2003, p. 92.

166. Ibid., p. 79.

167. CARRU et GAGNiÈre 1992, p. 78; Bruna 2003, p. 76. 

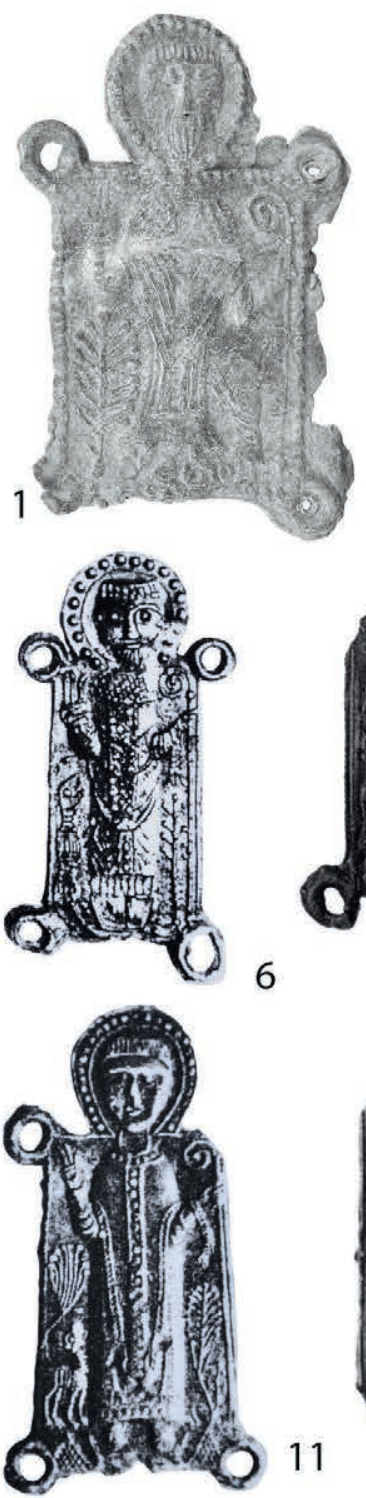

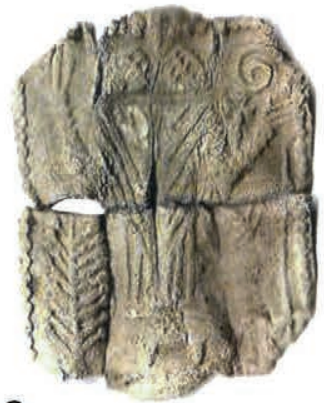

2

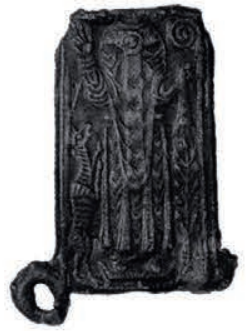

7

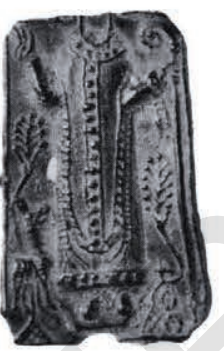

12

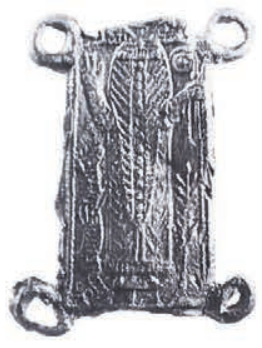

8

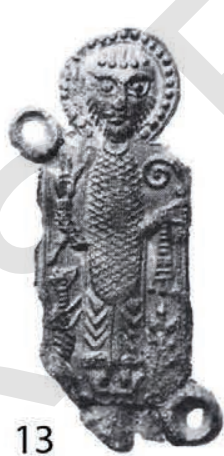

4
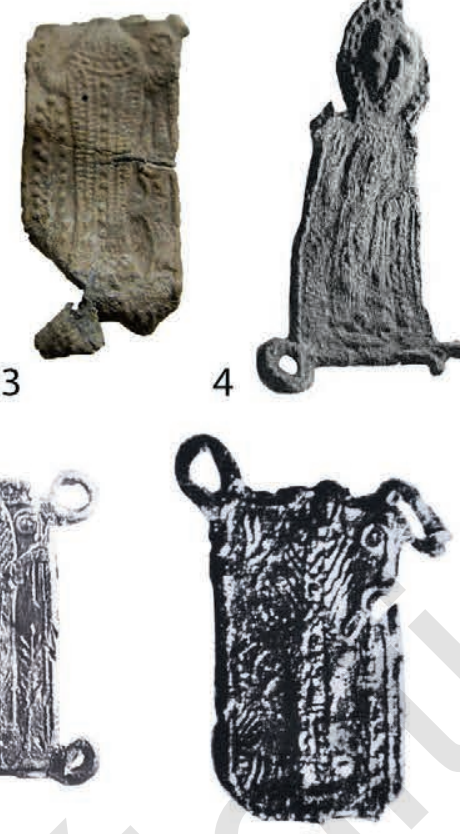

9

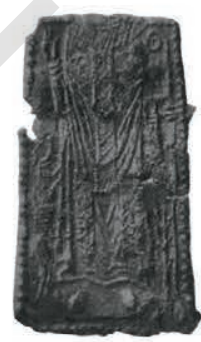

14
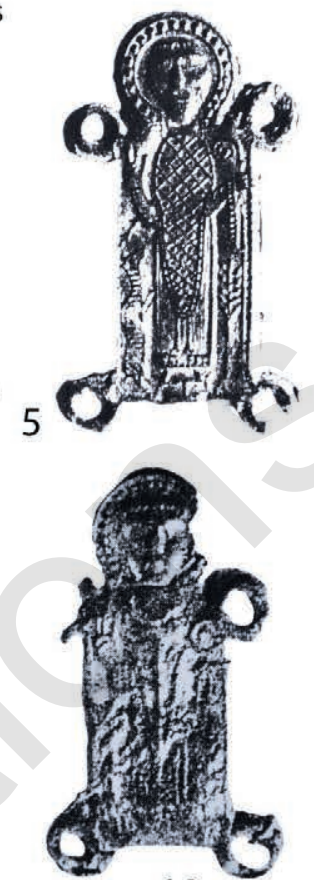

10

\begin{tabular}{|c|c|c|c|}
\hline $\begin{array}{l}\text { Contexte non } \\
\text { précisé }\end{array}$ & $\begin{array}{l}\text { Trainecourt } \\
\text { (Grentheville, Calvados) }\end{array}$ & Fig. $15, \mathrm{n}^{\circ} 1$ & VIVRE AU MOYEN ÂGE 2002, notice 279. \\
\hline \multirow[t]{2}{*}{$\begin{array}{l}\text { Ramassé par un } \\
\text { particulier }\end{array}$} & $\begin{array}{l}\text { Dives-sur-Mer } \\
\text { (Calvados) }\end{array}$ & Fig. $15, n^{\circ} 2$ & BERTON 2011, $\mathrm{n}^{\circ} 7$ \\
\hline & Eure-et-Loir & Fig. $15, n^{\circ} 3$ & BERTON 2011, $\mathrm{n}^{\circ} 6$. \\
\hline $\begin{array}{l}\text { Sépulture des } \\
\text { XIII }^{\mathrm{e}}-\mathrm{XIV}^{\mathrm{e}} \mathrm{s} \text {. }\end{array}$ & $\begin{array}{l}\text { Prieuré Saint-Jean de } \\
\text { Jérusalem (Toulouse) }\end{array}$ & Fig. $15, n^{\circ} 4$ & VALLET 2008 , p. 240 \\
\hline \multirow[t]{3}{*}{ Dragage au XIX ${ }^{e}$ s. } & \multirow[t]{3}{*}{ Saône (Lyon) } & Fig. $15, n^{\circ} 5$ & \multirow[t]{3}{*}{ KÖSTER 1983, p. $103-104, n^{\circ}$ G5, G6 et G12. } \\
\hline & & Fig. $15, n^{\circ} 6$ & \\
\hline & & Non figuré & \\
\hline Collec. particulière & Groningue (Pays-Bas) & Fig. $15, \mathrm{n}^{\circ} 7$ & BEUNINGEN et KOLDEWEIJ 1993, p. 161. \\
\hline Collec. particulière & Dordrecht (Pays-Bas) & Fig. $15, n^{\circ} 8$ & BEUNINGEN et al. $2000, \mathrm{n}^{\circ} 1129$. \\
\hline \multirow[t]{3}{*}{1} & \multirow{3}{*}{$\begin{array}{l}\text { Lit de l'Escaut ? } \\
\text { (Pays-Bas) }\end{array}$} & Fig. $15, n^{\circ} 9$ & \multirow[t]{3}{*}{ KÖSTER 1983, p. 104, n G7 à G9. } \\
\hline & & Fig. $15, \mathrm{n}^{\circ} 10$ & \\
\hline & & Non figuré & \\
\hline $\begin{array}{l}\text { Opération de } \\
\text { dragage }\end{array}$ & $\begin{array}{l}\text { 8, Hunnenstraße, } \\
\text { Schleswig (Allemagne) }\end{array}$ & Fig. $15, \mathrm{n}^{\circ} 11$ & $\begin{array}{l}\text { KÖSTER } 1983, \text { p. } 99, \mathrm{n}^{\circ} \text { G10 ; SANTIAGO } \\
1985 \text {, p. } 318, \mathrm{n}^{\circ} 274 \text { b. }\end{array}$ \\
\hline \multirow[t]{3}{*}{1} & Vintry House (Londres) & Fig. $15, n^{\circ} 12$ & SPENCER 2010 , p. 238 , fig. $246 \mathrm{c}$ \\
\hline & \multirow[t]{2}{*}{$\begin{array}{l}\text { Billingsgate market } \\
\text { lorry park (Londres) }\end{array}$} & Fig. $15, \mathrm{n}^{\circ} 13$ & $\begin{array}{l}\text { SANTIAGO } 1985, \text { p. } 317, \mathrm{n}^{\circ} 271 \text { (figure } \\
\text { inversée) et SPENCER } 2010 \text {, p. } 238 \text {, fig. } 246 \mathrm{~b}\end{array}$ \\
\hline & & Fig. $15, \mathrm{n}^{\circ} 14$ & SPENCER 2010 , p. 238 , fig. $246 \mathrm{a}$ \\
\hline T & Bull Warf (Londres) & Fig. $15, \mathrm{n}^{\circ} 15$ & $\begin{array}{l}\text { SANTIAGO } 1985, \text { p. } 317, \mathrm{n}^{\circ} 272 \text {; SPENCER } \\
2010, \text { p. } 238 \text {, fig. } 246 \mathrm{~d}\end{array}$ \\
\hline
\end{tabular}

Fig. 15 Enseignes du sanctuaire de Saint-Gilles du type 4; $n^{\circ}$ 1, cl. L. Berton (BERTON 2011); $n^{\circ} 2$, cl. auteur inconnu (Vivre au Moyen Âge 2002); $n^{\circ}$ 3, cl. L. Berton (BeRTON 2011); no 4, cl. Materia viva (VAlLet 2008); $n^{\circ} 5$ et 6, cl. auteur inconnu (KÖSTER 1983); $n^{\circ} 7$, cl. H.J.E Beuningen et A.M. Koldeweij (BeUNINGen et al. 2000); $n^{\circ}$ 8, cl. H.J.E Beuningen et A.M. Koldeweij (Beuningen et Koldewelj 1993); $n^{\circ} 9$ et 10, cl. Schloßmuseum de Berlin (KÖSTER 1983); no 11, cl. Schleswig-Holteinisches museum (KÖSTER 1983); no 12, cl. London museum (SPENCER 2010²); $n^{\circ} 13$, cl. LONdOn Museum (SPENCER 20102); no 14, cl. London Museum (SPENCER 2010²); no 15, cl. London Museum (SPENCER 2010²)2). 

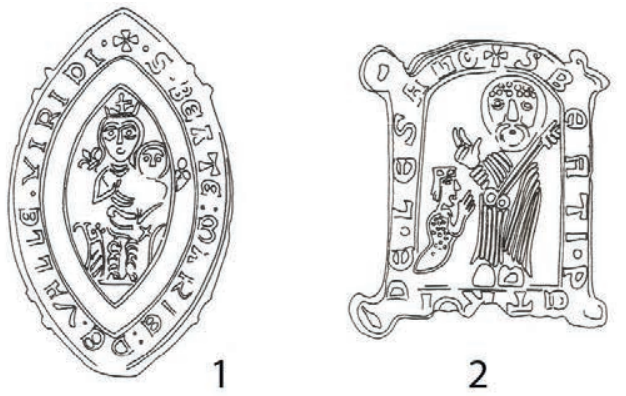

1
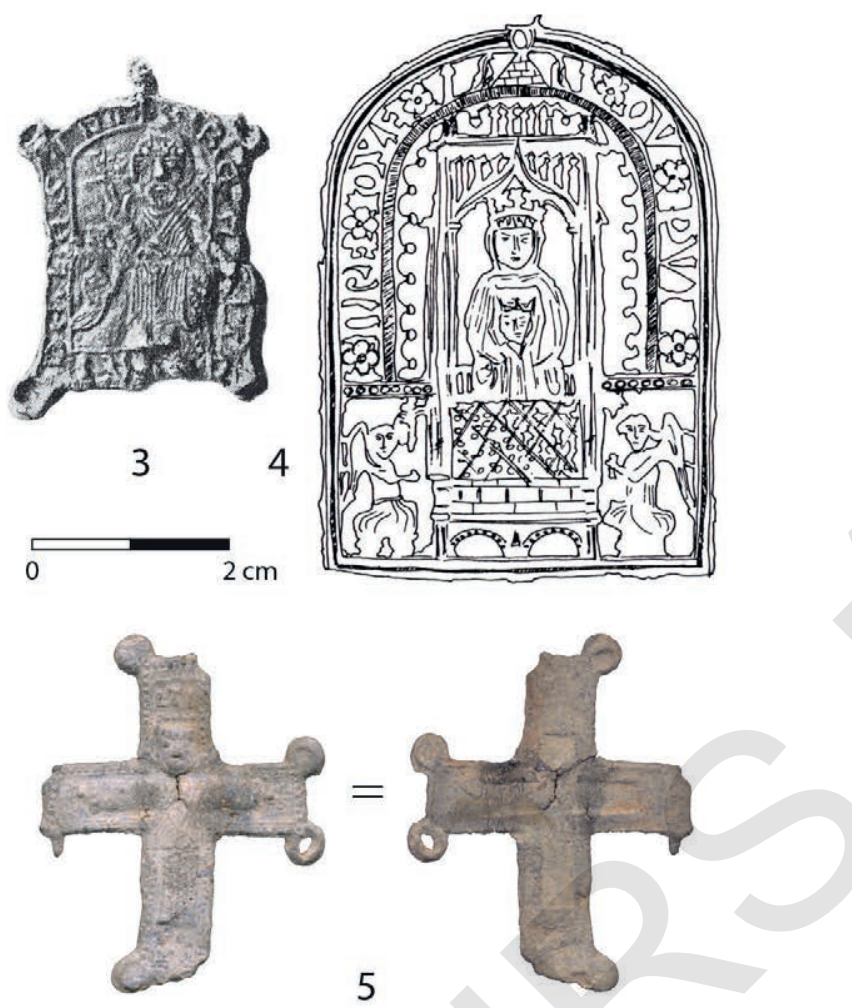

Fig. 16 Enseignes de sanctuaires hors de Provence; no 1 et 2, rue Guillaume Puy, Avignon, Vaucluse, dessin: D. Carru (CARRU et GaGNière 1992); no 3, Rhône, Arles, Bouches-du-Rhône, cl. F. Benoît (BeNOît 1927); no 4, Épave Lardier, dessin: G. Massebeuf (MASSEBEUF 1987); no 5, Ploungue, Fox-Amphoux, Var, Service archéologique du Var, dessin: O. Thuaudet.

$\left.n^{\circ} 3\right)^{168}$. Tous deux sont rectangulaires, au sommet légèrement arrondi et comportaient quatre œillets. À l'intérieur d'un encadrement contenant la légende S[IGNUM] BEATI PETRI DE LESANO ${ }^{169}$, saint Pierre, nimbé, les cheveux rendus par un grènetis, portant une robe à plis verticaux, est figuré debout et de face, tenant dans la main gauche deux clefs et bénissant de la main droite un personnage agenouillé, de profil, portant une coiffe et les mains jointes en prière. En se fondant sur des

168. Benoît 1927, p. 711-113; CARru et Gagnière 1992, p. 79; Bruna 2003, p. 6.

169. L'objet étudié par Fernand Benoît était en mauvais état, ce qui l'a conduit à une mauvaise lecture - SANO au lieu de LESANO - et à une erreur d'attribution (BENOÎT 1927, p. 111-113). critères stylistiques, Dominique Carru et Sylvain Gagnière datent l'enseigne de la fin du XIII ${ }^{\mathrm{e}}$ siècle $^{170}$.

Trois enseignes ont été achetées au sanctuaire de Notre-Dame du Puy (Haute-Loire). Un premier exemplaire (fig. 16, no 4), ajouré et en forme de rectangle avec le tiers supérieur arrondi, a été découvert sur l'épave Lardier, datée du XVII siècle par la céramique, peut-être même de la seconde moitié de ce siècle ${ }^{171}$. La légende inscrite en bordure des deux tiers supérieurs permet son authentification : N[OST]RE D [A]ME DV PVY ${ }^{172}$. De petites fleurs séparent les mots. Au centre, la Vierge couronnée est figurée assise sur un trône sous un baldaquin gothique, l'Enfant Jésus également couronné apparaît devant elle. Le trône, très travaillé est flanqué de deux anges porteurs de flambeaux. D'après l'abbé Gabriel Massebeuf, cet objet est à rapprocher d'une gravure figurant la statue de la Vierge du Puy telle qu'elle fut modifiée à la suite d'un don de Louis XI en $1476^{173}$ : deux anges porteurs de cierges flanquent la Vierge à l'Enfant sous un dais. L'auteur date de façon hardie l'enseigne de 1502 et le naufrage du bateau sur lequel voyageait le pèlerin la portant, du mois d'avril de la même année ${ }^{174}$. La présence de cet objet, probablement datable du $\mathrm{XVI}^{\mathrm{e}}$ siècle, sur une épave dont le mobilier date de la seconde moitié du XVII ${ }^{e}$ siècle, s'explique peut-être par le fait que l'objet a été collectionné, ou était cousu sur un livre.

Déjà évoqué précédemment, le livre d'heures d'Antoine Bourdin, exécuté entre 1485 et 1490, a conservé la trace de cinq enseignes en tôle et de deux véroniques peintes sur le dernier feuillet (fig. 5). Outre la plaquette circulaire de SaintMaximin, son propriétaire a disposé une enseigne inconnue qui était maintenue par huit points de couture, deux enseignes quadrangulaires appartenant au pèlerinage de Notre-Damedu-Puy et une dernière enseigne presque carrée, qui était fixée par huit points, contenant une scène désormais illisible. La plus grande des deux enseignes de la Vierge noire du Puy montre la Vierge à l'Enfant dans la partie supérieure, encadrée d'une légende indéchiffrable. Le registre médian pourrait représenter le Christ entouré de personnages sous arcades figurant les apôtres. Un chef reliquaire entouré d'anges semble apparaître dans le registre inférieur. La plus petite enseigne est occupée par la figure de Marie avec l'Enfant, sous un dais caractéristique, encadrée dans les écoinçons supérieurs de deux bustes d'anges, et en bas de deux anges agenouillés tenant un cierge. Ces deux pièces ainsi que celle à l'image de Marie-Madeleine partageaient quelques-uns des dix-huit points de couture relevés dans cette zone. La seule des deux véroniques conservées, perforée de huit trous, figure la Sainte Face, avec de sombres carnations, nimbée de rouge ${ }^{175}$.

170. Carru et Gagnière 1992, p. 92.

171. Pollino et Viallant 1987, p. 98.

172. La forme du M est assez particulière.

173. Massebeuf 1987.

174. Ses arguments sont l'écoulement nécessaire des stocks d'enseignes des modèles antérieurs à 1476, la tenue de jubilés en 1502 et 1513, une datation de 1513 attribuée d'autorité à la gravure dont l'inscription est droite et non pas courbe comme sur l'enseigne, des difficultés climatiques lors du jubilé de 1513, des flottes de guerre participant à la conquête du royaume de Naples de 1501 à 1503. Cette suite d'arguments sans valeur n'a pas grand sens.

175. Bruna 1998, p. 43. La totalité de la lecture de ce document est l'œuvre de Denis Bruna. 

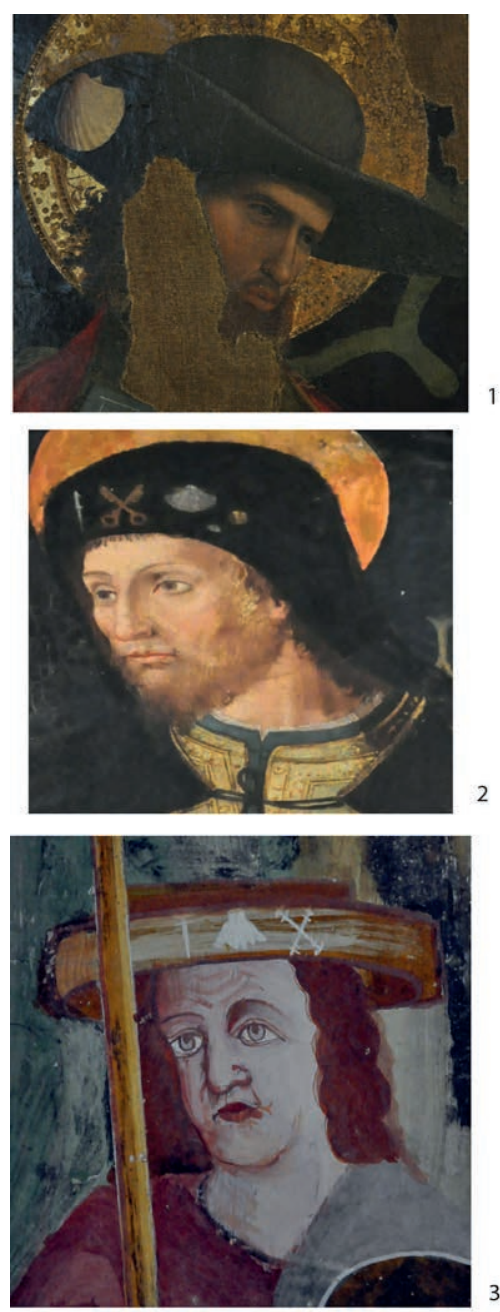

Fig. 17 Représentations de coquilles Saint-Jacques dans la peinture du sud-est de la France

no 1: Enguerrand Quarton, La Vierge et l'Enfant entre saint Jacques et un saint évêque, milieu xve siècle, Avignon, musée du Petit Palais, cl. O. Thuaudet.

$n^{\circ} 2$ : Attribué à Antoine Ronzen ou à Antoine Bréa, Saint Roc, Retable du Maître-autel, xve siècle, Villars-sur-Var, Église Saint-Jean-Baptiste, Alpes-Maritimes, cl. O. Thuaudet.

$n^{\circ} 3$ : Andrea de Cella, peintures murales (détail d'un pèlerin) de la chapelle Saint-Bernard-et-Saint-Sébastien de Roure, 1510, AlpesMaritimes, cl. O. Thuaudet.

D'Italie provient une enseigne cruciforme à bordure de grènetis avec initialement huit œillets. Retrouvée en prospection sur le site de Ploungue à Fox-Amphoux (Var) (fig. 16, n 5), elle représente le Christ vêtu d'une longue tunique plissée couvrant ses bras jusqu'aux poignets et descendant jusqu'aux chevilles. Un point rond symbolisant la tête d'un clou se perçoit au centre des deux mains. L'inscription LTI s'inscrit dans un cadre de grènetis, au-dessus de la tête du Sauveur. Elle rappelle une inscription visible sur certaines enseignes en provenance du sanctuaire de Volto Santo de Lucques découvertes à Londres : S[IGNUM SANCTI] VVLTI ${ }^{176}$ LVCENSIS. Le Christ y est également vêtu d'un vêtement long plissé ${ }^{177}$. L'enseigne varoise

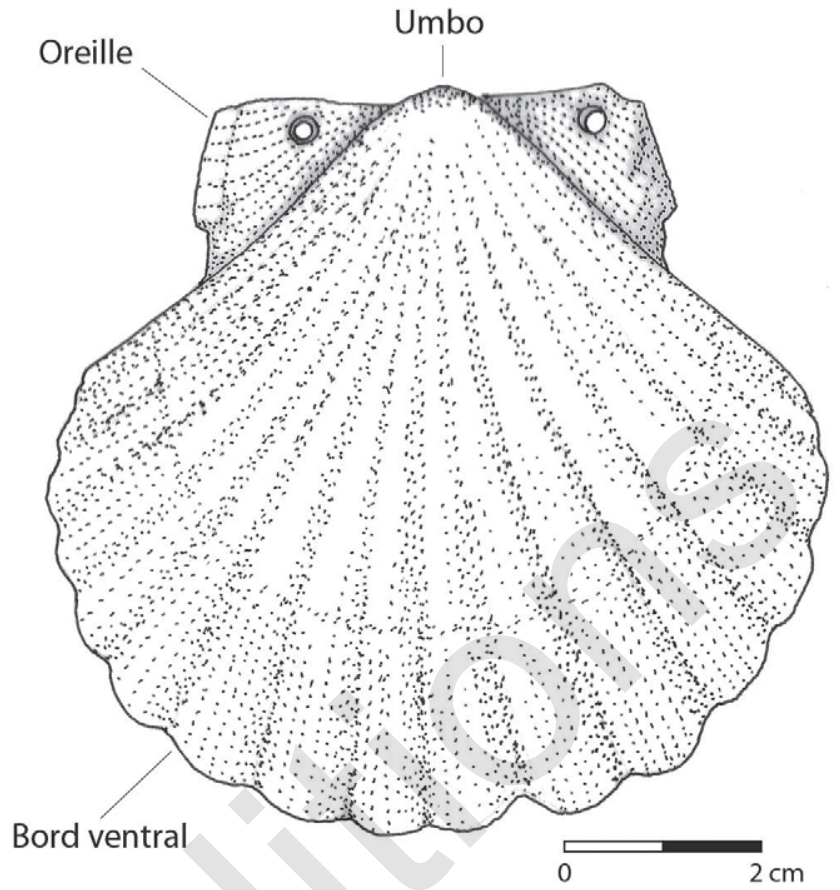

Fig. 18 Description anatomique d'une coquille Saint-Jacques du site de Régina à Avignon, service archéologique du Vaucluse, dessin: D. Carru.

présente une légère dépression cruciforme au revers qui permettait sans doute d'économiser un peu de métal.

\subsubsection{Saint-Jacques de Compostelle}

Plusieurs souvenirs de pèlerinage se rapportant au sanctuaire de Saint-Jacques en Gallice ont été retrouvés en Provence. La plupart d'entre eux sont des valves de coquilles. Elles étaient cousues sur le chapeau (fig. 17), la besace ou le manteau. Elles sont, avec le bourdon ou bâton de marche - souvent figurés sous forme de petites enseignes miniatures croisées sur le chapeau (fig. 17) -, l'un des attributs traditionnels des pèlerins de Saint-Jacques de Compostelle. Les coquilles Saint-Jacques, enseignes du sanctuaire de Galice, sont de l'espèce Pecten maximus qui vit de la mer du Nord à Gibraltar, mais aussi aux Açores et aux Canaries. La Pecten Jacobeus, se rencontre en Méditerranée ${ }^{178}$. Par erreur, Carl von Linné a attribué cette dénomination à ce coquillage, ce qui engendre une confusion dans les esprits. Les deux espèces se distinguent principalement par le profil des côtes, arrondies pour la première, plus anguleuses et à la partie supérieure aplatie pour la seconde (fig. 14, $\mathrm{n}^{\circ} 1$ ). De loin la plus fréquente en contexte archéologique, notamment dans les inhumations, la vente de la Pecten maximus a suscité bien des convoitises par l'aspect fructueux de son commerce. L'archevêque de Compostelle reçoit en conséquence des papes Alexandre III, dans le troisième quart du $\mathrm{XII}^{\mathrm{e}}$ siècle, et Grégoire IX, dans le second quart du XIII ${ }^{\mathrm{e}}$ siècle, le pouvoir d'excommunier ceux qui vendraient de tels insignes

178. Gruet et Bonnissent 2002, p. 115; VAllet 2008, p. 242-244. 


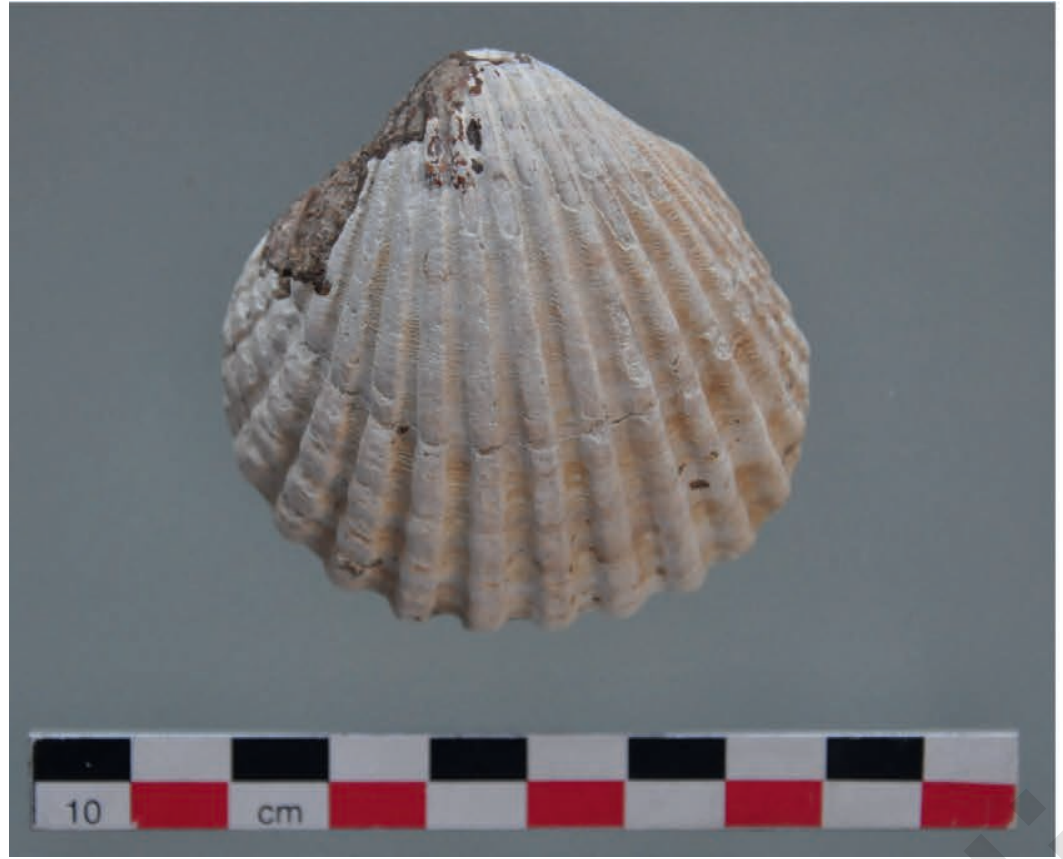

2

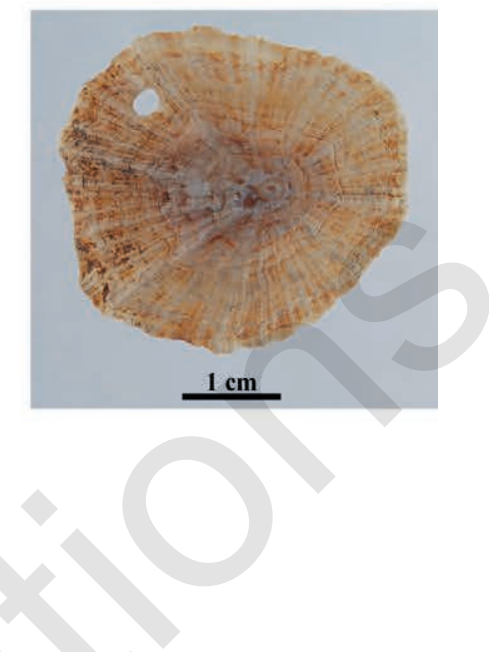

Fig. 19 Coquillages découverts dans des sépultures médiévales dans la Cathédrale Notre-Dame du Bourg à Digne; $n^{\circ} 1$ : Valve de Rudicardium tuberculatum, musée Gassendi, cl. O. Thuaudet; $n^{\circ} 2$ : Coquille de patelle, musée Gassendi, cl. P. Groscaux.

hors de la ville ${ }^{179}$, sans grand succès certainement. L'espèce méditerranéenne Pecten jacobeus, fréquente dans le sud-est de la France, a pu être distribuée par un sanctuaire provençal, être utilisée comme simulacre, ou vendue comme une enseigne du pèlerinage espagnol par des marchands indélicats. D'autres coquillages (fig. 19) comme l'Acanthocardia tuberculata ou le Rudicardium tuberculatum ont aussi pu avoir ce rôle. Faut-il mettre en cause la bonne foi de l'acheteur? En 1476, le roi René acquiert une valve de coquille d'une espèce indéterminée et la confie à un homme de Valence (Drôme) qui la perce pour permettre sa fixation (fig. 18). Cet épisode semble indiquer qu'il ne faut pas uniquement voir dans le port de coquilles Saint-Jacques, quelle que soit l'espèce, une enseigne attestant d'un pèlerinage, mais également un objet protecteur, un témoin de la vivacité de la foi. La célébrité du sanctuaire de Galice, mais plus surement de saint Jacques et de son insigne, ont assurément pu inciter certains à demander à être inhumé avec une coquille. Qu'importe alors qu'ils aient cru ou non que sa provenance fût de Compostelle! L'objet ne serait plus simplement acquis pour accréditer un pèlerinage et son rôle serait plus celui d'un talisman propre à éloigner les menaces, une sorte de passeport pour l'au-delà. En effet, une personne peut-elle espérer tromper sa famille, ses voisins, ses relations de travail, en arborant l'enseigne d'un pèlerinage non effectué ${ }^{180}$ ? En outre, un défunt peut-il espérer tromper Dieu? Il n'est pas certain que les coquilles figurées ici ou là sur des maisons, des églises, des croix de chemin ou sur des dalles funéraires garantissent toujours l'existence d'une voie usuellement fréquentée par les pèlerins de Saint-Jacques, ou témoignent de la réali-

179. Cohen 1976, p. 197.

180. Bien évidemment, il est toujours possible qu'une personne entame le voyage, s'arrête en cours de route, achète une coquille Saint-Jacques puis rebrousse chemin en ne revenant pas trop vite pour éviter les soupçons. sation du pèlerinage. D’après Kurt Köster, la coquille ne caractérise assez rapidement "plus seulement l'apôtre Jacques ni le seul pèlerin de Saint-Jacques, mais bien tous les saints pèlerins et, de manière générale, tous les pèlerins ${ }^{181}$. Dans certains cas, il est probable que la fonction protectrice évoquée soit l'explication plausible de telles figurations : protection des voyageurs dans leur parcours terrestre et vers l'au-delà. Il est même possible que ces coquilles aient été spécialement acquises pour être inhumées avec les défunts.

La plupart du temps, comme pour l'ensemble des coquilles du catalogue, il est retrouvé des valves droites, convexes. Les valves gauches, plates, sont moins appréciées. Aucune n'a actuellement été retrouvée en Provence. L’absence de traces d'animaux marins sur les coquilles indique qu'elles étaient presque toujours pêchées, celles récupérées sur le rivage sont donc rares ${ }^{182}$. Les perforations sont usuellement au nombre de deux et disposées sur l'umbo, plus solide que les oreilles. Dans le corpus, le lot le plus important de coquilles Saint-Jacques vient des fouilles réalisées dans la cathédrale Notre-Damedu-Bourg à Digne : dix-huit exemplaires sont connus. Elles possèdent deux perforations circulaires, disposées symétriquement sur l'umbo, de part et d'autre de l'axe dorso-ventral, réalisées depuis l'intérieur de la coquille grâce à un poinçon circulaire. D’après une méthode de calcul biométrique proposée par Yves Gruet et Daniel Bonnissent ${ }^{183}$, la longueur des objets dignois atteint, après taille, entre 50 et $85 \%$ de la longueur originelle sans qu'une évolution chronologique puisse être mise en évidence. L'objectif était d'enlever les parties les plus fines de la coquille pour que l'objet soit plus solide. Ces caractéristiques ont pu être observées sur quelques coquilles d'autres

181. KöSTER 1985 , p. 86

182. VALLET 2008, p. 245.

183. Gruet et Bonissent 2002. 
sites provençaux. Sur les dix-huit exemplaires de coquille SaintJacques de Digne, toutes sont de l'espèce Pecten Jacobeus ${ }^{184}$. Quatorze spécimens proviennent de sépultures individuelles ou de caveaux de la fin du Moyen Âge et de l'époque moderne. La localisation sur le squelette n'est connue que dans un cas : un spécimen sous le bassin (XII ${ }^{\mathrm{e}-\mathrm{XIII}}{ }^{\mathrm{e}}$ siècles). Deux coquillages d'une autre espèce proviennent également de sépultures : une valve de Rudicardium tuberculatum ( $\mathrm{XIV}^{\mathrm{e}}-\mathrm{XVI}^{\mathrm{e}}$ siècle) - retaillée? - avec une seule perforation sur l'umbo, retrouvée "sous le corps» d'un défunt (fig. 19, n ${ }^{\circ} 1$ ), et une patelle avec un trou en bordure (XVII ${ }^{e}-\mathrm{XVIII}^{\mathrm{e}}$ siècles), récupérée à hauteur du genou gauche d'un squelette d'homme adulte âgé de plus de 50 ans (fig. 19, n 2).

Dans le jardin situé à l'est de l'ancien presbytère de Saint-Maximin, une sépulture d'adulte des XIII ${ }^{\mathrm{e}}$-XIV ${ }^{\mathrm{e}}$ siècles conservait trois coquilles Saint-Jacques disposées sur le devant du corps, à hauteur des épaules et en haut du torse ${ }^{185}$. Elles étaient peut-être cousues au vêtement, simplement posées sur le corps ou portées en collier. Les objets n'ont pu être retrouvés et la photographie du rapport de fouille ne permet pas une identification de l'espèce. L'une d'elles au moins comportait deux perforations sur l'umbo. Sur la même commune, à Cadrix, dans une couche de destruction du $\mathrm{XVI}^{\mathrm{e}}$ siècle, une coquille de type Pecten Jacobeus a été répertoriée ${ }^{186}$. Non loin de là, à Hyères, une tombe de l'église Saint-Pierre de l'Almanarre, datée entre le XII ${ }^{e}$ et le XIV ${ }^{e}$ siècle, a livré deux coquilles dont l'espèce n'est pas déterminée ${ }^{187}$. À la Gayole, sur la commune de La Celle, toujours dans le Var, une coquille de type Pecten percée de deux trous a été découverte dans des terres remaniées, datées entre le début du XII ${ }^{\mathrm{e}}$ siècle et la seconde moitié du XIII ${ }^{\mathrm{e}}$ siècle ${ }^{188}$.

Des coquilles Saint-Jacques ont aussi été mises au jour dans le Vaucluse. Un exemplaire identifié, grâce à l'intervention du naturaliste $\mathrm{H}$. Nicolas, comme de type Pecten Jacobeus, provient d'une sépulture en coffrage, présente sur le plateau de Cancabeau à Châteauneuf-de-Gadagne. Elle contenait trois corps et un petit récipient en verre. Elle datait, d'après le mobilier et le type de sépulture retrouvés, des XII ${ }^{\mathrm{e}}$-XIII ${ }^{\mathrm{e}}$ siècles ${ }^{189}$. Un deuxième spécimen retaillé avec deux perforations sur l'umbo fut trouvé place de la Principale à Avignon. Un autre exemplaire, découvert dans l'église Notre-Dame-la-Principale à Avignon, de datation non renseignée, est de l'espèce Pecten Jacobeus. Trois autres coquilles avignonnaises de la même espèce proviennent pour l'une d'un contexte inconnu du site de Régina, pour la deuxième d'un contexte de la seconde moitié du XIV ${ }^{e}$ siècle de l'Impasse de l'Oratoire, pour la dernière, hors stratigraphie, du site de la rue Banasterie. La première, entière, mais qui n'a pu être observée, présente une perforation sur

184. Identification par Philippe Columeau (CCJ, UMR 7299, Université d'Aix-Marseille, CNRS). Une seule coquille sans aucune perforation et non retaillée, de type Flexopecten Glaber a été mise au jour dans une tombe datée par ${ }^{14} \mathrm{C}$ avec un intervalle de deux sigmas entre 592 et 759 . Une coquille de cette espèce provient d'un remblai daté de la deuxième moitié du XII siècle ou du début du XIII siècle dans l'église Saint-Laurent de Grenoble (Colardelle 1999, p. 362 ; ColARdelle 2008, p. 298).

185. GuYON 1996, p. 19-20.

186. Objet inédit.

187. PASQuAlini et al. 1991, p. 50.

188. Objet inédit.

189. Sagnier 1987, p. 188; Gagnière et Granier 1971, p. 173, 184, 186.

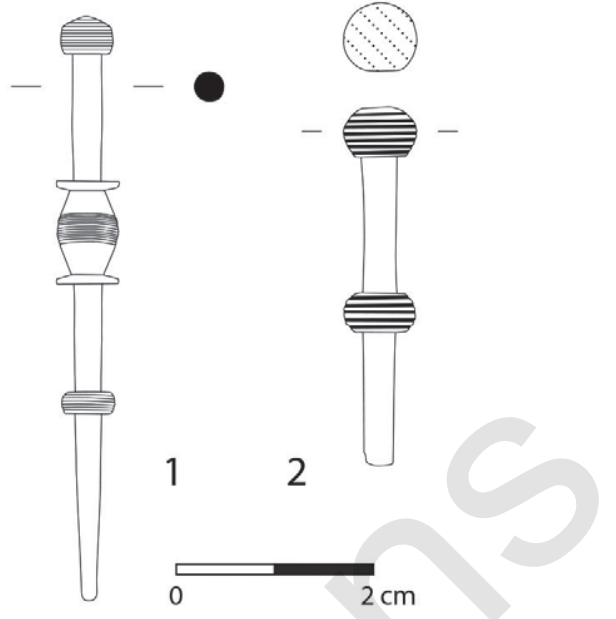

Fig. 20 Bourdons miniatures en os;

no 1 Jardin ouest du Petit Palais, Avignon, musée du Petit Palais, dessin : O. Thuaudet;

$n^{\circ}$ 2, Impasse de l'Oratoire, Avignon, musée du Petit Palais, dessin : O. Thuaudet.

chaque oreille; la seconde, fragmentaire, affiche des traces de taille et ne comprend qu'une unique perforation sur l'umbo. La troisième est retaillée et possède deux perforations sur l'umbo ${ }^{190}$.

Un ultime spécimen a été découvert dans le cloître de SaintGilles, sous le coude droit d'un homme adulte inhumé dans un coffre en bois entre la seconde moitié du XIII ${ }^{e}$ siècle et le milieu du XVII ${ }^{\mathrm{e}}$ siècle ${ }^{191}$.

À l'image du corpus provençal, les coquilles Saint-Jacques sont le plus souvent découvertes en un, parfois deux exemplaires, dans les sépultures d'Europe occidentale ${ }^{192}$. Sophie Vallet enregistre 129 inhumations avec une seule coquille pour l'Aquitaine et la nouvelle région Occitanie, vingt avec deux coquilles, treize avec trois, quatre, cinq, six ou onze coquilles ${ }^{193}$. Elle ne rencontre qu'un seul spécimen de Pecten Jacobeus, répertorié sur le site de Saint-Côme-et-Damien à Montpellier ${ }^{194}$. Dans le corpus provençal, la majeure partie des coquilles sont découvertes isolées. À Digne, un caveau et un ossuaire en ont chacun

190. L'ensemble de ces artefacts mis au jour à Avignon est inédit. 191. Objet inédit.

192. Kurt Köster (1983 et 1985) puis Denis BRUNA (1991) ont établi des cartes de répartition des coquilles Saint-Jacques. Elles sont désormais largement incomplètes. L'établissement d'une telle cartographie ne peut mettre en évidence les routes du pèlerinage, mais seulement donner une idée de l'étendue de la renommée du pèlerinage de Saint-Jacques-de-Compostelle et du choix de l'espèce de Pecten. L'échelle géographique et temporelle à couvrir est si importante qu'une telle démarche ne peut être l'œuvre d'une seule personne, mais le résultat conjugué du travail de chercheurs de régions et de pays variés pour combler les vides liés à la méconnaissance de la bibliographie régionale. Par exemple, dans les cartes publiées par les auteurs susmentionnés, l'Espagne, à l'exception de sa partie septentrionale apparaît désespérément vide, ce qui est plus que surprenant. L'Italie s'affiche également vierge de toute attestation. Il y a quelques années, cependant, est paru sous la direction de Francesca Bulgarelli et al. l'ouvrage Archeologia dei pellegrinaggi in Liguria (2001), qui présente plusieurs dizaines de spécimens de Pecten Jacobeus et de Pecten Maximus, provenant de contextes datés entre le XIII ${ }^{e}$ et le XVI ${ }^{e}$ siècle. 193. VAllet 2008, fig. 2.

194. Ibid., p. 242. 
deux, mais la présence avérée de plusieurs individus dans ces deux espaces ne permet pas d'affirmer qu'elles appartenaient au même défunt. Une unique sépulture, datée entre la fin du XII ${ }^{e}$ siècle et le début du XIII ${ }^{e}$ siècle, contenait deux exemplaires, une autre, antérieure à 1335 , en comprenait trois. D'après Denis Bruna, les coquilles apparaissent en plus grand nombre dans les sépultures dès la fin du XIVe siècle ${ }^{195}$; pour Kurt Köster, c'est à partir de la fin du Xvie siècle que leur quantité, tout comme leur taille, s'accroissent ${ }^{196}$. Denis Bruna ne perçoit pas d'emplacement caractéristique d'une époque, pour les coquilles, sur les squelettes, même si, du XI ${ }^{e}$ au XIII ${ }^{e}$ siècle, elles sont, dans la plupart des cas, situées à hauteur du bassin, mais cette disposition perdure ultérieurement. Il relève que, dans l'iconographie des XII et XIII siècles, l'enseigne figure toujours sur la besace. $\mathrm{Au} \mathrm{XIV}^{\mathrm{e}}$ siècle, la panetière est encore le support majoritaire, mais un ou deux spécimens peuvent être placés sur une autre partie du costume. Dans la seconde moitié du XIVe siècle, le chapeau à large bord fait son apparition et devient le plus souvent, porteur d'insignes (fig. 17). Le manteau reste peu orné. À la fin du XVIe siècle, le mantelet, un large col qui s'attache au-dessus de la pèlerine, se révèle un emplacement privilégié ${ }^{197}$.

Les sculptures et peintures figurant des saints pèlerins et des pèlerins les représentent toujours avec un bâton de marche en bois, le bourdon, qui à l'occasion, permet de se défendre. Celui-ci peut être travaillé de fort belle manière, mais en contexte archéologique, il n'en est retrouvé que l'extrémité ferrée lorsqu'il en comportait une. Le bourdon ou bâton de marche est, avec la coquille, un objet caractéristique du pèlerin de SaintJacques et participe de l'identification ${ }^{198}$. Il existe des reproductions de bourdons à échelle réduite, en os, qui se portaient sur le manteau ou sur le chapeau, isolément ou beaucoup plus couramment croisées par paires (fig. 17, n 3 ), posées de part et d'autre d'une coquille Saint-Jacques, ou partiellement recouvertes par celle-ci. Ces bourdons semblent donc être spécifiques du pèlerinage de Saint-Jacques-de-Compostelle et apparaissent toujours accompagnés de coquilles, ou dans le cadre d'un costume où se retrouvent des coquilles. Les deux bourdonnets avignonnais présentés ici (fig. 20), de section circulaire, ont été identifiés par Marie-Astrid Chazottes ${ }^{199}$. Ils ont été fabriqués par tournage. Le premier (fig. 20, no 1 ) a été découvert hors stratigraphie sur le site de l'Impasse de l'Oratoire. Le second (fig. 20, no 2) provient d'un contexte remanié à l'époque contemporaine dans le jardin ouest du Petit Palais à Avignon. Ces objets apparaissent relativement tardivement que ce soit dans l'iconographie - à partir du $\mathrm{xV}^{e}$ siècle - ou en contexte archéologique - à partir du XVI ${ }^{e}$ siècle actuellement ${ }^{200}$. Leur fabrication s'est faite à grande échelle durant l'époque moderne : un document de 1604 fait ainsi allusion à la confection à SaintJacques en Galice de 7000 pièces en os tourné201. Ces objets ne sont pas toujours correctement interprétés dans la documentation archéologique et il ne serait donc pas étonnant qu'un certain nombre d'exemplaires aient échappé de ce fait à la

\footnotetext{
195. BRUNA 1991, p. 184.

196. KÖSTER 1985, p. 88.

197. BRUNA 1991, p. 184-186; BRUNA 2003, p. 108

198. Se reporter à JACOMEt 1990.

199. Doctorante Aix Marseille Université, CNRS, LA3M (UMR 7298).

200. Rodet-Belarbi 2013, p. 49.

201. KÖSTER 1985, p. 87.
}

publication ${ }^{202}$. L'emplacement de leur découverte sur les corps est rarement précisé : signalons six bourdonnets relevés dans une inhumation du XviI ${ }^{e}$ siècle sur le site Raynaldy-Jacobins à Rodez (Aveyron); ils étaient disposés, avec des coquilles SaintJacques, à hauteur des épaules et du cou du squelette ${ }^{203}$. Tous ces objets, lorsqu'ils sont complets, possèdent une excroissance entaillée de gorges à leur extrémité supérieure et deux autres renflements rainurés encadrés de disques le long de la tige. Leur extrémité inférieure est parfois pourvue d'un petit ressaut qui rappelle certainement la ferrure métallique des bâtons. Leur datation, sur la foi des sources iconographiques, est à situer entre le $\mathrm{xv}^{e}$ et le $\mathrm{xvIII}{ }^{e}$ siècle, voire le début du XIx ${ }^{e}$ siècle d'après Isabelle Rodet-Belarbi ${ }^{204}$. Les données archéologiques rassemblées n'en attestent pour le moment que pour les $\mathrm{XVI}^{\mathrm{e}}$ et XVII ${ }^{e}$ siècles.

\subsubsection{Les enseignes non identifiées}

Les ultimes pièces étudiées sont des enseignes ou des souvenirs religieux dont le sanctuaire d'origine est indéterminé. C'est le cas de deux objets en matériau blanc représentant un avant-bras. Ils font probablement référence à un bras reliquaire. Le premier (fig. 21, no 1), découvert au castrum Saint-Jean de Rougiers, dans un niveau daté entre 1370/1375 et 1415/1420, est orné de trois bandes de grènetis et de petites fleurs à quatre pétales ${ }^{205}$. Une dernière bande de grènetis, à l'emplacement des premières phalanges, pourrait symboliser des bagues à chaton. Des excroissances de part et d'autre du bras marquent probablement la position de deux oillets de fixation disparus. Le second exemplaire (fig. $21, \mathrm{n}^{\circ} 2$ ), provenant d'un niveau du début du $\mathrm{XVI}^{\mathrm{e}}$ siècle du château des Baux-de-Provence, est habillé d'une large manche plissée, décorée par une bande de grènetis côté coude ${ }^{206}$. L'auriculaire et l'annulaire sont repliés pour former le signe de la bénédiction. Des œillets de fixation sont situés aux extrémités des manches, côté poignet. Les deux artefacts ont un revers partiellement concave, pour économiser du métal. Une enseigne similaire au spécimen des Baux-de-Provence a été découverte aux Pays-Bas. Elle est datée stylistiquement de la seconde moitié du XIVe siècle ${ }^{207}$.

La figuration d'un saint personnage masculin n'a pu être rattachée à un sanctuaire. L'enseigne (fig. 21, n 3), abîmée, représente le buste d'un homme barbu, la tête nimbée. Il tient un livre de la main gauche. Le lieu de découverte de cet objet - le Castelet à Fontvieille? - est incertain. Un trou dans la partie supérieure a servi à la fixation. Philippe Ferrando propose d'y voir une enseigne de l'abbaye de Montmajour à l'effigie de saint Antoine ${ }^{208}$. Peut-être est-ce une enseigne de Saint-Gilles?

\footnotetext{
202. En Alsace, par exemple, trois individus fragmentaires, dont deux datés du $\mathrm{XVI}^{\mathrm{e}}$ siècle et de la fin du XVI ${ }^{e}$ siècle, ont été mis au jour à Ramstein et à Ortenbourg (Bas-Rhin), et interprétés comme des éléments de rouet (МоттEAU [dir.] 1991, no 239 à 241).

203. Rodet-BeLARbi 2013, p. 88.

204. Ibid., p. 48.

205. Démians d'Archimbaud 1980a et b.

206. Objet inédit.

207. Beuningen et al. 2000, nº 1566.

208. Ferrando 2001b, p. 37.
} 

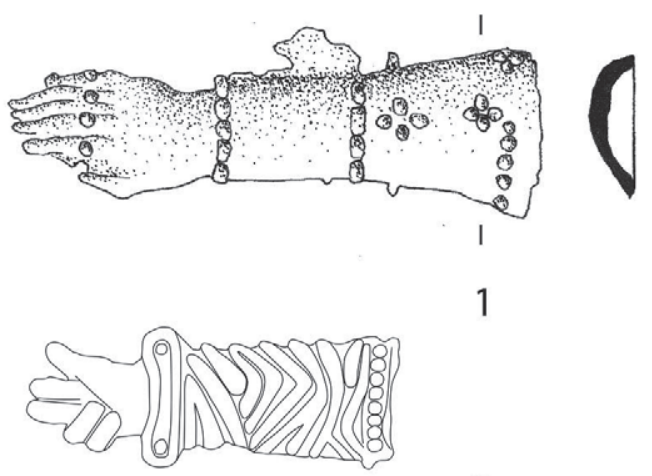

1
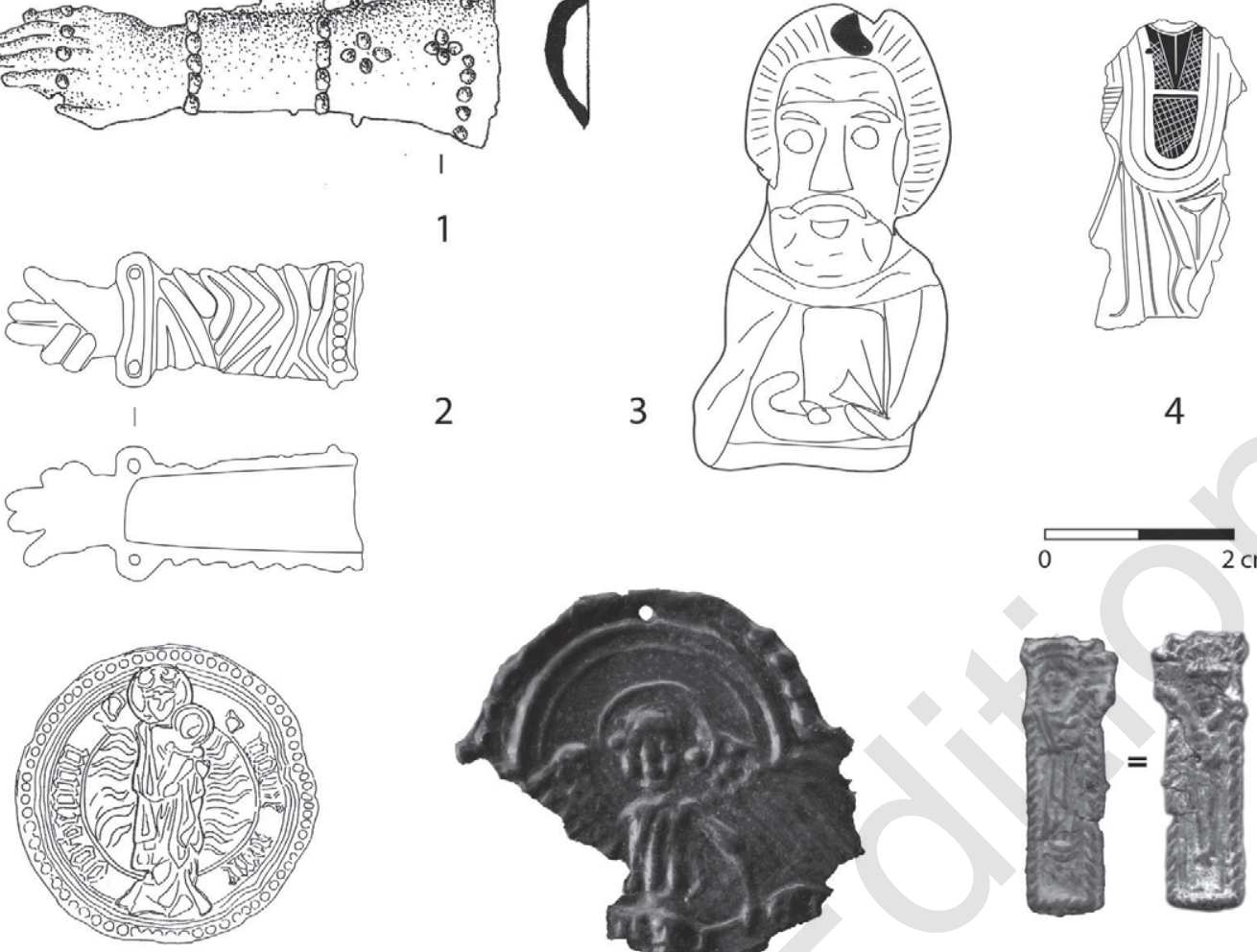

5

2

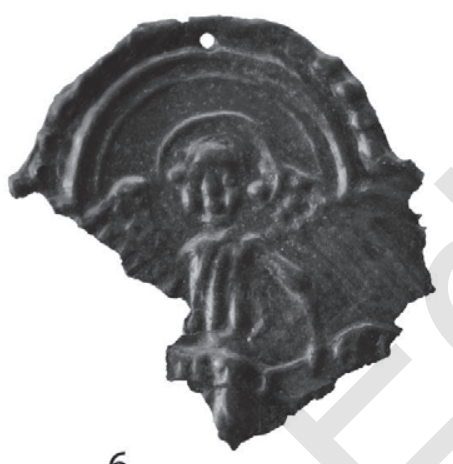

6

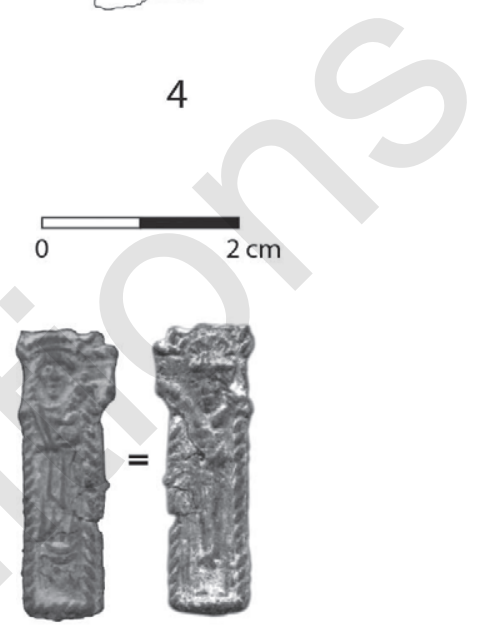

7

Fig. 21 Enseignes de sanctuaires inconnus;

no 1 : Castrum Saint-Jean, Rougiers, Var, Dépôt archéologique de La Ripelle, dessin : L. Vallauri (DémIANS D'ARCHIMBAUD 1980a et b);

$n^{\circ} 2$ : Château des Baux, Les Baux-de-Provence, Bouches-du-Rhône, Maison de l'Archéologie des Baux-de-Provence, dessin : O. Thuaudet;

$n^{\circ} 3$ : Le Castelet?, Fontvieille?, Bouches-du-Rhône, dessin : P. Ferrando (FERRANDo 2001b);

$n^{\circ} 4: 65$, place de Cabassole, Cavaillon, Vaucluse, dessin : O. Thuaudet;

$n^{\circ} 5$ : La Sorgue, Avignon, Vaucluse, service archéologique du Vaucluse, dessin: D. Carru;

$n^{\circ} 6$ : Cathédrale Notre-Dame du Bourg, Digne, Alpes-de-Haute-Provence, cl. P. Groscaux;

$n^{\circ}$ 7: Rue Racine, Avignon, service archéologique du Vaucluse, cl. O. Thuaudet.

Un fragment de personnage (fig. $21, \mathrm{n}^{\circ} 4$ ) a été découvert hors stratigraphie, 65 place de Cabassole, à Cavaillon ${ }^{209}$. La tête et les bras manquent, le corps est drapé dans un long vêtement aux plis lourds. Sur le devant, un pan retombe et découvre un vêtement de dessous couvert de hachures en relief positif, au col en $\mathrm{V}$, ceinturé sous la poitrine. La disposition de la ceinture est typique de la mode féminine et se rencontre couramment au XVe siècle.

Une enseigne emboutie (fig. 21, $\mathrm{n}^{\circ}$ 5), vraisemblablement en tôle d'argent, fut découverte lors d'un curage de la Sorgue à Avignon en 1851, près de l'église des Cordeliers. La Vierge pose en majesté, couronnée, avec l'Enfant sur son bras gauche; tous deux sont nimbés et entourés de flammes radiantes limitées par un cercle. Le cadre est formé de grènetis et de bandes circulaires encadrant une légende en lettres gothiques anguleuses et serrées que Denis Carru et Sylvain Gagnière proposent de lire NO[S ?]TRE DAME DORBE(MIA ?) ${ }^{210}$. Les enseignes en tôle

209. Objet inédit.

210. Carru et Gagnière 1992, p. 82. apparaissent dans la seconde moitié du Xve siècle pour disparaître au cours du XVI ${ }^{e}$ siècle d'après Denis Bruna ${ }^{211}$.

Un autre morceau d'enseigne en tôle emboutie, mais cette fois en alliage cuivreux (fig. 21, n ${ }^{\circ}$ ), figure un ange aux ailes déployées, la tête auréolée disposée dans un lobe du cadre décoré de gros grènetis et cordons nus ${ }^{212}$. Il tient un phylactère sur lequel se perçoivent des lettres difficilement lisibles : [MA] RIE ? Cet objet devait être de très grandes dimensions. Il provient d'un niveau de charnier des $\mathrm{XVII}^{\mathrm{e}}$-XVIII ${ }^{\mathrm{e}}$ siècles de la cathédrale Notre-Dame du Bourg à Digne.

Enfin, un fragment de crucifix (fig. 21, no 7 ) retrouvé dans un contexte daté par la céramique des années 1530-1540, rue Racine à Avignon ${ }^{213}$, présente sur une face le Christ crucifié portant le perizonium et, au revers, la Vierge vêtue d'une longue tunique, portant l'Enfant sur son bras gauche. La fixation a dû se faire au moyen d'une ouverture au bout du bras supérieur 
disparu ainsi que l'indique un objet similaire, découvert à Raversijde (Pays-Bas) et daté stylistiquement du Xve siècle ${ }^{214}$.

\subsection{LES AMPOULES DE PÈLERINAGE}

Les sites provençaux, et notamment ceux d'Avignon, ont livré de nombreux exemplaires d'ampoules de pèlerinage. Toutes ont été confectionnées par soudure de deux moitiés moulées séparément. Les lèvres du col ont été pincées afin d'assurer leur fermeture. Aucune des pièces étudiées n'a pu être attribuée à un sanctuaire particulier, comme c'est souvent le cas. Cependant, la fréquence des découvertes faites à Avignon est d'un intérêt évident. Il peut être envisagé, même si cela ne peut être prouvé, que des ampoules aient pu recueillir un peu d'eau d'un puits fondé, d'après la légende, par saint Dominique et situé dans l'enceinte du couvent des Prêcheurs. Ces eaux étaient réputées guérir les fièvres ${ }^{215}$.

Les exemplaires les plus fréquemment retrouvés sont en forme de gourde et présentent deux courtes anses de part et d'autre du goulot. La plupart proviennent d'Avignon. Un premier objet, aux anses graciles, recueilli en 1989 au cours des terrassements, chemin Saint-Jean, au début de la route de Montfavet (fig. 22, no 1 ), est orné, sur la face plate de la panse, d'un blason palé dont les pals sont alternativement nus et quadrillés. L'écu est encerclé d'une bande de chevrons, superposés tête-bêche, limitée par deux listels. Au revers, sur la face bombée, une rosace à huit pétales est entourée de lobes. Un écu schématique à trois pals est visible sur le col. Rue Carreterie (fig. 22, $\mathrm{n}^{\circ}$ 2), une ampoule trouvée dans un contexte des années 1360-1380, conserve sur sa face plane, le motif très dégradé d'un large écu entouré de chevrons. La face bombée est couverte par une rosace à huit pétales au sein d'un champ de losanges et de chevrons. Un quadrilobe est perceptible sur le col. Contrairement aux deux précédentes, l'ampoule exhumée dans des niveaux de jardin des années 1340-1390 sur le site d'un ancien garage, rue Régina (fig. $22, \mathrm{n}^{\circ} 3$ ), possède des anses épaisses qui débordent largement. Ses parois sont très massives mais l'ampoule comporte toujours une face plate et une face bombée. Sur une des faces, un médaillon circulaire contient une forme trapézoïdale dont le champ est décoré de deux lignes droites et d'un segment bouleté. La quatrième ampoule (fig. 22, no 4 ) accompagnait le premier spécimen étudié, au chemin Saint-Jean à Avignon. Elle est proportionnellement plus allongée et n'est décorée que d'une simple fleur de lys. Les fleurs de lys sont au nombre de trois sur un écu brochant une croix, dans le large médaillon (fig. 22, n 5 ) d'une ampoule mise au jour dans des remblais de jardin, sur le site de l'ancien Garage Régina, datés vers 1340-1390. Sur le col, un écu à la croix se distingue. Cet objet possède deux faces bombées, mais une seule est ornée. L'écu de France "moderne »216 se retrouve sur l'une des faces bombées d'une petite ampoule de type gourde qui aurait été retrouvée à Avignon (fig. 22, nº 6). Son col a été cassé, probablement pour récupérer le contenu.

214. KoldeweiJ 2006, p. 203, n 15.9.5.k.

215. Montagnes 1978, p. 109-115.

216. L'écu de France «ancien» comporte un semis de fleur de lys alors que celui de «France moderne" n'en possède que trois en l'honneur de la SainteTrinité. Charles V est à l'origine de cette modification en 1376.
Au Quartier du Thor, à Sisteron, deux ampoules de type gourde (fig. $22, \mathrm{n}^{\circ} 7$ et 8 ) à l'avers bombé et au revers plat ont été découvertes, lors de fouilles clandestines, avec une ampoule rectangulaire (fig. $23, \mathrm{n}^{\circ} 2$ ) et deux petites reproductions de pistolets dont la crosse courbe est caractéristique du $\mathrm{XVIII}^{\mathrm{e}}$ siècle ${ }^{217}$. Toutefois, l'absence de stratigraphie ne permet pas de relier ces deux groupes d'objets entre eux. L'une des ampoules est décorée d'une fleur de lys, l'autre d'un paon (?) dont la queue est symbolisée par deux plumes terminées en pique encadrant une plume en queue de pelle. Une bande quadrillée surmonte le tout.

À Marseille, place Villeneuve-Bargemon, un comblement de puits du XIV ou du XV siècle a fourni une ampoule écrasée, aux deux faces bombées (fig. 22, no 9) ${ }^{218}$. Elle présente sur une face un quadrillage oblique limité à la base par des traits parallèles. Le même quadrillage se retrouve sous le pied où l'on perçoit distinctement la ligne de jonction des deux parties moulées séparément. Cet objet se distingue légèrement des précédents par son col dans la continuité du corps et ses longues anses. La forme générale est assez proche d'une outre.

L'ampoule suivante (fig. 22, n 10) a été découverte dans un niveau de dépotoir des années 1440-1450, rue Banasterie à Avignon. Elle est la plus ornée et la plus travaillée du catalogue. Sa forme, proche des exemplaires en forme de gourde, comporte un pied qui la fait ressembler à un vase. Les anses coudées, de section losangique, sont rattachées d'une part, à un col évasé et, d'autre part, à un corps aux deux faces bombées portant un écu sur un fond quadrillé oblique. L'un des écus est celui de "France moderne», le second est écartelé de lys et de coticé, un écu au lion (?) rampant sur le tout. Ce dernier est celui des comtes de Bourgogne, postérieurement à Philippe le Hardi, et l'objet peut donc probablement être daté du $\mathrm{XV}^{e}$ siècle. Sur le col, une fleur de lys, encadrée par deux volutes, est figurée sur une face, centrée au-dessus de deux demi-cercles disposés sur une ligne de motifs de trois points. Sur l'autre face, trois demi-cercles reposent pour partie sur deux ensembles de trois points, au-dessus desquels un cadre contient une fleur de lys couchée (?). Denis Carru et Sylvain Gagnière proposent d'y voir un signe d'ordre politique ${ }^{219}$. Cette hypothèse n'est pas totalement convaincante, car les ampoules sont traditionnellement des objets religieux. Les écus ornant cette ampoule indiquent, selon toute vraisemblance, qu'elle a été produite pour un sanctuaire situé en territoire bourguignon.

Un objet circulaire recueilli dans une couche de dépotoir du dernier tiers du XIV ${ }^{e}$ siècle sur le site du Petit-Palais d'Avignon, n'est peut-être pas une ampoule de pèlerinage, mais le fait qu'il soit creux permet de l'envisager (fig. 22, n 11 ). Il est orné d'une rosace à huit pétales incluse dans un cercle sur la face supérieure bombée. La face inférieure est actuellement concave. Les quelques trous plus ou moins circulaires, visibles sur ses faces, ne paraissent pas le fait d'un acte volontaire. De larges portions de l'objet ont disparu ainsi que probablement le dispositif d'attache.
217. Montagnes 1978, p. 7.

218. Thuaudet et Chazottes 2014, fig. 247, n 10.

219. CARru et GAGNière 1992, p. 89. 

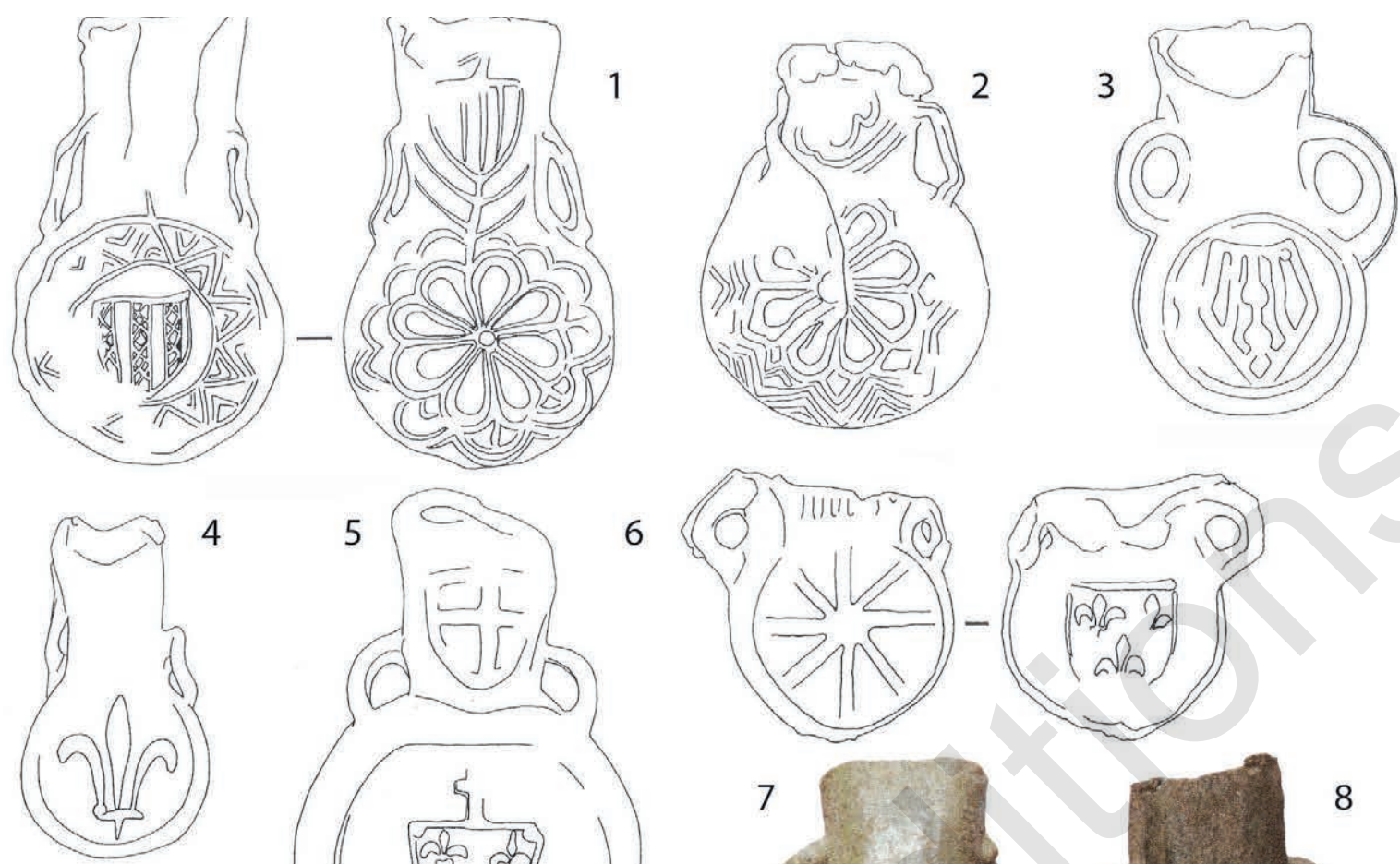

4$$
5
$$

\section{5}

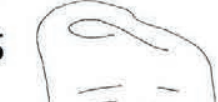

\section{6}
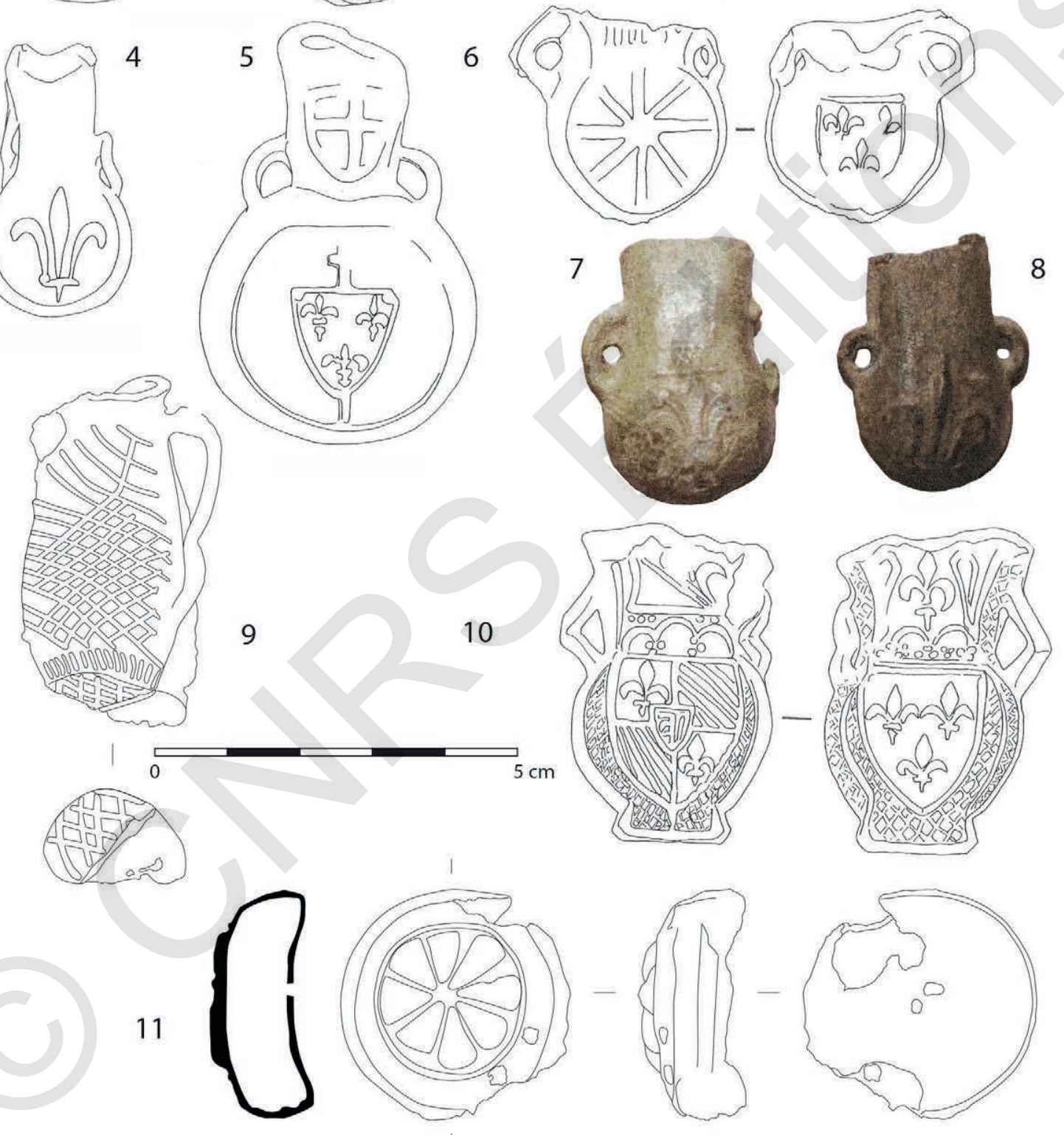

Fig. 22 Ampoules de pèlerinage en forme de gourde; $n^{\circ} 1$ et 4 : Chemin Saint-Jean, Avignon, Vaucluse, service archéologique du Vaucluse, dessin : D. Carru (CARru et GaGnière 1992); no 2 : Rue Carreterie, Avignon, Vaucluse, service archéologique du Vaucluse, dessin : D. Carru (Carru et GAGNIÈre 1992); no 3 et 5 : Garage Régina, Avignon, Vaucluse, service archéologique du Vaucluse, dessin: D. Carru (CARRU et GAGNière 1992); $n^{\circ}$ 6: Avignon, Vaucluse, service archéologique du Vaucluse, dessin: D. Carru; no 7 et 8 : Quartier du Thor, Sisteron, Alpes-de-Haute-Provence, cl. S. Bleu et I. Gannet (Bleu et GANET 1996); no 9: Place Villeneuve-Bargemon, Marseille, Bouches-du-Rhône, service archéologique municipal de Marseille, dessin: O. Thuaudet (Thuaudet et Chazottes 2014); no 10 : Rue Banasterie, Avignon, Vaucluse, service archéologique du Vaucluse, dessin : D. Carru (no 11) (CARRU et GAGNIÈRE 1992); no 11 : Jardin ouest du Petit Palais, Avignon, Vaucluse, service archéologique du Vaucluse, dessin : O. Thuaudet. 

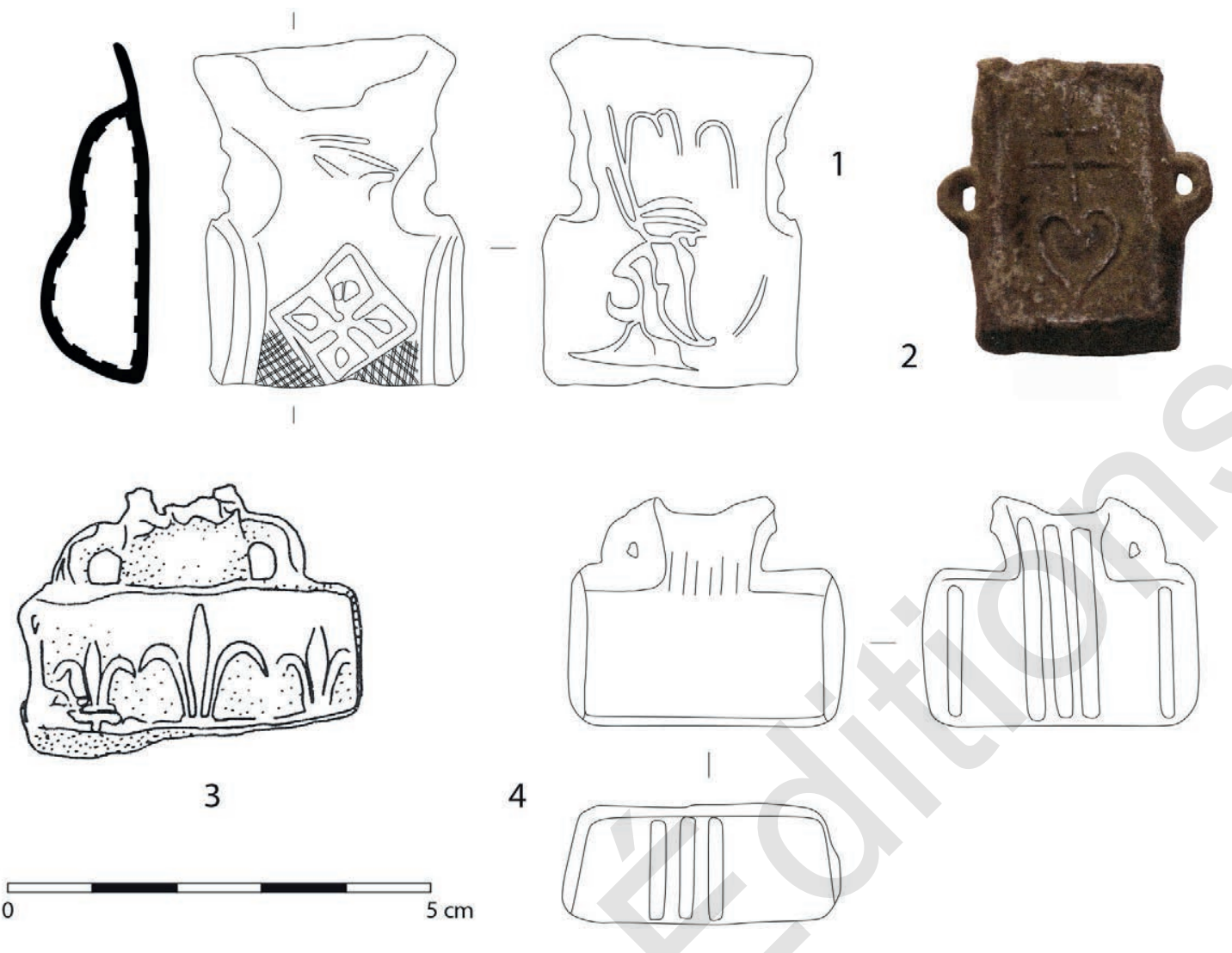

3

4

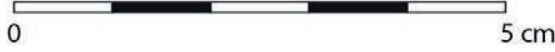

Fig. 23 Ampoules de pèlerinage; $n^{\circ} 1$ : Rue Banasterie, Avignon, Vaucluse, service archéologique du Vaucluse, dessin : O. Thuaudet ( $n^{\circ}$ 10); $n^{\circ}$ 2: Quartier du Thor, Sisteron, Alpes-de-Haute-Provence, cl. S. Bleu et I. Gannet (Bleu et GANet 1996). no 3 et $4:$ Rue Carreterie, Avignon, Vaucluse, service archéologique du Vaucluse, dessin : D. Carru (no 3) (CARRU et GAGNIÈre 1992) et O. Thuaudet ( $\left.n^{\circ} 4\right)$.

Quatre ampoules provençales adoptent une forme de panse quadrangulaire. Une première pièce, découverte avec un exemplaire en forme de gourde (fig. $23, \mathrm{n}^{\circ} 1$ ) dans un niveau de dépotoir des années 1440-1450, rue Banasterie à Avignon, a été amputée volontairement de ses anses et un trou perce la panse. Celle-ci est de profil semi-cylindrique. Le col est particulièrement large. Le décor de la face plane n'est plus compréhensible. La face bombée est ornée d'un losange contenant des gouttes rayonnantes. Un quadrillage oblique s'observe au-dessous. Denis Carru et Sylvain Gagnière distinguent une mitre avec cordons sur le col; en conséquence, ils proposent que cette ampoule soit en rapport avec la dévotion rendue à un saint évêque ${ }^{220}$.

Une ampoule quadrangulaire sans col (fig. $23, \mathrm{n}^{\circ} 2$ ), avec deux anses disposées au milieu de la hauteur de l'objet, a été retrouvée lors de fouilles illégales dans le quartier du Thor à Sisteron. Elle est ornée d'un cœur surmonté d'une croix de Lorraine ${ }^{221}$.

Deux autres ampoules avignonnaises, en forme de barillet, ont été mises au jour, rue Carreterie, la première (fig. 23, no 1 ) dans une latrine des années 1390-1410, la seconde (fig. 23, $\mathrm{n}^{\circ} 2$ ) sur un sol en terre battue des années 1360-1380. Le col bas se fixe à un corps rectangulaire décoré d'un seul côté. Les anses sont en quart-de-cercle. Trois fleurs de lys ornent

220. Carru et Gagnière 1992, p. 7.

221. Bleu et Ganet 1996, p. 89. la face d'une des ampoules, des bandes verticales - celles du centre se prolongeant sur le col - sont visibles sur l'autre. Ces bandes continuent sur la face inférieure ainsi que sur l'avers, où subsistent encore quelques traces.

\section{LES SOUVENIRS DE PÈLERINAGE}

\subsection{PRODUCTION ET COMMERCE DES ENSEIGNES}

Des documents présentés auparavant révèlent que la fabrication d'enseignes ou d'autres souvenirs pouvait être contrôlée par les religieux des sanctuaires concernés: l'abbaye de Montmajour pour la confection d'images de saint Pierre et de saint Antoine, l'abbaye de Saint-Maximin pour les enseignes à l'effigie de Marie-Madeleine. Dans ce dernier cas, des commerçants cherchent à leur faire concurrence. Dans les comptes du roi René, les enseignes sont obtenues par l'intermédiaire de familiers, par commande auprès d'orfèvres, mais rarement auprès de marchands ${ }^{222}$. Il en est autrement pour les quelques achats réalisés par son fils: ses acquisitions se font toujours auprès de marchands qui, pour certains d'entre eux, ne sont pas spécialisés dans la vente d'enseignes, comme le montrent les

222. Par exemple, Arnaud d'Agnel 1908, nº 2461. 
autres achats qui leur sont faits ${ }^{223}$. Les informations manquent pour savoir si ces intermédiaires vendent exclusivement les enseignes d'un sanctuaire de la ville où ils sont implantés, ou s'ils font également le commerce des enseignes propres à d'autres lieux de culte. De fait, rien ne prouve formellement que le roi René, son fils, ou tout autre pèlerin, ait réellement visité tous les sanctuaires auxquels se rattachent les enseignes acquises. Les commandes effectuées auprès d'orfèvres ne prouvent rien dans un sens ou dans l'autre : une enseigne du sanctuaire a pu servir de modèle.

Certains comptes rapportent que, dans les grands centres de pèlerinage européens, des dizaines ou même des centaines de milliers d'enseignes pouvaient être vendues en quelques semaines ou quelques mois ${ }^{224}$. Ces assertions peuvent paraître surprenantes au vu du nombre d'enseignes de pèlerinage retrouvées en Provence, mais elles contribuent à relativiser la portée des données obtenues sur la quantité du mobilier découvert en contexte archéologique, témoin ayant échappé au recyclage et à l'oxydation totale. De même, il n'est actuellement recensé qu'une seule possible matrice pour des enseignes ou des médailles dans la région. Toutefois, la diversité des enseignes pour un même sanctuaire - les exemplaires identiques sont extrêmement rares - indique que plusieurs moules ou plusieurs gravures fonctionnent simultanément : quatre moules en pierre pour la fonte avec une ou deux gravures distinctes sont connues pour le seul et éphémère pèlerinage de la Vierge de Ratisbonne, qui apparaît en 1519 et ne dure que six ou sept ans ${ }^{225}$; au moins vingt et une gravures différentes ont été identifiées parmi les vingt-cinq enseignes de Notre-Dame du Puy, du modèle «à pignon", répertoriées par J. Berger ${ }^{226}$; quarante empreintes d'enseigne ont été reconnues parmi les fragments de moule trouvés à l'emplacement d'un atelier métallurgique au Mont Saint-Michel ${ }^{227}$.

Le coût des enseignes ne peut être évoqué que succinctement, au moyen des comptes du roi René (fig. 3). Le prix varie en fonction du matériau et de la taille. Lorsqu'il est connu ou peut être calculé, il est d'environ 2 ou 3 deniers la pièce en matériau blanc, de 1,5 gros ou 3 gros l'exemplaire en argent, de 4 gros l'objet en argent doré. Les enseignes en argent, fabriquées par l'orfèvre d'Avignon Ligier, en 1447, coûtent environ 3,4 gros la pièce et celles en or 7,5 gros la pièce. L'artisan reçoit pour ces commandes respectivement deux et six gros par exemplaire. Le coût du travail équivaut respectivement à 55,6\% et $44,4 \%$ du prix total. Les enseignes en matériau blanc sont peu coûteuses, car faciles et rapides à produire et créées dans un matériau de faible prix. Elles peuvent être achetées à hauteur de plusieurs exemplaires par le pèlerin pour être offertes à des proches.

223. Il a cependant existé des marchands spécialisés dans la vente des enseignes et ex-voto. Le compte-rendu d'une visite épiscopale à Saint-Mathurin de Larchant rapporte que des femmes vendaient dans l'église des enseignes de pèlerinage et des chandelles (GASNAUlt 1989). Une étude iconographique d'une marchande d'enseigne figurée sur une stalle du premier quart du $\mathrm{XVI}^{\mathrm{e}}$ siècle de la cathédrale d'Amiens a été réalisée par D. BRUNA (1994).

224. BRUNA 1992, p. 317, 320.

225. Ibid.

226. Berger 2009, p. 93

227. Labaune-JeAn (dir.) 2016, p. 140.

\subsection{QUELLE RENOMMÉE POUR LES PÈLERINAGES?}

Des indications sur le rayonnement des pèlerinages sont fournies par la documentation historique (compilations de miracles, procès en canonisation). Elle a été signalée lors de l'étude des enseignes. D'autres données peuvent être tirées de l'analyse conjointe de la répartition du mobilier archéologique et des sources d'archives.

Dans son étude des testaments aixois entre 1390 et 1450 , N. Coulet enregistre une proportion de $4 \%$ de testateurs mentionnant le pèlerinage qu'ils ont entrepris, étant sur le point de faire ou entendant accomplir. Ils appartiennent à toutes les classes de la société, sans prédominance de l'une d'entre elles. Cependant, comme le souligne l'historien, rien n'oblige le testateur à signaler les pèlerinages qu'il a effectués. La proportion des pèlerins était donc sans doute plus importante, sans qu'il soit possible d'établir un chiffre. La plupart des pèlerinages mentionnés sont hors de Provence et lointains : Saint-Jacques de Compostelle apparaît 34 fois parmi les 70 destinations notées dans ces documents, Rome sept fois, quatre voyages ayant été accomplis au moment du jubilé de 1400 et trois autres pour celui de $1450^{228}$. Les sanctuaires de Rome sont absents des enseignes retrouvées en Provence, au contraire du Volto Santo de Lucques et de Saint-Jacques-de-Compostelle (fig. 1 et 2). Accéder à ces sanctuaires éloignés exige un investissement important d'un point de vue moral et spirituel, mais aussi physique et financier. Toutefois, les nombreuses coquilles de type Pecten Jacobeus trouvées en Provence - au moins 24 sur 32 coquilles de Pecten - n'attestent pas exclusivement du voyage jusqu'en Galice, mais aussi de la célébrité du saint.

Les autres lieux de culte non provençaux cités dans les testaments aixois sont Notre-Dame-du-Puy, avec treize pèlerinages, puis Saint-Antoine de Viennois, trois fois ${ }^{229}$. Ces données sont à comparer avec la découverte, en Provence, d'enseignes de Notre-Dame-de-Vauvert, de Saint-Pierre-de-Lézan et de Notre-Dame-du-Puy (fig. 1 et 2). La relative proximité de ces sites a pu favoriser les déplacements : s'y rendre prend peu de temps et le voyage à accomplir comporte moins de périls. Le sanctuaire de Saint-Pierre-de-Lézan semble jouir d'une renommée plus locale comme l'illustre la localisation, à Arles et à Avignon, des deux seules enseignes connues.

Les pèlerinages régionaux n'apparaissent que quinze fois dans la documentation de N. Coulet ${ }^{230}$. Cependant, il est fort probable qu'un plus grand nombre de pèlerinages se faisait en direction d'un sanctuaire local, plus accessible, auprès d'un saint que l'on avait coutume de prier. La nature de l'acte notarié est sans doute en cause : le testament est avant tout un document dans lequel le testateur évoque les évènements à survenir après sa mort et donc aussi l'au-delà. Or, plus le sanctuaire est lointain, plus le mérite et les bienfaits pour le salut de l'âme sont importants. Parmi les destinations régionales relevées, le tombeau de Pierre de Luxembourg au couvent des Célestins d'Avignon prédomine, puisqu'il est cité par quatre personnes,

\footnotetext{
228. Coulet 1972, p. 248-249, 251.

229. Ibid.

230. Ibid. N. Coulet donne le chiffre de seize mais ne fournit que quinze exemples.
} 
suivi de Saint-Honorat-de-Lérins ${ }^{231}$, désigné trois fois, de Saint-Eutrope d'Orange, indiqué par deux testateurs. Les autres lieux, Notre-Dame-des-Doms d'Avignon, Saint-Siffrein de Carpentras ${ }^{232}$, Saint-Jean-de-Garguier, Notre-Dame-deMiremer ${ }^{233}$, Notre-Dame-de-Moustiers et Notre-Dame-de-laGarde à Marseille figurent chacun dans un seul document ${ }^{234}$. De ces sanctuaires, seul celui de Notre-Dame-des-Doms a livré une enseigne en Provence, mais des souvenirs à l'effigie de Pierre de Luxembourg sont connus hors de cette zone (fig. 23). Les sept autres sanctuaires provençaux pour lesquels sont identifiés des enseignes, et notamment Saint-Gilles, sont absents. Il n'est de même nullement fait mention de la comtesse Delphine de Puimichel, invoquée essentiellement dans le pays aptésien et à Marseille à la fin du XIV siècle, ou encore d'Urbain V qui, à la même époque, fait l'objet de sollicitations provenant de presque toute la chrétienté méridionale ${ }^{235}$.

Les données rassemblées pour la Provence montrent qu'il existe à l'évidence une certaine dichotomie entre les pèlerinages mentionnés dans les testaments et ce qu'illustre l'archéologie. Dans le contexte aixois des années 1390-1450, les mentions de pèlerinages provençaux sont en proportion minoritaires. Or le contraire est observé pour les enseignes répertoriées pour le bas Moyen Âge. Arnaud Tixador a également mis en évidence la provenance essentiellement locale, ou des régions limitrophes, des souvenirs retrouvés à Valenciennes ${ }^{236}$. Il a déjà été évoqué que la nature de l'acte peut influencer le choix des testateurs et il est probable que cette raison est la principale cause de cette contradiction apparente. Il faut aussi considérer que l'étude de $\mathrm{N}$. Coulet s'applique à une ville unique et à un laps de temps réduit; qu'en est-il ailleurs? Un autre travers, et non des moindres, est le choix du support de dévotion fait par le sanctuaire : une statuette en plâtre, une estampe sur papier, un objet végétal, un simple chapelet, etc., peuvent constituer des souvenirs de pèlerinage. L'intensité, variable, des recherches archéologiques entreprises sur le territoire provençal, qui se conjugue avec la nature des sites étudiés et les contextes stratigraphiques rencontrés constituent d'autres biais. À Aix-en-Provence, les fouilles archéologiques intra-urbaines sont rares, car le centre-ville est protégé, il n'est donc guère surprenant qu'aucune enseigne de pèlerinage n'ait été découverte. À Marseille, en dépit de nombreuses opérations archéologiques dans la ville médiévale, aucune enseigne n'a été retrouvée et une seule et unique ampoule a été mise au

231. Les îles de Lérins sont une destination prisée entre l'Ascension et la Pentecôte, au temps des indulgences. Les pèlerins, originaires de France, d'Italie, d'Espagne et, pour une majorité, de Provence, embarquent à Cannes. Les habitants de Pertuis et Lérins y faisaient une procession tous les ans sous la conduite de leurs consuls (Grassi 1970, p. 51).

232. Dans les Miracles de sainte Marie-Madeleine, le $n^{\circ} 75$ rapporte le cas d'une jeune fille devenue folle, à qui saint Siffrein dont le corps repose à Carpentras et qui «ne refuse pas habituellement d'aider avec le Seigneur les malades de cette sorte " refuse la guérison, ceci afin de «rendre plus manifestes les mérites de Madeleine» qui lui redonnera la raison (SCLAFERT [éd.] 2009, p. 156-158). 233. Situé près de La Garde.

234. Coulet 1972, p. 251.

235. VeysSiÈre 1987, t. 1, p. 19-21, t. 2, p. 90-392; VEYSSIÈre 1994, p. 209.

236. Tixador 2004, p. 16. La seule enseigne issue d'un sanctuaire très éloignée est de Villalcàzar de Sirga en Espagne. Un coquillage du genre Tellina est interprété par erreur comme provenant de Compostelle et une bulle papale est identifiée comme une enseigne (TIXADOR 2004, p. 28, 47 et 51). jour. Les causes probables sont l'entretien régulier des sols, le faible nombre de dépotoirs domestiques et l'absence de dépotoirs collectifs dans l'emprise des fouilles. La gestion des déchets semble avoir fait l'objet d'une politique municipale ${ }^{237}$. À l'opposé, les contextes funéraires de la cathédrale de Digne et les fouilles d'habitats à Avignon se sont révélés propices à la découverte des enseignes. Le site du Castelet de Fontvieille constitue un cas particulier puisque la presque totalité des objets a été récupérée lors de travaux par un propriétaire. Il paraît bien difficile, au regard de ces données disparates et des difficultés de fouilles rencontrées dans certains lieux, d'envisager actuellement des réflexions plus avancées sur la pratique du pèlerinage en Provence. Une dernière constatation doit cependant être faite : alors que les découvertes anciennes proviennent essentiellement des cours d'eau, les objets apparaissant lors des basses eaux ou lors de dragages, les trouvailles récentes sont presque exclusivement terrestres, grâce au développement de méthodes de fouilles scientifiques et à la diffusion à grande échelle des détecteurs de métaux. Les rivières et fleuves représentent de gigantesques dépotoirs à ciel ouvert. La lecture des comptes rendus de l'abbé Desnoyers sur les artefacts retrouvés dans la Loire dans le dernier tiers du XIX ${ }^{e}$ siècle ${ }^{238}$ en est une illustration : on y trouve de tout. Aucun document ne permet de prouver l'existence du jet dans un cadre apotropaïque ${ }^{239}$ ou pour empêcher l'appropriation des enseignes par des condamnés au pèlerinage pénitentiel.

La répartition des lieux de découverte d'enseignes provenant de sanctuaires provençaux (fig. 23) peut éclairer sur la renommée des pèlerinages. Toutefois, une certaine prudence est de mise, du fait de l'aléa des découvertes. Les sanctuaires de Saint-Gilles et de Saint-Maximin-la-Sainte-Baume viennent en tête. Ils sont connus sur une large aire géographique et le premier paraît plus visité que le second, d'après le nombre des enseignes inventoriées : 32 contre 6. D’une façon assez surprenante, l'Allemagne est pauvre en découvertes alors qu'elle est un foyer notoire du culte à saint Gilles. Les deux sanctuaires apparaissent comme une destination prisée des pèlerins venant de loin, un objectif principal au cours de leurs pérégrinations. À un niveau inférieur, le pèlerinage auprès des reliques de saint Antoine, à l'abbaye de Montmajour à Arles, touche tout le midi de la France. Méconnu, si ce n'est inconnu, il y à peine plus d'une dizaine d'années, des publications récentes offrent une idée beaucoup plus précise d'un culte qui n'est pratiquement pas renseigné par les sources textuelles. À cet échelon intermédiaire se situe également l'église des Célestins d'Avignon avec la sépulture du bienheureux Pierre de Luxembourg. D'après les témoignages de miracles du procès en canonisation, Pierre de Luxembourg fait, avant tout, l'objet d'une vénération dans le diocèse d'Avignon et les évêchés limitrophes ${ }^{240}$. À ces deux premiers niveaux s'ajoute un troisième, regroupant des sanctuaires provençaux à renommée locale : Notre-Dame de Doms, Saint-Cézaire d'Arles, l'abbaye de Montmajour avec la dévotion à saint Pierre et à la sainte Croix. Les enseignes, à l'exception de celles découvertes au Castelet de Fontvieille, où

237. Thuaudet et Chazottes 2014, p. 347; Abel et Parent 2014, p. 259. 238. Par exemple Desnoyers 1873 et 1876.

239. Interprétation encore reprise récemment dans l'ouvrage sur les enseignes sacrées et profanes découvertes à Valenciennes (Tixador 2004, p. 9-13). 240. VeYssiÈre 1987, t. 1, p. 19-21, t. 2, p. 390-392; ID. 1994, p. 209. 
un atelier de fabrication pourrait avoir existé, sont au mieux attestées par quelques unités. L'enseigne à l'effigie de saint Césaire retrouvée à Londres est trop isolée pour être représentative de la célébrité du lieu de culte : cet objet a pu être acquis par un pèlerin ayant ajouté, à son périple initial, la visite d'un sanctuaire voisin, ou par un marchand étranger ayant eu affaire à Arles.

\subsection{COQUILLES SAINT-JACQUES, ENSEIGNES ET AMPOULES MÉTALLIQUES : DES FONCTIONS DIFFÉRENTES}

L'analyse des contextes archéologiques révèle que les ampoules de pèlerinage sont pratiquement absentes des zones funéraires provençales et les enseignes métalliques y sont rares - seulement deux exemplaires - au contraire des coquilles Saint-Jacques, beaucoup moins fréquentes en dehors des espaces funéraires. Ce constat peut être étendu, avec peu d'adaptation, au territoire ouest européen ${ }^{241}$. Les coquilles sont essentiellement découvertes isolées dans les sépultures, parfois avec un bâton ferré242 ou avec d'autres dépôts tels qu'un pégau ou une lampe en verre ${ }^{243}$. Il est d'usage de considérer que ces coquilles sont cousues sur le vêtement du défunt, mais elles peuvent également avoir été disposées sur le corps, éventuellement sur des zones où elles sont habituellement portées. Une telle discrimination dans la nature des contextes de découverte des insignes religieuses n'est pas anodine. Elle montre que la coquille Saint-Jacques et les ampoules et enseignes métalliques possédaient des fonctions différentes. Les enseignes métalliques semblent avoir eu avant tout un rôle de protection durant la vie terrestre. En revanche, il est attesté dans les temps préhistoriques, durant l'Antiquité et le haut Moyen Âge, que les coquillages, parfois percés, servaient d'ornements ou d'offrandes mortuaires ${ }^{244}$. Ce rôle protecteur dans l'au-delà s'est très certainement transmis aux coquilles diffusées par le sanctuaire de Galice. Sans doute a-t-il joué un rôle important dans le succès de ce pèlerinage. La fortune du saint de Galice tient également à ce que, dans l'imaginaire médiéval, fondé sur une interprétation de l'Épître de saint Jacques, celui-ci

241. Rares sont les découvertes d'ampoules en contexte funéraire: il en a été mise une au jour dans une sépulture du $\mathrm{x}^{e}$ ou de la première moitié du $\mathrm{XI}^{\mathrm{e}}$ siècle dans l'église Saint-Laurent de Grenoble en Isère (Colardelle 1999, t. 2, p. 49; Colardelle 2008, p. 297). Les enseignes de pèlerinage ne sont guère plus fréquentes : se reporter à SPENCER 1990, p. 144 pour un relevé de quelques découvertes dans le nord de l'Europe.

242. Dans le quart sud-est de la France, il y a le cas des sépultures 1193 et 1201 $\left(\mathrm{XIV}^{\mathrm{e}}-\mathrm{XVI}^{\mathrm{e}}\right.$ siècle) du site de la cathédrale Notre-Dame du Bourg de Digne. Non loin de là, en Ardèche, deux sépultures avec coquilles (fin XII ${ }^{\mathrm{e}}$-XIII ${ }^{\mathrm{e}}$ siècle et fin XIII $^{e}-\mathrm{XIV}^{e}$ siècle) contenaient un bâton ferré (EsQUIEU et al. 1988, p. 71). Dans la Drôme, à Notre-Dame de Montcham, à Malataverne, une inhumation $\left(\mathrm{XI}^{\mathrm{e}}-\mathrm{XIV}^{\mathrm{e}}\right.$ siècle) contenait un pégau près de la tête, une coquille sur la poitrine et une ferrure de bâton près du tibia gauche (GAGNiÈre et Granier 1971, p. 184).

243. L'inhumation 1022 ( $\mathrm{XIV}-\mathrm{XVI}^{e}$ siècle) de la cathédrale de Digne contenait trois coquilles et deux pégaus, la $\mathrm{n}^{\circ} 1118$ ( $\mathrm{XIV}^{\mathrm{e}}-\mathrm{XVI}^{\mathrm{e}}$ siècle), une coquille, une lampe en verre et deux pégaus, la $\mathrm{n}^{\circ} 1148$ ( $\mathrm{XII}^{\mathrm{e}}-\mathrm{XIII}{ }^{\mathrm{e}}$ siècle), deux coquilles et une lampe en verre, la $n^{\circ} 1193$, une coquille, un fer de bâton et une gargoulette, la $\mathrm{n}^{\circ} 1216$ (XII -XIII $^{\mathrm{e}}$ siècle), une coquille, une lampe en verre et un pégau, la $\mathrm{n}^{\circ} 1402$, une coquille et deux pégaus ( $\mathrm{XIV}^{\mathrm{e}}-\mathrm{XVI}^{\mathrm{e}}$ siècle).

244. Köster 1985, p. 86. est censé se manifester à l'heure de la mort, accompagnant le défunt lors du passage de la Terre vers le Ciel, mais aussi être présent dans le Royaume des Morts, lors du Jugement dernier, et être lui-même capable de procéder à des résurrections ${ }^{245}$. La présence d'une statue de saint Jacques, avec son chapeau porteur d'une coquille sur le tombeau du cardinal Philippe de Cabassole, mort en 1372, autrefois à la Chartreuse de Bonpas, n'est pas sans valeur symbolique ${ }^{246}$. Il n'est nul besoin d'être allé à Saint-Jacques en Galice pour se mettre sous sa protection. Par extension, la coquille de type Pecten suffit, quelle que soit son origine, pour peu qu'elle ressemble à celle donnée aux pèlerins en Galice. Le signe matériel, ou l'image, ont la même valeur que la coquille véritable.

Le rôle prophylactique et de souvenir, des enseignes et ampoules, est largement renseigné, mais les enseignes peuvent également tenir un rôle signifiant dans le costume. Un exemplaire particulièrement remarquable est la commande par le roi René à un orfèvre, en 1451, de trois grandes enseignes d'or pour la reine, sa fille Yolande et lui-même, de six petites pour les chambellans, de deux douzaines de grandes enseignes d'argent pour des gentilshommes et damoiselles, de quatre douzaines de plus petites pour les officiers. Une mise en scène du rang social apparaît nettement, car le matériau et la taille ont été choisis en fonction de l'attribution des enseignes et selon une progression pyramidale chargée de symbolique. Ces enseignes matérialisent la condition et la position de leur possesseur dans le microcosme de la cour, tout en participant de la magnificence royale. A contrario, le roi fait acheter à d'autres occasions des enseignes de plomb (fig. 3), parfois peut-être pour son usage personnel. Sans doute faut-il considérer l'acquisition de ces objets, intrinsèquement sans valeur financière, comme un «signe» réel d'humilité ${ }^{247}$, à l'image du comportement vestimentaire de Louis XI, qui avait l'habitude de porter sur son chapeau une enseigne en étain de la Vierge, et d'autres enseignes similaires à son col $^{248}$. En 1566, des nobles néerlandais se mettent à arborer des enseignes de plomb en forme de besace et de sébile, après le soulèvement des Pays-Bas, en réaction à l'insulte de "gueux» dont ils avaient fait l'objet par les autorités espagnoles. Très rapidement, cependant, ces insignes deviennent en or ou en argent, des matériaux plus appropriés au rang social des personnage ${ }^{249}$.

\subsection{LA DÉSAFFECTION DES ENSEIGNES ET AMPOULES}

Au bas Moyen Âge, les enseignes et ampoules de pèlerinage peuvent être produites concurremment avec d'autres souvenirs. Des clochettes et des sifflets en matériau blanc (fig. 24) ont ainsi peut-être été fabriqués en Provence. Comme signalé précédemment, des statuettes en plâtre de saint Pierre

245. PÉRICARD-MÉA 2000, p. 12, 57-76.

246. Les éléments restants de ce tombeau sont conservés au musée du Petit Palais à Avignon.

247. Le roi René se déplaça à plusieurs reprises jusqu'à des sanctuaires de pèlerinage, parfois en faisant une partie du parcours à pied.

248. La tenue du roi fut le sujet de moqueries de la part des espagnols lors d'une rencontre à Bayonne en 1468 (KoLDEwEIJ 2006, p. 30).

249. Ibid., p. 28. 

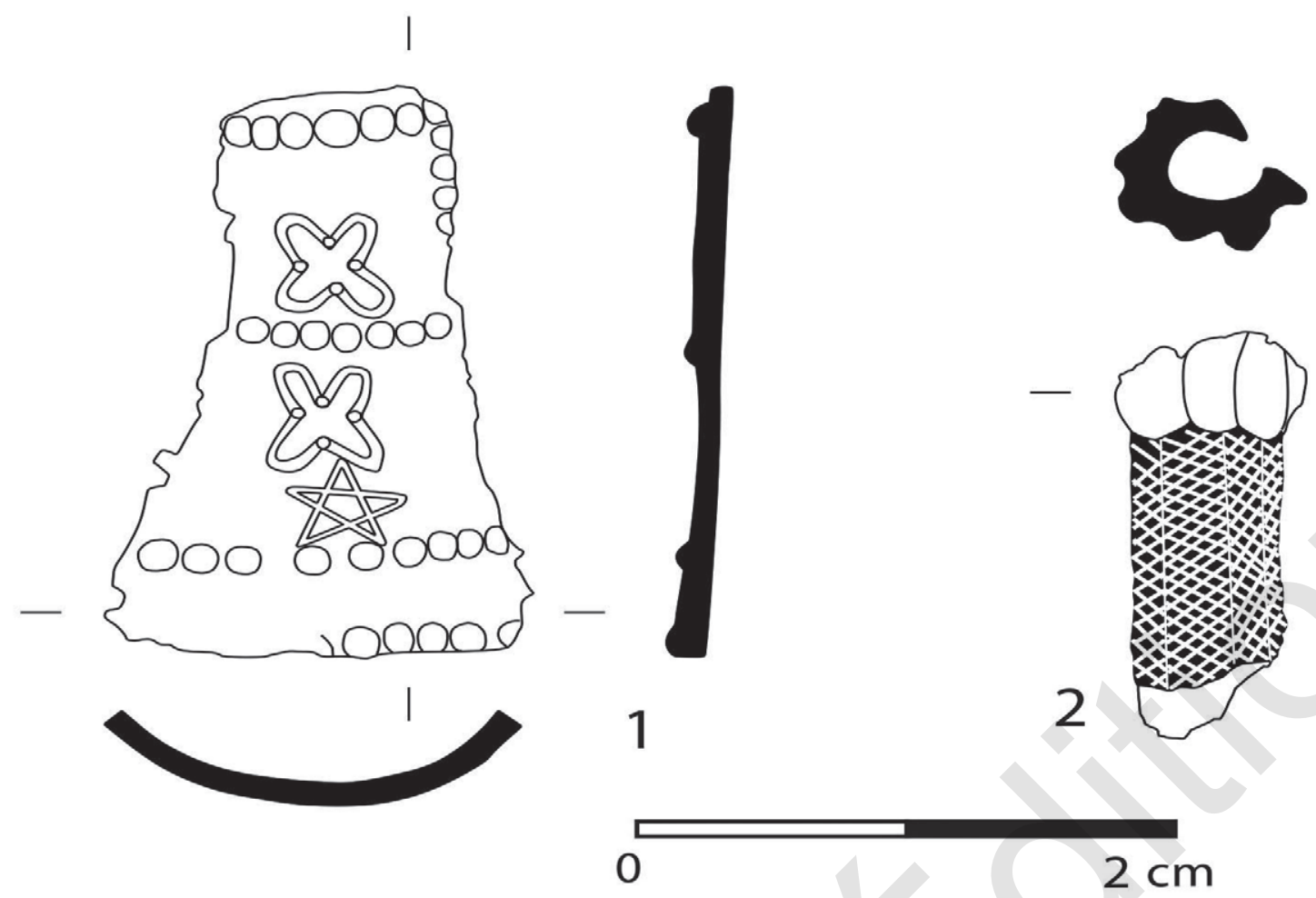

Fig. 24 Possibles souvenirs de pèlerinage;

$n^{\circ} 1$ : Jardin ouest du Petit Palais, Avignon, Vaucluse, service archéologique du Vaucluse, dessin : O. Thuaudet; $n^{\circ}$ 2, Castrum Saint-Jean, Rougiers, Var, Dépôt archéologique de La Ripelle, Toulon, dessin : O. Thuaudet;

sont produites dans la seconde moitié du XIV ${ }^{\text {e }}$ siècle pour l'abbaye de Montmajour, et des images peintes à l'effigie de Pierre de Luxembourg au milieu du $\mathrm{Xv}^{\mathrm{e}}$ siècle à Avignon. L'impression d'images religieuses par xylographie est attestée à Avignon dès $1420^{250}$. L'inventaire des biens saisis en 1561 à Jean Cogorde, travailleur d'Aix, signale une "Veronicque de toille» et «trois pièces de imagerie en papier» probablement à sujet religieux. Chez le boucher aixois Jean Barnou, il est relevé après son décès, en 1573, "deux Magdallenes en papier» et dans le testament du procureur à la sénéchaussée d'Aix Claude Arnaud, « une imaige en papier ${ }^{251}$. C. Thiriet relève également de nombreuses images de papier à iconographie religieuse dans les inventaires après-décès à Marseille, du troisième quart $\mathrm{du} \mathrm{XVI}^{\mathrm{e}}$ siècle $^{252}$. Ces images étaient sans doute, pour une part, vendues aux pèlerins et, pour une autre part, distribuées par des colporteurs et merciers s'approvisionnant chez des imprimeurs.

Ces objets ont-ils concurrencé les enseignes et ampoules jusqu'à provoquer leur désaffection au cours du XvI ${ }^{\mathrm{e}}$ siècle? La réalité est probablement plus complexe. Denis Bruna pense que le développement des techniques de reproduction sur papier est une des causes. Mais, il mentionne également la banalisation de l'enseigne, suite au développement d'un pèlerinage de masse et de la prolifération des pèlerinages locaux, mais aussi le

250. Il se raréfie à la fin du XviI e siècle dans la cité vauclusienne; il est alors remplacé par la gravure sur cuivre, notamment au moyen de la taille-douce (Сhobaut 1943, p. III-IV).

251. Fournand 2001, p. 116, 121.

252. THIRIET 1997, p. 17. commerce illicite des enseignes hors des sanctuaires, ainsi que l'apparition de mendiants et escrocs portant le costume et les enseignes des pèlerins pour provoquer plus de dons. Associés, ces faits ont eu d'après lui raison de la valeur symbolique détenue par l'objet ${ }^{253}$.

Toutefois, la pratique du pèlerinage perdure et la fabrication d'objets souvenirs par les sanctuaires est documentée pour des périodes tardives. À l'époque de la peste de 1720 , il est ainsi fabriqué à Carpentras des petits clous d'or et d'argent qui, mis en contact avec le Saint-Clou, étaient considérés comme un talisman contre l'épidémie ${ }^{254}$. Au début du XIX ${ }^{\text {e }}$ siècle, l'érudit Aubin-Louis Millin remarque lors de sa visite du sanctuaire contenant les reliques de Marie-Madeleine à Saint-Maximin qu'il y a "une boîte remplie d'anneaux de verre, que l'on fait toucher à la châsse, et que l'on distribue à six sous pièce ${ }^{255}$. Le pouvoir des reliques est transmis par contact à la bague en verre, et la porter au doigt équivaut peut-être à s'unir avec cette protection.

\section{L'ÉTUDE DES MÉDAILLES RELIGIEUSES MODERNES : UNE RECHERCHE À INITIER}

La disparition progressive des enseignes et ampoules de pèlerinage est marquée, au même moment, par l'apparition et le développement des médailles religieuses. Les premières

253. BRUNA 2006, p. 234-235.

254. Courrier de l'Institut 1925, p. 225.

255. Millin 1808, t. 3, p. 128. 
médailles métalliques apparaissent au milieu du $\mathrm{Xv}^{\mathrm{e}}$ siècle, en Italie, où elles sont étroitement liées aux transformations des habitudes emblématiques. Elles sont exclusivement circulaires et conçues pour être bifaces ${ }^{256}$. La production des premières médailles religieuses a pu suivre peu de temps après. La maladrerie de Saint-Firmin de la Fère (Aisne) achète, en 1490, du fil à pendre des enseignes de saint Firmin, et en 1548, elle reçoit livraison de petites "ymaiges de plomb" à pendre au $\mathrm{cou}^{257}$. Il est probable qu'elles aient comporté une bélière de suspension comme des enseignes figurant la Sainte Tunique d'Argenteuil, datées de fin $\mathrm{XV}^{\mathrm{e}}$-début $\mathrm{XVI}^{\mathrm{e}}$ siècle, et qui portent au droit le Christ sur sa croix, et, au revers, la Vierge à l'Enfant ${ }^{258}$. Les médailles religieuses modernes ont cette même bélière. Mais, les images de La Fère étaient-elles bifaces et circulaires? S’agit-il donc de médailles ou de médailles naissantes ainsi que les qualifie Denis Bruna ${ }^{259}$ ? Des enluminures du livre d'Heures Metteneye, du début du Xvi ${ }^{e}$ siècle, comportent des marges figurant des chapelets porteurs de médailles circulaires et de croix avec bélière ${ }^{260}$. De petits disques blancs sont suspendus au chapeau de personnages masculins dans des peintures de Bruegel datées de la fin des années $1560^{261}$. En 1565, l'inventaire des marchandises du marchand d'Avignon Adrien Moret mentionne cinq «medailles » noires, six jolies médailles bien dorées, une douzaine de médailles dorées moins belles ${ }^{262}$. Leur nature n'est pas précisée : s'agit-il d'objets religieux? Si oui, sont-ce des souvenirs de pèlerinage? À sa mort en 1566, Honoré de Tributis, conseiller au parlement de Provence, possède parmi ses bijoux deux médailles en or portant des inscriptions en l'honneur de Dieu ${ }^{263}$. Le musée national du Moyen Âge conserve des médailles en matériau blanc portant l'image de la sainte Larme de Vendôme que D. Bruna date du $\mathrm{XVI}^{\mathrm{e}}$ siècle $^{264}$. Dans le mobilier archéologique provençal, les médailles religieuses antérieures à 1650, toutes en alliage cuivreux, sont particulièrement rares : la plus ancienne, produite à l'occasion du Jubilé de 1600, provient d'une sépulture du carré Saint-Jacques à La Ciotat ${ }^{265}$.

À la fin $\mathrm{du} \mathrm{XV}^{\mathrm{e}}$ siècle et au $\mathrm{XVI}^{\mathrm{e}}$ siècle, l'enseigne perd rapidement son rôle de signe d'identité. Dépossédée de son sens, submergée par d'autres objets souvenirs, elle se transforme, influencée par le développement de la médaille profane. La parenté de matériau entre la plupart des premières médailles religieuses et la majorité des enseignes tardives l'illustre, alors que les médailles profanes contemporaines sont en alliage cuivreux. Le stade final de la transformation est l'emploi systématique, d'après les données archéologiques, des alliages cuivreux pour les médailles religieuses.

Contrairement à l'enseigne, la médaille n'est, en tout cas au $\mathrm{XVII}^{\mathrm{e}}$ siècle, plus que rarement rattachée à un sanctuaire précis. La Contre-Réforme catholique, au milieu du XVI ${ }^{e}$ siècle, a eu une influence sur l'iconographie. Cette période marque un tournant dans la pratique de la foi et dans la liturgie. Les résultats du concile de Trente sont pour beaucoup diffusés, de manière progressive dans la société, par deux ordres religieux : les Capucins et les Jésuites. Des thèmes disparaissent des nouvelles productions d'images, quel qu'en soit le support, au profit des thématiques du mystère du Rosaire, de la bonne mort ou des âmes du Purgatoire. Progressivement, au $\mathrm{XVII}^{\mathrm{e}}$ siècle, de nouvelles figures saintes sont mises en avant: François de Sales, François Xavier, Ignace de Loyola, Charles Borromée. De nombreuses médailles religieuses découvertes en Provence les représentent. La dévotion aux saints traditionnels, et notamment à Marie-Madeleine, reste néanmoins vivace régionalement dans la sphère privée, mais aussi dans les églises. En outre, que ce soit avant ou après le concile de Trente, la dévotion au Christ souffrant et à la Vierge à l'Enfant reste de loin la plus importante en Provence ${ }^{266}$. Ces deux dernières thématiques sont courantes sur les médailles religieuses des $\mathrm{XVII}^{\mathrm{e}}$-XIX ${ }^{\mathrm{e}}$ siècles $^{267}$.

Au XVII ${ }^{e}$ siècle, d'après l'iconographie et les découvertes en contexte funéraire, la médaille est presque systématiquement intégrée à des chapelets, traduction d'une évolution des pratiques religieuses dont témoignent déjà les marges du livre d'Heures Metteneye précédemment signalé. Elle a pu aussi être portée en pendentif autour du cou, contre la peau, et recouvrer un lien encore plus intime avec le divin. Des changements d'ordres symboliques s'observent également : le chapelet avec ses médailles est un signe identitaire de catholicité face aux protestants ${ }^{268}$; alors que l'enseigne est pratiquement absente des contextes sépulcraux, la médaille, généralement incluse dans un chapelet, accompagne les morts dans leur dernier voyage et ce indépendamment de l'âge et du sexe.

Le développement du chapelet et de la médaille, est le témoin visible de modifications dans les pratiques et les symboliques religieuses, ainsi que l'a mis en évidence Emmanuelle Friant ${ }^{269}$ par l'étude des sources écrites et iconographiques. Même si l'élément mobilier prend une place significative dans son travail, il apparaît cependant nécessaire de procéder à un inventaire systématique, sur une large échelle géographique, des chapelets, et des médailles et crucifix qui leur sont ou non associés. En effet, la forme des médailles, leur iconographie et leur diffusion ont évolué au fil du temps. Ces objets sont des témoins privilégiés, avec l'iconographie et les sources écrites, de l'évolution des sujets de piété.

266. Se conférer à Coulet 1972 pour un dépouillement de testaments aixois des années 1350-1450, à BERTON 2000 pour une étude d'inventaires aprèsdécès varois des années 1693-1769, à Cousin 1999 pour une analyse des tableaux et ex-voto provençaux du XVII ${ }^{e}$ au XIX ${ }^{e}$ siècle. On lira également avec intérêt le travail de Henin 1984 sur la maison et la vie domestique à Marseille au XVII ${ }^{e}$ siècle, plus particulièrement les pages 342 à 351 .

267. Données extraites d'une base de données en cours d'élaboration sur les médailles religieuses modernes.

268. Friant 2009, p. 314-330.

269. Ibid. 


\section{BIBLIOGRAPHIE}

Abel V. et Parent F.

2014, «L'exception marseillaise : absences surprenantes et luxe étonnant», dans Abel V., Bouiron M. et PArent F. (dir.), Fouilles à Marseille, Objets quotidiens médiévaux et modernes, Arles, Éditions Errance, Aix-en-Provence, Centre Camille Jullian, Bibliothèque d'Archéologie Méditerranéenne et Africaine, 16; Études massaliètes, 13, p. 351-365.

Albanès J.-H.

1879, La vie de sainte Douceline, fondatrice des Biguines de Marseille composé au treizième siècle en langue provençale publiée pour la première fois, avec la traduction en français et une introduction critique et historique, Marseille, Camoin.

1897, Actes anciens et documents concernant le bienheureux Urbain $V$, pape, sa famille, sa personne, son pontificat, ses miracles et son culte, Paris, Picard.

Albanès J.-H. et Chevalier U.

1899, Gallia christiana novissima, histoire des archevêchés, évêchés et abbayes de France, t. 2, Marseille (évêques, prévôts, statuts), Valence, Imprimerie Valentinoise.

1901, Gallia christiana novissima, histoire des archevêchés, évêchés et abbayes de France, t. 3, Arles (archevêques, conciles, prévôts, statuts), Valence, Imprimerie Valentinoise.

1920, Gallia christiana novissima, histoire des archevêchés, évêchés et abbayes de France, t. 7, Avignon (évêques, archevêques, prévôts), Valence, Imprimerie Valentinoise.

Arnaud d'Agnel G.

1906, «Notice sur le reliquaire de Saignon dit de la Reine Jeanne», Annales de la Société d'études provençales, $3^{\mathrm{e}}$ année, p. 383-390.

1908-1910, Les comptes du roi René, 3 t., Paris, Picard.

Audisio G.

1988, «Deux contrats de travail temporaire au XV siècle», dans Avignon au Moyen Âge : recueil de textes originaux, Avignon, IREBMA, Publications de la Faculté des Lettres d'Avignon, p. 154-157.

BARATIER É.

1969, Enquêtes sur les droits et revenus de Charles I'r d'Anjou en Provence (1252 et 1278) avec une étude sur le domaine comtal et les seigneurs de Provence au $\mathrm{XIII}^{e}$ siècle, Paris, Bibliothèque nationale.
Baratier É., Duby G. et Hildesheimer E. 1969, Atlas historique: Provence, Comtat, Orange, Nice, Monaco, Paris, Armand Colin.

BAUDAT M.

1994, De la Thébaïde à Montmajour: les reliques de Saint-Antoine Abbé, Arles, Société des Amis du Vieil Arles (Collection "Histoire d'Arles", 6).

1999, «Les reliques de saint Antoine abbé, une vénération "municipale" arlésienne?», dans Bastié A. (dir.), Abbaye Saint-Pierre de Montmajour : histoire et patrimoine, Arles, Les Amis du Vieil Arles, p. 75-91.

2001, «La dévotion à saint Antoine abbé», Bulletin des amis du Vieil Arles, $\mathrm{n}^{\circ} 111$, p. 29-38.

BenOIT F.

1927, «Note sur une inscription carolingienne et des objets provenant de l'abbaye de Montmajour», Bulletin de la Société nationale des antiquaires de France, p. 110-114.

Berger J.

2009, «Les enseignes de pèlerinage du Puy", dans Maes B., Moulinet D. et VinCENT C. (dir.), Jubilé et culte marial (Moyen Âge-époque contemporaine), Actes $d u$ colloque international organisé au Puy-en-Velay, du 8 juin au 10 juin 2005, Saint-Étienne, Publications de l'université de Saint-Étienne, p. 87-114 (tiré à part avec pagination différente).

BERTON O.

2000, Les objets de piété dans les inventaires après décès de l'arrière-pays varois: 1693-1789, mémoire de maîtrise d'histoire moderne sous la direction de G. Audisio, Aix-en-Provence, Université d'Aix-Marseille I.

BERTON L.

2011, «Les enseignes médiévales en plombétain ", Détection-Passion, n 92, p. 16-23.

Beuningen H. J. E., Koldeweij A. M. 1993, Heilig en profaan 1, 1000 laatmiddeleeuwse insignes uit de collectie H. J. E. Beuningen, Cothen, Stichting Middeleeuwse Religieuze en Profane Insignes (Rotterdam Papers, VIII).

Beuningen H. J. E., Koldeweij A. M. et Kicken D.

2000, Heilig en profaan 2, 1200 laatmiddeleeuwse insignes uit openbare en parti- culiere collecties, Cothen, Stichting Middeleeuwse Religieuze en Profane Insignes (Rotterdam Papers, XII).

Biraben J.- N.

1976, Les hommes et la peste en France et dans les pays européens et méditerranéens, Paris, Mouton et École des hautes études en sciences sociales.

Bleu S. et Ganet I.

1996, Commune de Sisteron, prospection - inventaire diachronique, déposé au Service régional de l'archéologie Provence-Alpes-Côte d'Azur.

BLIGNy-Bondurand É.

1915, Les coutumes de Saint-Gilles (XII ${ }^{e-}$ XIV siècles), Paris, Picard.

BONDURAND É.

1890, "Les péages de Tarascon», Mémoires de l'Académie de Nîmes, VII e série, t. XIII, p. 135-160.

1901, «La leude et les péages de Saint-Gilles au XII ${ }^{\mathrm{e}}$ siècle, textes en langue d'oc et en latin ", Mémoires de l'Académie de Nîmes, VII e série, t. XXIV, p. 267-292.

BONNEMANT L.

1876, «Mémoires de Bertrand Boysset contenant ce qui est arrivé de plus remarquable, particulièrement à Arles et en Provence depuis M.CCC.LXXII jusqu'en M.CCCC.XIIII» (copié et annoté par Laurent Bonnemant), Le Musée, revue arlésienne, historique et littéraire, pag. mult.

BosQ L.-C. et BosQ P.-J.,

1854, «Notice sur divers objets de l'Antiquité et du Moyen Âge", Répertoire des travaux de la Société de statistique de Marseille, t. XVII, p. 318-322.

BRETON R.

1991, «Le voyage, le passage en Provence et la visite en Avignon du cardinal d'Aragon (1517)», Annuaire de la société des amis du Palais des papes et des monuments d'Avignon, LXVII ${ }^{\mathrm{e}}$ LXVIII ${ }^{\mathrm{e}}$ années, p. $45-55$.

BRUN R.,

1935, «Annales avignonnaises de 1382 à 1410 extraites des Archives de Datini», Mémoires de l'Institut historique de Provence, t. XII, p. 17-142. 
BRUNA D.

1991, «Les enseignes de pèlerinage et les coquilles Saint-Jacques dans les sépultures du Moyen Âge en Europe occidentale", Bulletin de la Société nationale des antiquaires de France, p. 178-190.

1992, «Un moule pour enseignes de pèlerinage à l'image de la Belle Vierge de Ratisbonne», Bulletin de la Société nationale des antiquaires de France, p. 317-324.

1994, «La marchande d'enseignes de pèlerinage des stalles de la cathédrale d'Amiens ", Bulletin de la Société nationale des antiquaires de France, p. 199-206.

1996, Enseignes de pèlerinage et enseignes profanes, Paris, Éditions de la Réunion des musées nationaux.

1998, «Témoins de dévotion dans les livres d'heures à la fin du Moyen Âge», Revue Mabillon, t. 70, no 9, p. 127-161.

2003, «Enseignes de pèlerinage de la Via Tolosana Provence et Languedoc: nouvelles découvertes et état de la question", dans Rucquor A. (dir.), SaintJacques et la France, Actes du colloque des 18 et 19 janvier 2001 à la fondation Singer-Polignac, Paris, Éditions du Cerf, p. 65-82.

2006, Enseignes de plomb et autres menues chosettes du Moyen Âge, Paris, Le Léopard d'Or.

2007, Saints et diables au chapeau. Bijoux oubliés du Moyen Âge, Paris, Seuil.

Bulgarelli F., Gardini A. et Melli P. (dir.)

2001, Archeologia dei pellegrinaggi in Liguria, Savone, Marco Sabatelli.

Carru D.

1998, "Notre-Dame des Doms au Moyen Âge, notice sur la représentation de la cathédrale d'Avignon au XIV siècle", Annuaire de la société des amis du Palais des papes et des monuments d'Avignon, LXXVe année, p. 47-54.

Carru D., Gagnière S.

1992, «Notes sur quelques objets de dévotion populaire, ampoules et enseignes de pèlerinage du Moyen Âge tardif provenant d'Avignon ", Mémoires de l'Académie de Vaucluse, $8^{e}$ série, t. 1, p. 55-92.

Charlet J.-L.,

1986, «Un petit trésor de florins découverts à Silvacane», Bulletin de la Société française de numismatique, $41^{\mathrm{e}}$ année, $\mathrm{n}^{\circ} 3$, p. 39-42.
Chobaut L.

1943, "Introduction sur les graveurs, marchands d'estampes et lithographes avignonnais », dans GAgnière S., Catalogue de l'imagerie populaire religieuse avignonnaise, Avignon, Imprimerie Rullière frères, p. 3-8.

Colardelle R.

1999, L'église Saint-Laurent, de la nécropole gallo-romaine au monument historique, Genoble (Isère), 10 vol. Thèse d'Archéologie médiévale sous la direction de G. Démians D'Archimbaud, Aix-enProvence, Université d'Aix-Marseille I.

2008, La ville et la mort: Saint-Laurent de Grenoble, 2000 ans de tradition funéraire, Turnhout, Brepols (Bibliothèque de l'Antiquité tardive, $\mathrm{n}^{\circ} 11$ ).

Cohen E.

1976, "In haec signa: Pilgrim-badge trade in southern France", Journal of Medieval History, t. II, fasc. 3, p. 193-214.

Coulet N.

1972, «Jalons pour une histoire religieuse d'Aix au bas Moyen Âge (1350-1450)», Provence historique, t. XXII, fasc. 89, p. 203-260.

Courrier de L'institut

1925, "Courrier de l'Institut Historique de Provence», Mémoires de l'Institut historique de Provence, t. II, p. 225.

Cousin B.

1999, «Image des saints et imaginaire de la sainteté en Provence (XVII ${ }^{\mathrm{e}}$-XIX ${ }^{\mathrm{e}}$ siècle)», Provence historique, t. XLIX, fasc. 195-196, p. 179-189.

DÉmians D’Archimbaud G.

1980a, Rougiers, village médiéval de Provence, Lille, Service de reproduction des thèses de Lille III.

1980b, Les fouilles de Rougiers (Var). Contribution à l'archéologie de l'habitat rural médiéval en pays méditerranéen, Valbonne, CNRS.

DeOnNa W.

1946, «Les crucifix de la vallée de Saas (Valais) : Sol et Luna. Histoire d'un thème iconographique (premier article)», Revue de l'histoire des religions, vol. 132, p. 5-47.

1947, «Les crucifix de la vallée de Saas (Valais) : Sol et Luna. Histoire d'un thème iconographique (deuxième article)", Revue de l'histoire des religions, vol. 133, p. 49-102.
Desnoyers F.-E.

1873, «Objets trouvés dans la Loire durant l'été de 1870 », Mémoires de la Société archéologique de l'Orléanais, t. XII, p. 245-295.

1876, «Nouveaux objets trouvés dans la Loire pendant les années 1872, 1873 et une partie de 1874 ", Mémoires de la Société archéologique de l'Orléanais, $\mathrm{t}$. XV, p. 113-196.

Duhil G., Chupin A., Girault M. et Girault P.-G. (éd.),

2007, «Livre des Miracles de saint Gilles, Liber miraculorum sancti Egidii», dans Girault M. et Girault P.-G. (dir.), Liber miraculorum sancti Egidii, Livre des Miracles de saint Gilles, Orléans, Paradigme, p. 33-207, Medievalia, $\mathrm{n}^{\circ} 60$.

ENLART C.

1916, Manuel d'archéologie française depuis les temps mérovingiens jusqu'à la Renaissance. Tome III. Le costume, Paris, Picard.

EsQuiEu Y.

1979, «L'église Sainte-Marthe de Tarascon», Congrès archéologique de France, 134, Arles, Paris, Société française d'archéologie, p. 126-151.

Esquieu Y., Leenhardt M., Olive C. et VALLAURI L.

1988, «Le cimetière du cloître cathédral de Viviers : rites et mobilier funéraires", dans Esquieu Y. (dir.), Viviers, cité épiscopale : études archéologiques, Lyon, Direction des antiquités historiques de Rhône-Alpes, Documents d'archéologie en Rhône-Alpes et en Auvergne, 2, p. $67-100$.

FAILLON E.-M.

1865, Monuments inédits sur l'apostolat de sainte Marie-Madeleine en Provence et sur les autres apôtres de cette contrée, saint Lazare, saint Maximin, sainte Marthe, les saintes Maries Jacobé et Salomé, etc., etc., 2 t., Paris, Migne.

FAlgairolle P.

1898, «Le péage de Saint-Gilles au XIV ${ }^{e}$ siècle", Revue du Midi, 12e année, $\mathrm{n}^{\circ} 7$, p. 553-562.

FERRANDo P.

2001a, «Quatre enseignes de pèlerinage inédites pour Sainte-Croix de Montmajour ", Bulletin des amis du Vieil Arles, no 110, p. 5-15. 
2001b, «Sept enseignes de pèlerinage consacrées à saint Antoine», Bulletin des amis du Vieil Arles, no 111, p. 39-45.

Feuillas M.

1985, «Une tradition hagiographique : les panégyriques latins du Bienheureux Pierre de Luxembourg dans l'église des Célestins d'Avignon au XVII ${ }^{\mathrm{e}}$ siècle", Mémoire de l'Académie de Vaucluse, 7 e série, t. VI, p. 87-105.

Fingerlin I.

1971, Gürtel des hohen und späten Mittelalters, Regensburg, Deutscher Kunstverlag.

Fixot M. et Pelletier J.-P. (dir.), 1990, «Porteries, bâtiments d'accueil et métallurgie aux abbayes de Silvacane et du Thoronet", Archéologie Médiévale, t. 20, p. 181-252.

Forgeais A.

1863, Collection de plombs historiés trouvés dans la Seine, deuxième série : enseignes de pèlerinages, Paris, Arthur Forgeais et Auguste Aubry.

1865, Collection de plombs historiés trouvés dans la Seine, quatrième série: Imagerie religieuse, Paris, Arthur Forgeais et Auguste Aubry.

Fournand A.

2001, Le cadre de vie à Aix et ses environs d'après les inventaires après décès (15601575), mémoire de maîtrise d'histoire moderne sous la direction de G. Audisio, Aix-en-Provence, Université Aix-Marseille I.

Friant E.

2009, Le catholicisme matériel: les objets de la piété privée dans la France des XVI et $\mathrm{XVII}{ }^{e}$ siècles, thèse d'histoire moderne sous la direction de P. Martin, Nancy, Université de Nancy 2.

GaGniÈre S.

1981, «Enseigne de pèlerinage de SainteCroix de Montmajour trouvée à Avignon ", Annuaire de la Société des amis du Palais des Papes, années 1980-1981, p. 49-53.

Gagnière S. et Granier J.

1971, «Le cimetière médiéval du plateau de Cancabeau à Châteauneuf de Gadagne (Vaucluse)", Revue d'études ligures, XXXVIIe année, p. 172-188.

Galtier C., Mille P., Poirot A., Bérard F., Cochet A., Médard F., Cécillon C. 2013, "Aspects de la vie quotidienne», dans Ayala G. (dir.), Lyon, Saint-Georges : archéologie, environnement et histoire d'un espace fluvial en bord de Saône, Paris, Maison des Sciences de l'Homme, p. 241-305.

\section{GANshof F. L.}

1966, «Pèlerinages expiatoires flamands à Saint-Gilles pendant le XIV ${ }^{\text {e }}$ siècle", Annales du Midi, t. 78, $\mathrm{n}^{\circ}$ 77-78, p. 391-407.

\section{Gasnault P.}

1989, «Un nouveau témoignage sur le pèlerinage de Larchant à la fin du $\mathrm{XV}^{\mathrm{e}}$ siècle», Cahiers saint Mathurin, t. I, p. $18-20$.

GAY V.

1887, Glossaire archéologique du Moyen Âge et de la Renaissance, t. 1, Paris, Librairie de la société bibliographique.

GazAy J.

1913, Le roman de saint Trophime et l'abbaye de Montmajour, Toulouse, Privat.

Girault M. et Girault P.-G.,

2007a, «Introduction », dans Girault M. et Girault P.-G. (dir.), Liber miraculorum sancti Egidii, Livre des Miracles de saint Gilles, Orléans, Paradigme (Medievalia, 60), p. 11-31.

2007b, «La vie d'un sanctuaire de pèlerinage au XII siècle», dans Girault M. et Girault P.-G. (dir.), Liber miraculorum sancti Egidii, Livre des Miracles de saint Gilles, Orléans, Paradigme, Medievalia, 60, p. 211-342.

Grassi M.-C.

1970, Les voies de communication en Provence Orientale de l'époque romaine à la fin $d u$ XVIII siècle, thèse d'histoire médiévale présentée sous la direction de G. Duby, Aix-en-Provence, Université Aix-Marseille I.

Gruet Y., Bonnissent D.

2002, «Des coquilles Saint-Jacques (Pecten Maximus) taillées avant d'être vendues aux pèlerins?", Revue d'Archéométrie, $\mathrm{n}^{\circ} 26$, p. 113-123.

GuARNieri C.

1998, «Due insegne di pellegrinaggio provenienti da scavi urbani a Ferrara ed Argenta (FE)», Archeologia medievale, t. XXV, p. 265-270.

Guillaume P.

1884, «Le mystère de Sant Anthoni de Viennès publié d'après une copie de l'an 1503 », Gap, Société d'étude des HautesAlpes, Paris, Maisonneuve.
Guyon J., Carrazé F., Fixot M. et JOUANAUD J.-L.

1996, Les premiers monuments chrétiens de Saint-Maximin (11) : rapport d'une fouille programmée sur le site de l'ancien presbytère, place de l'Hôtel-de-Ville avril-mai 1996, déposé au Service régional de l'archéologie Provence-Alpes-Côte d'Azur.

\section{Hayez A.-M.}

1985, "Les environs de l'église Saint-Pierre d'Avignon au XIV" siècle", Annuaire de la Société des amis du Palais des papes et des monuments d'Avignon, LXI ${ }^{\text {- }}$ LXIIe années, p. 25-44.

1987, "À la cour pontificale d'Urbain V, réceptions et déplacements", Annuaire de la Société des amis du Palais des papes et des monuments d'Avignon, LXIII ${ }^{\text {- }}$ LXIVe année, p. 15-24.

2003, «La paroisse Notre-Dame la Principale au temps des papes d'Avignon", Annuaire de la Société des amis du Palais des papes et des monuments d'Avignon, LXXX ${ }^{\mathrm{e}}$ année, p. 85-108.

HÉNIN B.

1984, Maisons et vie domestique à Marseille au XVII siècle, 3 t., thèse d'histoire médiévale sous la direction de P. Joutard, Aix-enProvence, Université d'Aix-Marseille I.

Hucher E.

1853, «Des enseignes de pèlerinage», Bulletin monumental ou collection de mémoires et de renseignements sur la statistique monumentale de la France, $2^{\text {e }}$ série, t. 9, p. 505-535.

JACOMET H.

1990, «Le bourdon, la besace et la coquille», Archéologia, n² 258, p. 42-51.

Janninck C., Du Sollier J.-B. et Pien J. 1719, Acta sanctorum julii : ex latinis et graecis, aliarumque gentium monumentis, servata primigenia veterum scriptorum phrasi, $1^{\text {ère }}$ édition, Anvers, Jacob du Moulin.

Koldeweij J.

2006, Foi et bonne fortune, parure et dévotion en Flandre médiévale, Arnhem, Uitgeverij Terra Lannoo.

KÖSTER K.

1983, Pilgerzeichen und Pilgermuscheln von mittelalterlichen Santiagostraben : SaintLéonard, Rocamadour, Saint-Gilles, Santiago de Compostela, Schleswiger Funde und Gesamtüberlieferung, Neumünster, Wachholtz. 
1985, «Les coquilles et enseignes de pèlerinage de Saint-Jacques de Compostelle et des routes de Saint-Jacques en Occident", dans Santiago de Compostela, 1000 ans de pèlerinage européen, Gand, Crédit Communal de Belgique, p. 85-95.

LABANDE L.-H.

1899, «Notes sur deux médailles du Bienheureux Pierre de Luxembourg et sur son portrait conservé au Musée Calvet», Mémoires de l'Académie de Vaucluse, t. XVIII, p. 409-413.

Labaune-Jean F. (dir.)

2016, Petits objets de dévotion pour les pèlerins du Mont-Saint-Michel, de la conception à la production (XIV ${ }^{e}-\mathrm{XV}^{e}$ siècles), Caen, Presses universitaires de Caen, Collection des Publications du Craham.

Laclotte M. et Thiébaut D.

1983, L'école d'Avignon, Paris, Flammarion.

Lassure J.-M. et Villeval G.

2002, «Enseignes de pèlerinage du XIV siècle trouvées à Toulouse et au Pouget (Hérault) ", L'Auta que bufo un cop cado mes, no 35 , p. 200-206.

LECOY DE LA MARChe A. DE

1875, Le roi René, sa vie, son administration, ses travaux artistiques et littéraires d'après les documents inédits des archives de France et d'Italie, Paris, Firmin-Didot Frères.

Massebeuf G.

1987, «À propos d'une gravure découverte sur l'épave Lardier, Notre-Dame du Puy et le jubilé du 25 mars 1502 ", Cahiers d'archéologie subaquatique, t. VI, p. 163-170.

Matton A.

1870, «Les enseignes et les lavages de SaintFirmin de la Fère», Bulletin de la Société académique de Laon, t. 18, 1866-1868, p. 115-119.

MAXe-Werly L.

1898, "Médaille du Bienheureux Pierre de Luxembourg du $\mathrm{xv}^{\mathrm{e}}$ siècle», Mémoires de la Société des lettres, sciences et arts de Bar-le-Duc, 3e série, t. VII, p. 49-56.

Michaud F.

2009, «Dévotions laïques. Le testament d'une pèlerine, Elena Sclavonia, en 1301 », dans PÉcout T. (dir.), Marseille au Moyen Âge entre Provence et Méditerranée. Les horizons d'une ville portuaire, MeolansRevel, Désiris, p.323-324.
Millin A.-L.

1808, Voyage dans les départemens du Midi de la France, t.3, Paris, Imprimerie impériale.

Mognetti É.

1981, «Francesco Laurana sculpteur du roi René en Provence", Le roi René en son temps 1382-1481, catalogue de l'exposition du musée Granet, Aix-en-Provence, Musée Granet, p. 132-182.

Montagnes B.

1978, «Une image de dévotion à saint Dominique thaumaturge", Mémoires de l'Académie de Vaucluse, sixième série, t. X, p. 109-115.

Motteau J.

1991, "Catalogue des objets des fouilles 1973-1977», Recherches sur Tours, n 5 , Tours, Association pour le développement des études d'archéologie urbaine à Tours (supplément à la Revue archéologique du Centre de la France, 2).

Moulinier J.-C.

1997, «Saint-Victor de Marseille, centre ancien de pèlerinage», Provence historique, t. 47 , fasc. 190 , p. 605-612.

Nicholson A.

1998, «The copper alloy», dans Hill P. (dir.), Whithorn and St. Ninian, The excavation of a monastic Town 1984-91, s.l., Sutton publishing, p. 360-384.

PAILlaRd P.

1969, «Vie économique et sociale à Salon de Provence. De 1470 à 1550 », Provence historique, t. XIX, fasc. 78, p. 277-306.

Pansier P.

1912a, «Les œuvres charitables d'Avignon en 1433 », Annales d'Avignon et du Comtat Venaissin, $1^{\text {ire }}$ année, p. 219-242.

1912 b, «Note sur une bulle de Callixte III accordant des indulgences à l'Euvre du Pont d'Avignon", Annales d'Avignon et $d u$ Comtat Venaissin, $1^{\text {ère }}$ année, p. 169-176.

1919, «Les débuts du théâtre à Avignon à la fin du Xve siècle", Annales d'Avignon et du Comtat Venaissin, 6e année, p. 5-52.

1926, «La version provençale des vies d'Elzéar et de Delphine de Sabran", Annales d'Avignon et du Comtat Venaissin, 12 ${ }^{\text {e }}$ année, p. 65-136.

1929, "Les anciens hôpitaux d'Avignon", Annales d'Avignon et $d u$ Comtat Venaissin, $15^{\mathrm{e}}$ année, p. 47-56.

1930, «Le guide d'Avignon à Saint-Jacques de Compostelle au XIV ${ }^{e}$ siècle», Annales
d'Avignon et du Comtat Venaissin, 16e année, p. 119-122.

PAPON J.-P.

1780, Voyage littéraire de Provence, Paris, Barrois l'aîné.

PARIs G. et Bos A. (éd.)

1881, La vie de saint Gilles par Guillaume de Berneville : poème du XII ${ }^{e}$ siècle, Paris, Didot.

Pasqualini M., Turc P. et Mafart B.

1991, Abbaye Saint-Pierre de l'Almanarre (Hyères), recherches 1988-1991 (rapport de fouilles), déposé au Service régional de l'archéologie Provence-Alpes-Côte d'Azur.

Pastoureau M.

1982, «La naissance de la médaille: le problème emblématique», Revue numismatique, $6^{e}$ série, t. XXIV, p. 206-221.

1988, «La naissance de la médaille: des impasses historiographiques à la théorie de l'image", Revue numismatique, 6e série, t. XXX, p. 227-247.

PÉRICARD-MÉA D.

2000, Compostelle et cultes de saint Jacques au Moyen Âge, Paris, PUF.

Pollino A. et Viallant J.-P.

1987, «Une épave au cap Lardier : sondages, couverture photographique, matériel», Cahiers d'archéologie subaquatique, t. VI, p. 85-98.

Puech A.

1885, «La vie de nos ancêtres d'après leurs livres de raison ou les Nîmois dans la seconde moitié du $\mathrm{XVII}^{\mathrm{e}}$ siècle d'après des documents inédits", Mémoires de l'Académie de Nîmes, VII série, t. VII, p. $439-490$.

Ramière de Fortanier A. (dir.) 1979, Testaments provençaux du Moyen Âge. Documents paléographiques, Marseille, Institut historique de Provence, Archives de la ville de Marseille.

RAPP F.

2000, «Jubilé et indulgences sous les papes d'Avignon", Annuaire de la société des amis du Palais des papes et des monuments d'Avignon, LXXVII' année, p. 85-97.

RAimbault M.

1921, Inventaire sommaire des archives départementales d'Auriol antérieures à 1790, Département des Bouches-duRhône, Marseille, Burotto \& Sauvon. 
RibBe C. DE

1898, La société provençale à la fin du Moyen Âge d'après des documents inédits, Paris, Perrin.

Richier A. (dir.),

2011, Bouches-du-Rhône, La Ciotat, Carré Saint-Jacques. L'îlot Saint-Jacques : du vignoble champêtre au cimetière paroissial (rapport de fouilles), déposé au Service régional de l'archéologie ProvenceAlpes-Côte d'Azur.

RODET-BELARBI I.

2013, «Le bourdonnet : une miniaturisation du bourdon du pèlerin de Saint-Jacques-deCompostelle : quelques exemples archéologiques en os », Bulletin Instrumentum, no 37 , p. $47-49$.

SAgNier A.

1988, «Les fouilles de Gadagne, un cimetière ligure», Mémoires de l'Académie de Vaucluse, t. VI, p. 183-202.

SAINT-JEAN R.

1985, «La sculpture à Saint-Gilles du Gard », dans Lugand J., Nougaret J., SAINT-JEAN R. et Burgos A. (dir.), Languedoc roman, le Languedoc méditerranéen, Saint-Léger-Vauban, Zodiaque.

SANTiago de Compostela

1985, Santiago de Compostela, 1000 ans de pèlerinage européen, Gand, Crédit Communal de Belgique.

SClAFERT J. (éd.)

2009, Miracles de sainte Marie-Madeleine, introduction et traduction de Jacqueline Sclafert, Paris, CNRS Éditions.

SPENCER B.

1990, Salisbury and South Wiltshire museum, medieval catalogue, part. 2, pilgrim souvenirs and secular badges, Salisbury, Salisbury and Southwiltshire museum.
2010, Pilgrim souvenirs and secular badges, Woodbridge, The Boydell Press (Medieval finds from excavations in London, 7).

Stouff L.

1991, «Deux voyageurs allemands à Arles à la fin du $\mathrm{XV}^{\mathrm{e}}$ siècle», Provence historique, t. XLI, fasc. 166, p. 567-573.

1999, «L'abbaye de Montmajour et la ville d'Arles", dans Bastié A. (dir.), Abbaye Saint-Pierre de Montmajour: histoire et patrimoine, Arles, Les Amis du Vieil Arles, p. 25-37.

TixAdor A.

2004, Enseignes sacrées et profanes médiévales découvertes à Valenciennes: Un peu plus d'un kilogramme d'histoire, Valenciennes, Service archéologique de Valenciennes.

Thiriet C.

1997, Les reflets de la foi dans les inventaires après décès. Marseille 1556-1575, 2 t., mémoire de maîtrise d'histoire moderne sous la direction de G. Audisio, Aix-enProvence, Université Aix-Marseille I.

Thuaudet O. et Chazottes M.-A.

2014, "Étude du mobilier manufacturé non céramique», dans AbEL V., Bouiron M., Parent F. (dir.), Fouilles à Marseille, Objets quotidiens médiévaux et modernes, Arles, Errance, Aix-en-Provence, Centre Camille Jullian (Bibliothèque d'Archéologie Méditerranéenne et Africaine, $\mathrm{n}^{\circ} 16$; Études massaliètes, 13), p. 295-349.

VALLET S.

2008, «La coquille du pèlerin dans les sépultures médiévales du sud-ouest de la France : nouveaux résultats et perspectives de recherches", Archéologie du Midi médiéval, t. 26, p. 238-247.

VAllet de Viriville A.

1857-1858, «Statue de cire du roi Charles VI offerte par ce prince au tombeau de saint Pierre de Luxembourg (à Avignon), novembre 1389 ", dans Montaiglon A. (dir.), Archives de l'art français, Paris, Dumoulin, t. 5, p. 342-346.

VALON L. de

1935, «Les pèlerinages expiatoires et judiciaires de la Belgique aux Sanctuaires de la Provence au Moyen Âge», Provincia, t. XV, p. 30-52.

VeYssière G.

1987, Société et vie en Provence à travers des sources hagiographiques $d u \mathrm{XIV}^{e}$ siècle, $2 \mathrm{t}$., thèse d'histoire médiévale sous la direction de L. Stouff, Aix-en-Provence, Université d'Aix-Marseille I.

1994, «Miracles et merveilles en Provence aux XIII ${ }^{e}$ et XIV $^{\text {e }}$ siècles à travers des textes hagiographiques", dans Miracles, prodiges et merveilles au Moyen Âge, Actes de la Société des historiens médiévistes de l'enseignement supérieur public, Orléans, juin 1994, Paris, Publications de la Sorbonne, p. 191-214.

Vielliard J. (éd.)

1984, Le guide du pèlerin de Saint-Jacques de Compostelle, texte latin du XII siècle, édité et traduit en français d'après les manuscrits de Compostelle et de Ripoll, Paris, Librairie philosophique J. Vrin.

Vivre Au Moyen Âge

2002, Vivre au Moyen Âge: archéologie du quotidien en Normandie, $\mathrm{XIII}^{\mathrm{e}}-\mathrm{XV}^{\mathrm{e}}$ siècles, Milan, 5 continents.

Wyzewa T. de (éd.)

1998, Jacques de Voragine, La légende dorée (traduit du latin), Paris, Le Seuil.

ZINGARELLI N.

1901, «Le roman de saint Trophime», Annales $d u$ Midi, t. XIII, p. 297-345.

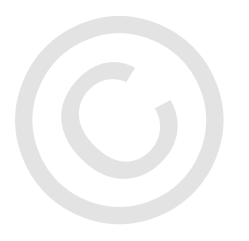




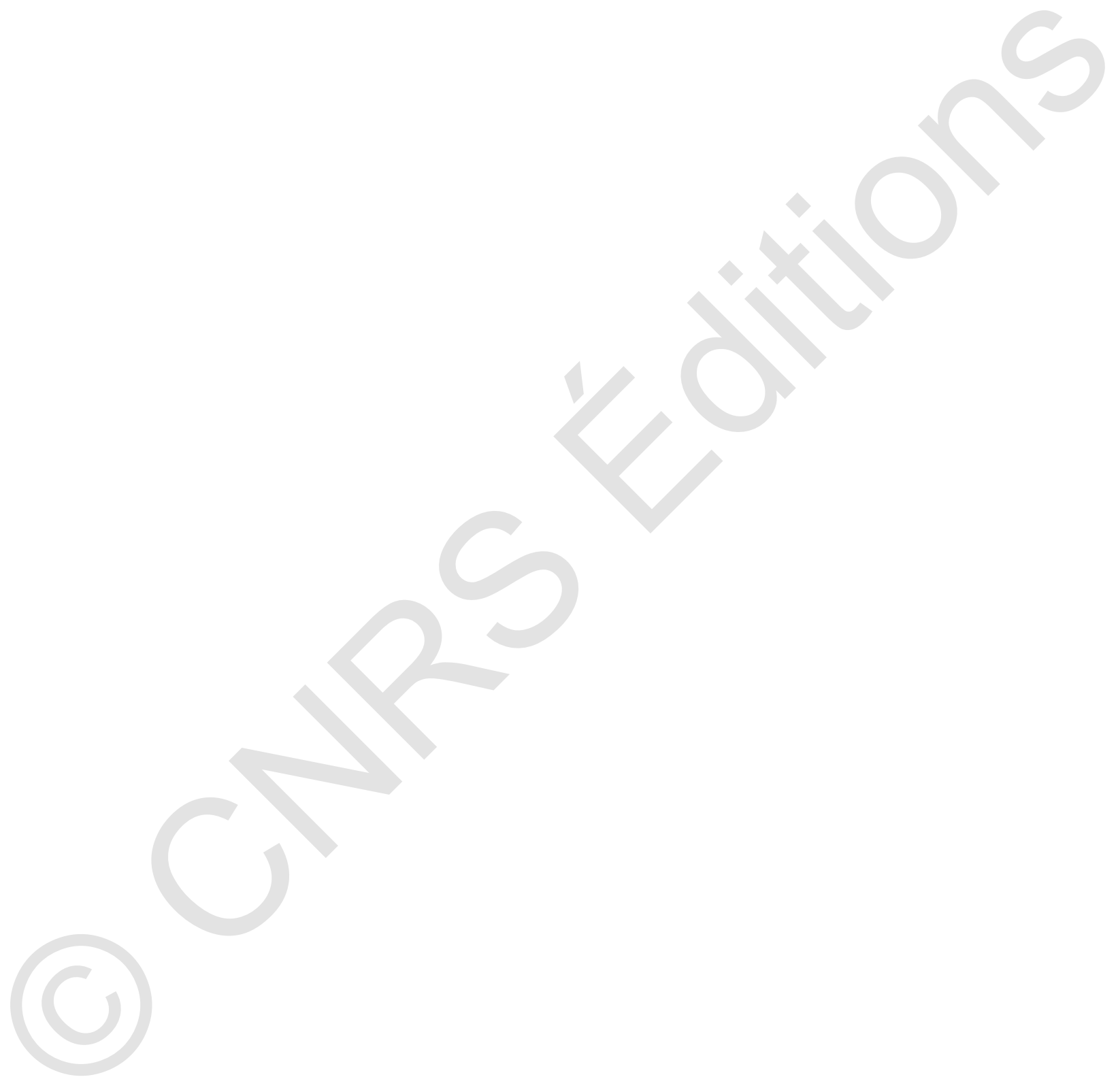

